\title{
Mild head injury and postconcussive sequelae : a study of brain and behavior relationships
}

Citation for published version (APA):

Bohnen, N. I. L. J. (1991). Mild head injury and postconcussive sequelae : a study of brain and behavior relationships. [Doctoral Thesis, Maastricht University]. Rijksuniversiteit Limburg.

https://doi.org/10.26481/dis.19910905nb

Document status and date:

Published: 01/01/1991

DOI:

10.26481/dis.19910905nb

Document Version:

Publisher's PDF, also known as Version of record

\section{Please check the document version of this publication:}

- A submitted manuscript is the version of the article upon submission and before peer-review. There can be important differences between the submitted version and the official published version of record.

People interested in the research are advised to contact the author for the final version of the publication, or visit the DOI to the publisher's website.

- The final author version and the galley proof are versions of the publication after peer review.

- The final published version features the final layout of the paper including the volume, issue and page numbers.

Link to publication

\footnotetext{
General rights rights.

- You may freely distribute the URL identifying the publication in the public portal. please follow below link for the End User Agreement:

www.umlib.nl/taverne-license

Take down policy

If you believe that this document breaches copyright please contact us at:

repository@maastrichtuniversity.nl

providing details and we will investigate your claim.
}

Copyright and moral rights for the publications made accessible in the public portal are retained by the authors and/or other copyright owners and it is a condition of accessing publications that users recognise and abide by the legal requirements associated with these

- Users may download and print one copy of any publication from the public portal for the purpose of private study or research.

- You may not further distribute the material or use it for any profit-making activity or commercial gain

If the publication is distributed under the terms of Article $25 \mathrm{fa}$ of the Dutch Copyright Act, indicated by the "Taverne" license above, 
Mild Head Injury and Postconcussive Sequelae A Study of Brain and Behavior Relationships 


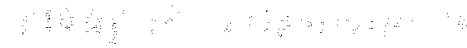




\section{Mild Head Injury and Postconcussive Sequelae}

\section{A Study of Brain and Behavior Relationships}

\section{Proefschrift}

ter verkriging van de graad van doctor aan de Rijksuniversitelt Limburg te Maastricht, op gezag van de Rector Magnificus, Prof. Mr. M.J. Cohen, volgens het besluit van het College van Dekanen,

in het openbaar te verdedigen

op donderdag, 5 september 1991 om 16.00 uur

door

Nicolaas Ida Leonardus Joseph Bohnen

geboren te Susteren in 1960 
Promotor

Beoordellingscommissie
Prof. Dr. J. Jolles

Prof. Dr. J.A. Knottnerus (voorzilter)

Dr. A. Keyser (K.U. Nijmegen)

Dr. H. Kingma

Prof. Dr. E. Thierry (Universiteit Gent)

Prof Dr. M.W. de Vries

\section{CIP-DATA KONINIKLIJKE BIBLIOTHEEK, DEN HAAG}

Bohnen, Nicolaas Ida Leonardus Joseph

Mild head injury and postconcussive sequelae. A study of brain and behawior relationships / Nicolaas Ida Leonardus Joseph Bohnen. - [S.1. : s.n.] (Meppel : Krips Repro). -III. Thesis Maastricht. - With ref. -With summary in Dutch. ISBN 90-9004334-9

Subject headings: mild head injuries.

Produktie: Germa Wijnen

Omslag: met dank aan Peter Dieteren

Druk: Datawyse Maastricht / Krips Repro Meppel

A.11 rolotes ress

No part of this book mar be meproduced

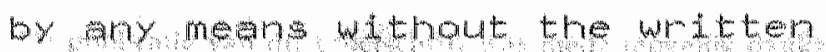

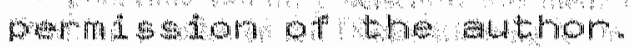


"LHasard ne favorise que les esprits favorises" naar Louis Pasteur

Aan mip ouders Woor Miriam 
1. Mild head injury and postconcussive sequelae: an introduction. . . . . . . . .

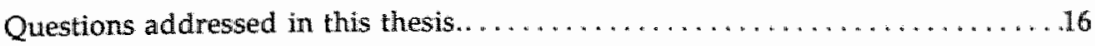

SECTION A: Diagnostic Measures of Mild Head Injury and Postconcussive Symptoms

2. A psychophysical method for assessing visual and acoustic hyperesthesia

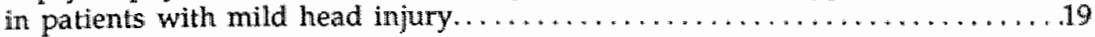

3. Modification of Stroop Color Word test improves differentiation between patients with mild head injury and matched controls. ............... 24

4. Post-traumatic and emotional symptoms in different subgroups of

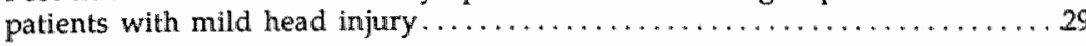

SECTION B: Recovery and Persistence of Symptoms up to Six Months after an Uncomplicated Injury.

5. Recovery from visual and acoustic hyperesthesia following mild head injury in relation to patterns of behavioral dysfunction.

6. Persistence of postconcussive symptoms in uncomplicated mild headinjured patients: a prospective cohort study.

7. Tolerance to light and sound of patients with persistent postconcussional symptoms six months after mild head injury. . . . . . . . . . . . . . . . 50

8. Neuropsychological deficits in patients with persistent symptoms six months

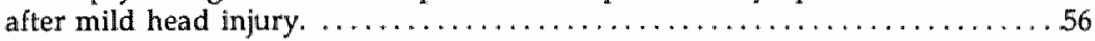

SECTION C: The Coping Hypothesis, Stress, Cognitive Performance and Postconcussive Symptoms

9. Coping style, trait anxiety, and cortisol reactivity during mental stress.

10. Cortisol reactivity and cognitive performance in a mental task paradigm. . . . .70

11. Coping styles, cortisol reactivity, and performance in a vigilance tasik of patients with persistent postconcussive symptoms after a mild head injury. . . 76

12. Concluding remarks $\ldots \ldots \ldots \ldots \ldots \ldots \ldots \ldots \ldots \ldots \ldots \ldots \ldots \ldots$

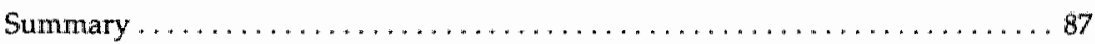

Samenvatting $\ldots \ldots \ldots \ldots \ldots \ldots \ldots \ldots \ldots \ldots \ldots \ldots \ldots \ldots \ldots$

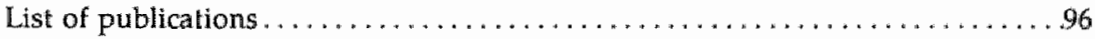

Dankwoord $\ldots \ldots \ldots \ldots \ldots \ldots \ldots \ldots \ldots \ldots \ldots \ldots \ldots \ldots \ldots \ldots \ldots$

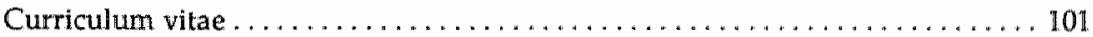


$\because$ 
Chapter 1

\section{Mild Head Injury and Postconcussive Symptoms: An Introduction}

\section{N. Bohnen}

Department of Neuropsychology \& Psychobialogy, University of Limburg, Maastricht. The Netherlands.

\section{Abstract}

The sequelae of severe closed head injury have received much attention in the literature but the effects of mild closed head injury (MHI) are less well established. Although patients may recover quickly after $\mathrm{MHI}$, there is a subgroup of patients who complain of persisting postconcussive symptoms ( $\mathbb{P} C S$ ) beyond the first weeks of recovery. Although the symptoms generally develop in the absence of clear neurological abnormalities, the condition of PCS can be chronic and disabling. It has been assumed that PCS result from an interaction between organic and psychological factors. Differentiating between the effect of primary neurological injuries and secondary psychosocial problems is often difficult for clinicians and engenders controversy. Neuropsychological, neurophysiological, and neuroimaging measures can be helpful in selecting patients at risk of developing PCS. Assessment of the level of cognitive functioning, individual susceptibility to stress, and environmental demands may be beneficial in treating symptomatic patients.

It is true that the vague and aspecific nature of the postconcussion syndrome may have given rise to the controversy over this entity, but the many methodological inconsistencies in the experimental approaches to the syndrome have certainly enhanced the confusion about this issue. The ensuing controversy surrounding research on the outcome of MHI and the postconcussion syndrome reflects ambiguities in definition, inconsistencies in criteria for patient selection, variation in procedures for neurobehavioral assessment, and difficulty in obtaining follow-up data.

\section{Introduction}

MHI has received much attention since the study of Rimel et al.[84] alerted health professionals to the high morbidily associated with these imjuries. In addition, it has become increasingly dear that minor head injuries are of great social and economic importance [107]. Not only does their care in the acute stages load hospital serwices, but persisting symptoms can lead to vocational disability and problems in interpersonal. relationships. Consequently, some patients become involved in litigation 1911). The majority of hospital admissions for head trauma are due to MHI. An even greater number of $\mathrm{MHI}$ patients are admitted to casualty departments and are not hospitalized or even seen by medical personnel, including their general practitioner [18].

Mild head injury can be defined in mathy ways, ranging from a loss of consciousness requiring hospitalization to lacerations of the scalp and face that clearly do not affect the brain. Rutherford [92] defines concussion as an accelerattion/deceleration injury to the head that is almost always associated with a period of amriesian and followed by a characteristic group of symptoms, such as headache, poor memory, and vertigo. Russell"s [89] classification of head injury is based upon the duration of Post-traumatic Amnesia (PTA): mild head injury (PTA less than 60 minutes); moderate head injury (PTA more than 60 minutes but less than 24 hours), and severe head injury (PTA over 24 hours). However, this approach assumes valid and rellable assessment of the duration of PTA [59]. An excessive intake of allcohol can mimic the effects of PTA and can therefore make the estimation of PTA inaccurate and complicates the diagnosis of MHI [27]. The study of Rimel et al. [84] was a milestone in the development of diagnostic 
criteria to define MHI. These authors defined MHI as a cranial trauma producing an initial loss of consciousness limited to 20 minutes or less, a GCS (Glasgow Coma Score) over 13-15 on admission, and hospitalization within less than 48 hours. Nevertheless, there are patients who have incomplete amnesia and who experience only a short period of feeling dazed, but who nonetheless complain of PCS [90]. The model of Ommaya and Gennarelli [80], which considers post-traumatic confusion as a minimal grade of concussion, is more appropriate for classifying these very mild types of head injury as the classification is not based upon the duration of PTA.

The term "postconcussion syndrome" refers to a number of PCS, which frequently occur after mild head injuries. PCS, which are based on self-reports, include memory impairment, difficulties in mental concentration, dizziness, reduced tolerance to light, sound and bustle, irritability, fatigue, anxiety, and headache [8]. Tinnitus, blurred vision, personality change, depression, sleep disturbance, decreased libido, intolerance to alcohol, and lowered tollerance to frustration have frequently been mentioned as well. Seizure disorders can be a sequel to all degrees of head trauma, as can psychiatric complications [65,74].

Unfortunately, the term 'postconcussion syndrome" has not been consistently and clearly defined in the literature. Gronwall and Wrightson [32] hypothesized that it is only when symptoms persist beyond the normal period of recovery that they emerge as the "postconcussion syndrome". Many critics have questioned the accuracy and utility of this diagnostic label. Lidvall et al. [64] found that the symptoms differed in terms of sieverity over time. Headache and dizziness tended to cease with time, whereas anxiety and irritability did not. In addition, Rutherford [92] distinguishes early and late symptoms. Vomiting, natusea, drowsiness, and blurred vision are short-lived complaints. Late symptoms, such as irritability and intolerance to noise, appear later: Given the differences in the time course for the various symptoms, Lidvall et al. [64] suggested that the use of the term "syndrome" is inaccurate and misleading. According to Rutherford et all. [90], PCS are best considered as part of the recowery from the pathologic process of concussion, rather than as a syndrome per se.

The fact that PCS develop along different time courses may reflect different underlying abnormalities. In syndrome one expects that certain symptoms are related to one another. It is only recently that new approaches toward the postconcussion syndrome acknowledge the heterogeneity of the entity [40, 104]. Multivariate analysis can facilitate identification of variables that form distinctive common factors. By means of a factor analysis of data collected in structured interviews, Levin et al. [59] were able to isolate salient dimensions of PCS that can be used to identify subgroups of patients. Results revealed three clusters of patient groups: one cluster of patients with predominantly cognitive and affective symptoms, another with somatic symptoms, and a third with relatively mild or no PCS.

The aspecific and subjective nature of PCS causes researchers methodological difficulties when they try to quantify or conceptualize these complaints, and this has led to an ensuing controversy about the psychogenetic versus physiogenetic origin of the complaints [see for revlew: 8,63 ]. The debate is tueled by different sources of controversy, such as inconsistencies in the definition of MHI and the postconcussion syndrome ${ }_{7}$ the problem of objective assessment and diagnosis of PCS, and issues related to the methodology and design of studies on the outcome of MHI.

\section{Historical Note}

Jacobson [45] provides a good historical perspective on the development of the concept of a postconcussion syndrome. An important early work in this regard was Erichsen's [25] book entitled 'On concussion of the spine, nervous shock and other obscure injuries to the nervous system',

Concussion seems to have become a much more common occurrence since the Industrial Revolution in the early nineteenth century, and especially since the construc- 
tion of extensive railway systems in the mid to late nimeteenth century [83]. Consequently, the concept of the postconcussion syndrome attained prominence in the later decades of the nineteenth century. It was also at this time that the rapid rise in the number of cases of real or fictitious post-traumatic disability that could not be diagnosed in a satisfactory way gave rise to controversies over medico-legal issues [see for review: 62,102$]$. In the second half of the twentieth century it became increasingly apparent that the clinical picture reflected a multifactorial state of affairs, in which organic, psychological, and sociomeconomic factors could play a role [7, 53]. Nonetheless, up to the late seventies, the prevailing view was that as there was no convincing evidence of an organic brain defect, the symptoms were psychogenic owing to the stress and insult of the accident, or feigned [51, 64]. The situation changed when it was recognized that the psychometry that had been used up to that time was not very sensitive to the effect of head injury $[32,44]$. With the use of sensitive and appropriate neuropsychological tests, it became possible to demonstrate subtle deficits of attention and information processing. In addition, the application of new neuroimaging techniques, such as MRI [58], has provided evidence of subclinical focal brain lesions, which made it clear that MHI may not be minor at all.

\section{Epidemiology of MHI and the Postconcussion Syndrome}

Traumatic brain injury is a condition occurring with a high incidence rate, varying between 130 and 208 hospitalizations per 100,000 inhabitants per year $[2,47,49,54]$. Not included in these numbers are MHI patients with slight concussion who are not hospitalized or seen by medical personnel [18]. Extrapolating from a Swedish study on the incidence of concussion in children [87], and a Dutch study of a representative sample of all concussed patients [103], one might expect that about $1 / 3$ to $1 / 4$ of all concussed patients are admitted to hospital. This would yield an overall incidence rate between 490 and 640 per 100,000 inhabitants. Depending on the strictness of criteria used to define head injury, the incidence ranges between 140 and 640 per 100,000 inhabitants [56]. A relatively high incidence of traumatic head injury in young male adults has consistently been reported [56,78]. The difference in injury rates between males and females may be partly explained by differences in alcohol consumption [78].

Table 1: Frequency of the past-concussiomal symptoms

\begin{tabular}{|c|c|c|c|c|c|c|}
\hline & $1 \mathrm{~m}$ & $6 w$ & $3 \mathrm{~m}$ & $6 \mathrm{~m}$ & $2 \mathrm{yr}$ & $3 y \mathbf{r}$ \\
\hline Russell 1932 [88] & & & & $49 \%$ & & \\
\hline Denker 1944 [20] & & & & & $33 \%$ & $.15 \%$ \\
\hline Jomes $1974[50]$ & $57 \%$ & & & & $1 \%$ & \\
\hline Lidvall et al. 1974 [64] & & & $24 \%$ & & & \\
\hline Rutherford et al 1977 [90] & $51 \%$ & & & & & \\
\hline Rutherford et al. 1979 [91] & & & & & $14.5 \%$ & \\
\hline Wrightson \& Gronwall $1980[107$ & & $20 \%$ & & & & \\
\hline Keshavan et al. 1981 [52] & & & $47 \%$ & & & \\
\hline Rimel et al 1981 [84] & & $84 \%$ & & & & \\
\hline Jakobsen et al. 1987 [48] & $29 \%$ & & & $15 \%$ & & \\
\hline Mahon \& Elger 1989 [70] & & $60 \%$ & & $21 \%$ & & \\
\hline
\end{tabular}

Although much is known about the incidence of traumatic head injury, less is known about the frequency and duration of PCS. For some time it was generally accepted that very few patients with minor head injury report PCS one month after injury. However, this view has been contradicted by studies of consecutive cases, which have shown that PCS are indeed reported for one year or longer after injury [15, 91]. Estimates of the frequency of the persistent syndrome vary widely, from 20 up to 80 per- 
cent $[48,84,92]$; see table 1 for more detalls. This discrepancy may be due to methodological differences, such as the heterogeneity of the patient group, the definition of MHI, the measures used to assess $P C S_{\text {, }}$ and the postinjury time $[21,92]$. Levin et al. [56] rightly commented that an exact count of PCS is difficult to make in a survey not assessing psychological impairments.

\section{Differential Diagnosis}

The principal differential diagnosis is of a neurotic reaction to head injury, ite., an adjustment disorder with depressed and anxious mood [85]. Major depression may complicate the PCS. In addition, the postconcussion syndrome should not be confused with post-traumatic stress disorder (PTSD). The PTSD diagnosis refers to emotional symptoms of an unusually distressing event [43]. Malingering must be considered in the differential diagnosis, especially when litigation is involved.

Lastly, the postwhiplash syndrome [108] consists of a number of subjective complaints that can occur after a whiplash injury to the neck. The subjective symptoms bear striking similarities to those of the postconcussion syndrome, such as headache, easy fatiguability, and irritability. More specific for the postwhiplash syndrome are vestibular symptoms, neckpain, and cervical paresthesias. Although a pure cervical whiplash injury is not characterized by a direct physical impact to the head, neurophysiological and neurochemical evidence is accumulating to indicate that a cervical injury may indirectly damage subcortical brain structures [14, 41, 46]. Bearing this in mind, it is plausible that cervical whiplash trauma and concussion may damage common brain structures. Moreover, the two conditions may sometimes occur together [75].

\section{Objective Measures of Assessment of MHI and PCS}

\section{NEUROPHYSIOLOGICAL AND NEUROMAGING MEASURES}

An exact quantification of the impairment is important, also in view of medico-legal problems. As clinical methods are not sensitive enough, neurophysiologicall and neuroimaging methods have been proposed as alternatives. Of the neuroimaging techniques, CT scanning and MRI have proven useful. For example, Sekino et al. [95] found that $7.6 \%$ of $171 \mathrm{MHI}$ patients who had been unconscious for less than 10 minutes had small lesions on CT scans. MRI has proven to be superior to CT scanning for the detection of lesions that may be relevant for neurobehavioral outcome, especially in the fronto-temporal region $[57,58,106]$. There is no role for EEG in the objecHive assessment of PCS (see Binder [8] for review). Schoenhuber and Gentilini[94] could not confirm the optimistic initial reports on the usefulness of Auditory Brainstem Evoked Responses in MHI [69, 79, 86].

The psychophysical assessment of tolerance to light and sound is another objective measure to assess the outcome of MHI. Waddell and Gronwall [105] demonstrated that MHI pattents had a significantly lower threshold to light 1-3 weeks after injury than healthy subjects. Using a computerized method that measures both maximal and submaximal levels of reduced tolerance. Bohnen et al. [13] found that MHI patients had a significantly decreased tolerance to sound stimuli over $71 \mathrm{~dB}$ and to light stimuli over 600 lux compared to nonconcussed controls, 3-6 days after injury.

\section{NEUROPSYCHOLOGICAL MEASURES}

Cognitive impairment is not uncommon after head injury, even when the injury is minor and does not require inpatient assessment or management. Neuropsychological investigations have been carried out ower the past few decades to evaluate behavioral and cognitive dysfunctions in patients with MHI. As can be seen from table 2 , there is a great difference between the various neuropsychological studies with respect to the 
definition of MHI, the measures of assessment, and a number of methodological factors, such as the appropriateness of the control group and the characteristics of the controll subjects for confounding factors. Gronwall and Wrightson [32] were two of the first researchers to suggest that a reduction in the capacity to process information could be an important factor in the genesis of the postconcussion syndrome. This reduction in information processing capacity has been used as a yardstick to measure the effect of MHI [31, 32]:

\section{Table 2}

Methodological characteristics and outcome of neuropsychological studies on MHI

[LOC=loss of consciousness; long=longitudinal; cross=cross-sectional; GCS=Glasgow Coma Score; hosp=hospitalisation (hours); $\mathrm{Y}=\mathrm{Yas} ; \mathrm{N}=\mathrm{Nol}$.

$\begin{array}{lllllllll}\text { Study: } & \begin{array}{l}\text { MHI } \\ \text { definition }\end{array} & \begin{array}{l}\text { long/ time Al A2 B } \\ \text { cross }\end{array} & \begin{array}{l}\text { post- } \\ \text { injury }\end{array} & \text { D2 } & \text { D2 }\end{array}$

\begin{tabular}{|c|c|c|c|c|c|c|c|c|c|c|c|c|}
\hline Gronwall \& Wrightson & 1974 & PTA $<24 h$ & long & $\begin{array}{l}35 \\
58 d\end{array}$ & $Y^{\prime}$ & $Y$ & $Y$ & 0 & $Y$ & 3 & $\mathbb{N}$ & $?$ \\
\hline Ewing et al. & 1980 & PTA $<48 h$ & cross & $1-3 y$ & $Y$ & $?$ & $\mathbf{N}$ & 0 & $x$ & 1 & $x$ & 7 \\
\hline Bartith et al. & 1983 & $\begin{array}{l}\text { LOC }<20 \\
\text { GCS } \\
\text { Hosp }<48\end{array}$ & $\begin{array}{l}\operatorname{coss} \\
13-15\end{array}$ & $3 \mathrm{~m}$ & $\mathbf{N}$ & $\mathbf{N}$ & $\mathbf{N}$ & 1 & $\mathrm{Y}$ & $x$ & $x$ & $\mathbb{N}$ \\
\hline McLean et al. & 1983 & $\begin{array}{l}\text { LOC }>10 \\
\text { PTA }>60\end{array}$ & long & $\begin{array}{l}3 \mathrm{~d}- \\
\mathrm{Imr}\end{array}$ & $\mathrm{N}$ & $\mathbb{N}$ & $\mathbf{Y}$ & 1 & $\mathbf{Y}$ & 1 & $\mathbb{N}$ & $?$ \\
\hline MacFymn et al. & 1984 & PTA $<24 h$ & $\operatorname{long}$ & $6 \mathrm{~m}$ & $?$ & $?$ & $\mathbf{Y}^{\prime}$ & 0 & $Y$ & 1 & $N$ & $p$ \\
\hline Gullbrandsen et al. & 1984 & $\mathrm{LOC}<15$ & gross & $\begin{array}{l}4 . \\
8 \mathrm{~m}\end{array}$ & $?$ & $Y$ & $?$ & 0 & $\mathbb{N}$ & 1 & $x$ & $?$ \\
\hline Gentilini et all. & 1985 & $\begin{array}{l}\text { Coma<20 } \\
\text { GCS13-15 } \\
\text { hosp }<72 \mathrm{~h}\end{array}$ & cross & $\operatorname{Im}$ & $\mathbf{Y}$ & $\mathrm{Y}$ & $?$ & 0 & $\mathbb{N}$ & 1 & $x$ & $"$ \\
\hline Dikmen at al. & $1986 \mathrm{a}$ & $\begin{array}{l}\text { Coma<60 } \\
\text { GCS12-15 } \\
\text { EMV }>12\end{array}$ & long & $\begin{array}{l}\operatorname{Im} \& \\
1 \mathrm{yr}\end{array}$ & $N$ & $\mathrm{Y}$ & $\mathbf{Y}$ & 1 & $\mathbf{Y}$ & 1 & $Y$ & $\mathbb{N}$ \\
\hline jakobsen et al & 1987 & PTA<24h & long & $3 \mathrm{~m}$ & $?$ & $?$ & $Y$ & 0 & $\mathbf{Y}$ & $\mathrm{N}$ & $N$ & $\ddot{p}$ \\
\hline Mchillan et al. & 1987 & $60<\mathrm{PTA}<24 \mathrm{~h}$ & noros & $1 w$ & $?$ & $?$ & $y$ & 1 & $\mathrm{~N}$ & 2 & $x$ & $?$ \\
\hline Levin at al. & $1987 \mathrm{~d}$ & $\begin{array}{l}\operatorname{LOC}<20 \\
\operatorname{CCS} 13-15 \\
\text { hosp }<43\end{array}$ & longs & $3 \mathrm{~m}$ & 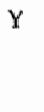 & $Y$ & Y. & 1 & $N$ & 1 & $N$ & 7 \\
\hline Hugenholltz et al. & 1988 & $\begin{array}{l}\text { Grade } 1-2 \\
\text { Ommaya \& } \\
\text { Gemnarelli (1 }\end{array}$ & $\begin{array}{l}\operatorname{lon} g \\
1974)\end{array}$ & $3 \mathrm{~m}$ & $Y$ & $?$ & $Y$ & 0 & $\mathrm{~N}$ & 1 & $Y$ & $?$ \\
\hline Barta et al. & 1989 & $\angle O C<2$ & long & $<1 y$ & $?$ & $\mathrm{Y}$ & ? & 0 & $\mathbb{N}$ & 2 & $Y$ & $?$ \\
\hline Gentilini et all. & 1989 & $\begin{array}{l}\text { LOC }<20 \\
\text { GCS13-15 } \\
\text { Hosp }<72\end{array}$ & long & $5 \mathrm{~m}$ & $Y$ & $Y$ & $Y$ & 0 & $\mathbb{N}$ & 1 & $Y$ & $x$ \\
\hline Leininger et al. & 1990 & $\begin{array}{l}\mathrm{LOC}<20 \\
\mathrm{CCS} 13-15\end{array}$ & ross & $\begin{array}{l}2- \\
22 m\end{array}$ & $Y$ & $N$ & $?$ & 0 & $Y$ & 1 & $x$ & $\mathbb{N}$ \\
\hline
\end{tabular}


Ail Exdmslon of patients with traumatic complicalions (such as neurological deficits, non-cerebral injuryt: Yes/No

\section{A2 Consecutive admissions: Yes/No}

B Exclusions of patients with confounding pre-existing conditions (such as previous head injury, neuropsychiatric disorder): Yes/No

C1 Outcome of measures other than neuropsychological measures: $0 / 1 \quad(1=$ psychosocial measure)

C2 Netropsychological results related to persistence of PCS: Yes/No

D1 Control group ( $0=$ none; $1=$ nonconcussed subjects; $2=$ traumatic orthopedic patients without head injury; 3 : MHI patients without symptoms).

\section{$\mathbb{D} 2$ Control for practice effect: Yes/No}

\section{G Exclusion of patients with compensation claims: Yes/No}

Whereas gross deficits in intelligence or memory have not been reported in MHI [21, $28,71]$, subtle deficits have been found [28, 44]. These deficits appear to selectively impair functions of attention and information processing and are most consistently seen with more complex and demanding tasks $[4,29,32,35,44,69,73]$. Therefore, refined and selective neuropsychological testing is required to detect subtle post-traumatic attentionall deficits [9, 72]. For example, Gentilini et al. [29] found significant differences between patients and controls on all tests from a battery dewised specifically to explore different aspects of attention, including measures of divided, selective, sustained, and attributed attention. Although these symptoms occurred in the absence of clear neurological abnormalities, these subtle cognitive deficits may be sufficiently disabling that patients may have difficulty returning to or maintaining employment, have siggnificant disruption of social life, and an increased incidence of depression or somatic illness [63].

With respect to the time course of recovery, the cognitive deficits are maximal in the first week after injury and tend to resolve spontaneously within three to four weeks in the majority of MHT patients [5, 61]. There is now evidence that the impairment may persist well beyond the first weeks of recovery, at least for some measures of reaction time and attention $[29,44]$, and may still be presient six months or even longer after the injury $[19,98]$. Th should be emphasized that a retum of test scores to a normal level does not necessarily imply full recovery from the trauma. For example, Ewing et al. [26] found that apparently recovered pattents showed cognitive deficits when exposed to a CNS stressor.

Although many patients recover substantially, there is a subgroup of MHI patients with persisting symptoms who may present with neuropsychological deficits [24, 55]. For example, Jakobsen et al. [45] were able to predict persisting PCS by means of a reaction time measure. In addition, Leininger et al. [55] found that symptomatic patients had deficits in tests of reasoning, information processing, and verbal learning in comparison with uninjured control subjects 1-22 months after the injury. This new approach of directly comparing symptomatic patients with nonconcussed control subjects or asymptomatic patients may be the most sensitive way of gaining insight into the cognitive correlates of persisting PCS rather than comparing an overall group of $\mathrm{MHI}$ patients with nonconcussed subjects. 


\section{Pathogenesis of Postconcussional Symptoms}

The pathogenesis of PCS has not been clearly establistied. Various avenues of investigation have been followed to explain the persistence of PCS. There is a striking disparity in the literature between those who argue for a psychogenic and those who argue for a physiogenic pathogenesis of the syndrome [63].

\section{PSYCHOLOGICAL EVIDENCE}

Psychological and motivational factors, especially litigation, have been cited as causes of continued PCS [76]. The lack of correspondence between the severity of injury and the persistence of symptoms has been interpreted as support for a psychogenic etiology of PCS. It is clear that the emotional repercussions of a life-threatening accident may be immense. The patient may fear the consequences of concussion and worry about the long-term impact of early symptoms. Depression is an ever-present risik, and feelings of guilt may emerge. Interruption of education or threats to a career can likewise have profound consequences on the patient's life (see Lishman [63] for review).

Apart from the direct emotional impact of concussion, Lishman [63] lists evidence to indicate that a neurotic personality, a history of psychiatric illness, and demographic variables, such as sex and marital status, are also important. A purely psychogenic viewpoint on the postconcussion syndrome is likely to consider the entity as a posttraumatic neurosis [76]. As mentioned above, the development and persistence of PCS has been attributed to secondary gain, particularly monetary $[17,76]$. Merskey and Woodforde [74], however, found no relationship between difficulties expressed after MHI and litigation, resolved or pending. In addition, resolution of compensation claims does not result in rapid cessation of postconcussion sequelae [96]. Guthkelch [37] reported a large series of 398 patients who all had compensation claims in this biased population only $6.8 \%$ were thought to have an accident neurosis or to be malingering" Alves et all. [1] assert that health care professionals should admit that they have overestimated the incidence of malingering and have failed to recognize that few patients exaggerate PCS for personal gain. It seems unreasonable to insist that patients with PCS suffer from accident neurosis [76], or are engaged in an active attempt to defraud, even though a few such cases exist. Litigation and compensation claims are an additional stressor and may contribute to the symptomatology of some patients, but there is no empirical evidence that the PCS are caused by the claims process (see Binder [8] for review).

\section{ORGANIC EVIDENCE}

Contrary to the view that emotional disturbances and/or motivation for compensa * tion primarily contribute to the morbidity of minor head trauma, evidence produced in the last decades supports an organic basis for the syndrome [101]. For example. Rutherford et al. [90] found that headache, anosmia, and diplopia 24 hours after injury were associated with higher symptom rates 6 weeks after the injury. Numerous reports show that the rotational and shearing forces genterated by head trauma result in neuronal damage $[42,81,82,97]$. The difference between severe and mild head injury is one of degree in this respect: mild head injuries result in less extensive neuronal damage [80]. In addition, there is evidence of neuropathological and neurophysiological alterations after these injuries, including neuronal damage, reduced cerebral blood flow, disturbances in water metabolism, altered brainstem-evoked potentials, neurotransmitters, brainstem dysfunction, and reduced speed of information processing $[6,10,32,79,81,86,93,100]$. For example, Taylor and Bell [100] reported that symptoms of headache, dizziness, and poor tolerance to effort were often seen to subside in parallel with a return of slowed circulation times to normal.

\section{THE INTERACTION CONCEPT}

It has become increasingly clear that both a purely psychogenic and a purely organic 
viewpoint have serious shortcomings in explaining the occurrence of persisting PCS [92]. For example, the dewelopment and exacerbation of symptoms weeks or months after MHI, as noted by Lidvall et al. [64], is difficult to explain on an organic basis. In addition, given the increasing amount of organic evidence, a purely psychogenic interpretation of PCS is allso umtenable.

Many years ago, Symonds [99] suggested that the etiology of PCS was cerebral damage, but that a symptomatic expression of PCS depended upon a psychological interaction with the neurological damage. He wrote that physiogenic and psychogenic factors were so closely intertwined that it would be unnatural to separate them. This interaction concept is now widely supported [68].: Multiple factors, such as pre-, peri- and post-traumatic factors, and their interaction, are probably responsible for the variability seen among patients with head injury $[22,24,66]$. Lishman [66] suggested that organic factors were chiefly relevant in the earlier stages, whereas persisting symptoms may be perpetuated by secondary neurotic developments.

Conflicting data are reported as to what factors predict the persistence of PCS after MHI. Age, sex, PTA, and duration may be of relewance $[20,77,78,90]$, but other studies report a lack of correlation between these prognostic factors and the persistence of PCS $[24,48$, 701. PTA has proven to be a reliable predictor of the outcome of head injury when applied to a population of patients with a broad range of severity of head injury [52, 60 , 92, 104]. With respect to selected populations of MHI patients, the duration of PTA is difficult to assess reliably if it is less than 1 hour $[34,73,90]$. Consequently, most studies do not report a consistent relationship between the duration of PTA and the persistence of PCS after MHI $[4,34,55,64,69]$. Although the evidence is not very strong, there are indications that elderly and less well educated subjects may be more vulnerable to protracted symptomatology after MHI $[4,18,20,24]$. It has been consistently shown that multiple concussions may have a cumulative effect in that they delay the cognitive and subjective recovery from new head injury [33].

\section{PCS AND ENVIRONMENTAL DEMANDS: THE COPING HYPOTHESIS}

Besides the possibility that an underlying cerebral dysfunction could manifest itself in

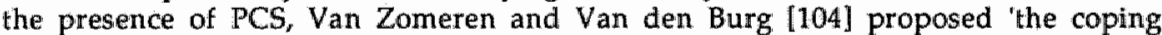
hypothesis' as an alternative explamation. The coping hypothesis asserts that PCS (in their terms: "intolerance" or 'neurotic' types of complaints) may result from a chronic effort made by patients to compensate for cognitive deficits. According to the coping hypothesis, it is when the patient is confronted with the stresses and strains of life that PCS develops. the fatigue and stress involved in attempting to deal with environmental demands may exacerbate certain PCS, such as headache and dizziness. [68]. For example, a patient who is lying quietly in bed is unlikely to develop complaints of irritability or intolerance to noise [92]. A rapid resumption of premorbid activities, resulting in stress when the patient's cognitive capacities prove deficient, may account for the increased incidence of PCS in MHI patients returning to school or work [32, 107]). Extending this idea, one might assume that these patients are under stress, and hypothesize that their symptoms are similar to those of stress reactions [40].

\section{Methodological Issues Surrounding Research on the Outcome of MHI}

It is clear that studies on the outcome of mild head injury and postconcussive symptoms are beset with many methodological problems. Most studies performed on MHI so far differ markedly with regard to a range of significant parameters Many factors can seriously flaw the reported outcome of a number of studies. The following points of ambiguity and methodological inconsistencies have to be considered in the evaltuation of research results on the outcome of MHI (see also table 2).

A. Ambiguities of definition of $\mathrm{MHI}$ in terms of severity, type of injury $r$ and medical complications. 
A-1 Inconsistencies in criteria for patient selection

There are great differences between studies with respect to the definition of patient populations in terms of selection criteria. Patients with focal neurological deficits should be excluded from studies on uncomplicated MHI. In addition, patients with traumatic noncerebral complications (e.g., orthopedic injuries) should be considered as a separate subgroup. Factors to be controlled include hospitalization, surgery; medication, and type of injury.

A-2 The sellection of consecutive admissions [21] as opposed to cases seen for clinicall reasons. These sources of selection bias of patient samples are reviewed by Dikmen and Temkin [23].

B: The confounding effects of pre-existing conditions and socio-cultural variables Civiliam head injury occurs in a nonrandom sample part of the population [59]. The confounding effects that can potentially obscure the effects of MHI include a history of head injury, CNS disease, neuropsychiatric disorders, alcoholism, and drug abuse. Patients with these factors should be excluded from studies on uncomplicated MHI. In addition, prognostic factors for neurobehawioral functioning, such as premorbid level of functioning, personality characteristics, age, and education, should be taken into consideration. Lastly, the three-center study by Levin and colleagues disclosed an immense contribution of socio-cultural factors to neurobehavioral performance despite the subjects hawing a similar educational background [61].

C. Variation in procedures for neurobehavioral assessment and the etiological factors chosen for scrutiny.

There is a lack of uniform and objective diagnostic criteria for defining a postconcussion symdrome. Consequently, different measures of outcome have been used such as neurological, neuropsychological, and functional aspects (employment, psychosocial measures). By lack of clear neurologicall parameters, neuropsychological measures have mostly been used as objective criteria for the evaluation of patients with persistent PCS. As the cognitive deficits after MHI may be subtle and may be better detected with more demanding tasks of attention and information processing [44], it is clear that cognitive criteria are arbitrary and depend on the selection and sensitivity of a particular task. The measures chosen for a study must be most sensitive to the presence of cognitive correlates of the pathological changes known to occur in MHI [9]. Most studies of MHI patients performed so far have mostly been limited to the study of a single diagnostic measure, and few studies have reported the serial psychological testing of adult patients with MHI $[44,61,69]$. Given the multifactorial nature of $\mathrm{MHI}$, studies should employ a multidiagnostic approach. Apart from neuropsychological measures, neurophysiological, neuroimaging, and behavioral measures should be applied for a more comprehensive assessment. Measures of psychological outcome can be used to assess primary and secondary emotional repercussions of the trauma. It should be noted that most researchers do not distinguish between patients who are merely inconvenienced and those who are disabled by their symptoms. The severity of the PCS has often been expressed as the total number of different symptoms per patient [90]. It will be clear that this a rather rough measure, the validity and reliability of which can be questioned. More reliable and valid approaches may be quantitative assessment of complaints by means of neurobehavioral rating scales [60].

\section{Appropriateness of the control group.}

Most studies have tended to rely on normal uninjured control subjects for assessment, rather than directly comparing patients with and without PCS following head injury [66]. It is evident that uninjured control subjects can only provide information about an overall effect of $\mathrm{MHI}$, but are less adequate to provide insight into the factors underlying PCS. A comparison group should also control for all prognostic factors related to the specific research questions, such as intelligence, socio-cultural background, and 
noncerebral traumatic complications.

\section{E. Timing of the study}

The vast majority of etiological investigations have been carried out during the early postinjury phase, usually within several weeks of the injury. Studies that cover a longer interval have often had difficulties with follow-up. The longer that PCS persist after the accident, the more evidence there is that nonorganic factors play a part. Complaining patients studied shortly after the accident will form a different population from those still complaining after several months or years [66]. Therefore, the time from injury to evaluation is an important factor in the evaluation of PCS.

\section{F. Environmental conditions and levels of stress}

According to the coping hypothesis, inadequate post-traumatic adaptive skills may enhance stress reactions when environmental demands are too high. Posit-traumatic adaptive skills can be viewed as the net effect of premorbid adjustment, coping ability, response to cognitive impairment, and the patient"s own standard, expectations and levels of perceived stress $[12,67,104]$. Studies on the pathogenesis of persisting PCS should consider these factors as well as the level of overall work load and type of ability under consideration.

\section{G. Compensation daims and litigation}

Taken together, our knowledge of the PCS is still quite fragmentary and not adequate to reconcile certain contradictory information that has begun to emerge [24]. The multifactorial pathogenesis of PCS warrants multidiagnostic approach with objective tests. MHI patients with evidence of a premorbid or traumatic compromising condition have to be excluded in order to focus on a homogeneous group of patients with a clearly defined uncomplicated MHI. Ideally, all etiological factors showld be measured simultaneously, and at repeated intervals during recovery, so as to assess their relative value, and, most importantly, how they might sometimes operate in conjunction with one and another [66].

\section{Discussion}

The essential point to be made about PCS is that several factors contribute to their development $[21,66]$. Each individual, then, needs to be evaluated for the contribution of these factors [22]. It is important to realize that MHI is often not an isolated injury, bul commonly occurs with a further injury to the head, skull, or neck. Other physical damage, particularly to the vestibular apparatus, can dictate important symptoms without being obvious. Vestibular concussion can cause post-traumatic vertigo with complaints of persistent dizziness or vertigo as well as tinnitus or hearing loss [39]. Head injuries may occur with neck trauma [75]. Cervical strain(s), disc disease, or exacerbation of pre-existing spondylosis may result. It is not surprising that these possibilities are often overlooked in the assessment of patients with head trauma. $X$-ray photographs may be normal despite considerable cervical strain(s), and standard veslibular assessment and electronystograms may miss perilymphatic fistulas or cupullolithiasis of the verticular semicircular canals [30]. Morbidity caused by injury to structures adjacent to the cranial wault may contribute to PCS [3]. In addition, some patients may develop, for the first time, typical migraines or experience an exacerbation of pre-existing nigraine after head trauma [38]. It is also important to note that the range of symptoms encompassed by PCS may be seen even where there has been no immediate loss of consclousness. In such cases, the term "post-traumatic syndrome" may be preferable.

The pendulum of the debate on PCS has swung between physiological and psychological theses. What the debate has tended to lack is an acknowledgment that the popula- 
tion of patients with PCS may not be homogeneous. Recent studies have indicated that most individuals who sustan MHI are free of a persistent neuropsychologicall dysfunction. Nevertheless, a subgroup of patients experience continuing postconcussive difficulties and neuropsychological deficits $[44,55]$. These subtle deficits of attention and information processing may adversely affect performance in any vocation or activity that entail decision-making or stress. New study designs, which focus directly on symptomatic patients, may deepen our insight into the neuropsychology related to PCS [55]. It might be even better to use a double control group design, in which symptomatic MHI patients are compared with both asymptomatic $\mathrm{MHI}$ patients and nonconcussed subjects. MHI patients experience difficulties whenever environmental demands exceed their cognitive capacities for dealing effectively with these demands ([68]. Patients often respond with an increased effort as a means of attaining their premorbid work output, resulting in rapid latigue, which further decreases their task efficiency and aggrevates a deficient cognitive functioning [32]. Given the frequent occurrence of depression and anxiety after MHI, th has been suggested that cognilive performance can deteriorate over time in cases when there are high levels of stress and emotional repercussions after the injury [32]. Bohnen et al. [11] demonstrated that deficits in divided attention are related to elevated levels of salivary cortisol in healthy nonconcussed subjects. By implication, an impaired post-traumatic performance in a neuropsychological test may by caused by different mechanisms and may result from structural brain damage. Alternatively, the cognitive dysfunction may result from emerging conditions of stress, and it is also possible that depression may compromise cognitive efficiency after the injury [59]. This may shed new light on the pathogenesis of post-traumatic cognitive deficits. Although cognitive deficits are currently interpreted as having an organic origin, there is also some evidence for a stress-related mechanism [11].

It may be clear that there is no place for dualistic thinking in the paradigm of $\mathrm{MHI}$ today. Even in the case of organic abnormalities, the symptoms of postconcussive syndrome provide the ideal nexus for neurotic elaboration because of the subjective, irrefutable, and unverifiable nature of the syndrome. It is also possible that some experimental etiological studies of PCS are revealing concomitants rather than etiologically relevant aspects of cerebral dysfunction [66].

Further research is needed to establish the etiology of the persistence of PCS. Neuroimaging may have far-reaching consequences for our current classification of MHI. Characterizing the type of brain injury by MRI (magnetic resonance imaging) could differentialte minor diffuse brain injury from MHI associated with occult intracranial lesions. For example, patients with bilateral orbitofrontal-temporal intracerebral lesions disclosed by MRI could represent a separate subgroup of patients with prominent memory problems [59].

\section{REFERENCES}

1. Alves WM, Colohan A, OtLeary TJ, Rimel RW and Jane I (1986) Undersianding poslitraumatic symptoms alter minor head injury. J Head Trauma Relvab 1: $1-12$.

2. Annegers JF, Grabow JD, Kurland LT, Laws Jt ER (1980) The incidence, causes and secular trend of thead trauma in Olmstead County, Minnesota 1935-1974. Neurology 30: 912-919.

3. Averbach HE (1987) The postconcussion syndrome: Formulating the problem Hosp Practice 22: 9-12.

4. Barth IT, Macciocchi 5N, Giordani B, Rimel R, Jane JA, Boll Th / (1983) Newropsychological sequelae of minor head injury. Neurosurgery $13.5291-533$.

5. Barth JT, Alyes WM, Ryan TV, Macciochi SN, Rimel RW, Jane JA, Neison WE (1989) Mild head imiury in sports: Neuropsychological sequelae and recovery of funckion. In: HS Levin, IM Eisenborg and AL Benton (eds) Mild head injury. New York, Oxford University Press, pp. 257-275.

6. Baron JB, Tamgapregassom MJ, Usho N, Debai A, Ponet f (1979) Neurotransmitkers dysregulation related to the orthostatic postural activity disorders in case of postconcussional syndrome after head or whiplash injuries. Int I Neurol 12: 237-249.

7. Benton AL (1989) Historical notes on the postconcussion syndrome. In: HS Levin, HM Eisenbergand Al. Benton (eds) Mild head injury. New York, Oxford Universily Press, pp.3\%7.

8. Binder LM (1986) Persisting symptoms after mild head injuryu review of the postconcussive 


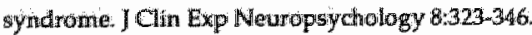

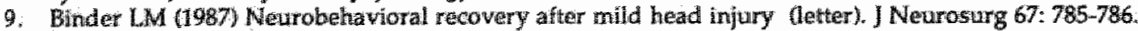

10. Bohnen N, Twinstra A, Terwel D, Jolles I (1990) Csf arginine wasopressin decreases during dehydra

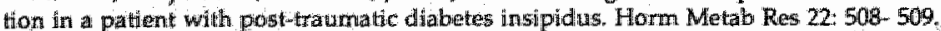

11. Bohnen $N_{\text {. Houx }} P$, Nicolson $N$, Jolles J (1991a) Cortisol reachivity and cognitive performance in a continuous mental task paradigrim. Biol Psychol in press.

12. Sohnen $N$, Nealson $N$, Sulon J. Jolles J (1991b) Cophing shylle, trait anxiaty and cortisol reactivity duting mental streas. J Psychosom Res: $35: 141-147$.

13. Bohnen $\mathrm{W}$, Iwifnittra A, Kroeze J, Jolles J 1991 d A psychophysical mathod for assessing wisual and acoutstuc hyperesthesid in patients with mild head injury. Br J Psychiat in press.

14. Boimare F, Boquet I, Moore N, Chreten P, Saligaut C, Datsit M (1985) Hemodynamic, behavioral and biochemical disturbances induced by an experimental cranio-cervical injury (whiplash) in rats. ) Aubon Nerw Syst 13: 137-147.

15. Cartidge WE (1977) Postconcussionial syndrome. Scott Med J 23* 103 .

16. Chadwick $O$, Rutter $M$, Brown $G$, Shaffer D, Traub M (1981) A prospective study of chlldren with head injury. 11 Cogniltwe sequelae. Psychol. Med. $11: 49-62$.

17. Cook J1 (1972) The posit-concussional syndrome and factors influencing recovery after minor head injury admitted to the hospital. Scand I Rehab Med 4: 27.30.

18. CoonleyHoganson $\mathrm{K}$, Sachs $\mathrm{N}$, Desal BT, Whitman $\mathrm{S}$ (1984) Sequelae associated with head injuries in patients who were not hospitalized: a follow-up survey. Neurosurgery 14: 315-317.

19. Dencker SW (1958) A follow-up study of 128 closed head injuries in twins using co-twins as controls. Acta Psychiat Neurol Seand 33 (supp 123) 1-125.

20. Denker PG (1944) The post-concussion synd nome: prognosis and ewaluation of the organic factors. New York State Med J $44: 379-384$.

21. Dikmen S, Melean A, Temkin N (1986a) Netropsychological and psychosocial consequences of minor head injury. I Neurol Neurosurg Psychiatry 49: 1227-1232.

22. Dikmen S, McLean A, Temikin NR (1986b) Neuropsychalogic outcome at one-month postinjury. Arch Phys Med Rehabil 67; 507.513.

23. Dikmem $S$, Temkin $N$ (1987) Determination of the effects of head injury and recovery in behavioral research. In HS Levin, I Grafman and HM Eisenberg (eds). Neurobehavioral recovery from head injury. New York, Oxford University Press, pp. 73-87.

24. Dikmen SS, Temkin N, Armsien $G$ (1989) Neuropsychological recovery: relationship to psychosocian functioning and postconcussional complaints. In: HS Levin. HM Eisenberg and AL Benton (eds) Mild head injury. New York, Oxford University Press, pp. 229-241.

25. Erichisen JD (1886) On concussion of the spine, nervous shock and o ther obscure injuries to the nervous system. Baltimore: Wilitiam Wood and Co.

26. Ewing $R$, MoCarthy D, Wrightson P (1980) Persisting effects of minor head injury observable during hypoxic stress.] Cin Neuropsychol 2: 147-155.

27. Galbraith $S$, Murray WR, Patel AR, Knill-Jomes $R$ (1976) The relationship between alcohol and injury and its effect on the conscious level. Br J Surg, 63: 128-130.

28. Gentilini M, Nichelli P, Schoenhuber R, Bortolotti P, Tonellí L, F alasca A, Merli GA. (1985) Neurapm sychological evaluation of mild head injury. I Neurol Neurosurg $\mathbb{P}_{\text {sychiatry }} 48: 137-140$.

29. Gentilini M, Nichelli $P$, Schoenhuber $R$. Assessmemt of attention in mild head injury. (1989) In: Levin HS, Eisenberg HM, Benton AL. (eds). Mild head injury. New York: Oxford University Press, PP. $163-175$.

30. Grimm RC, Henimway WG, Libray PR, Black FO (1989) The perilymph if istula syndrome defined in mild head tratima. Acta Otolaryngol Suppl $464: 140$.

31. Gronwall D, Sampson, H, (1974) The psychological effects of head injury. Auckland: University Press.

32. Gronwall D, Wrightson P (1974 Delayed recovery of intellectual function after minor head injury. Lancet 2:605-609.

33. Gronwall D, Wrightson $P$ (1975) Cumulative effects of concussion. Lancet 2: 995-997.

34. Cronwall D, Wrightson P (1980) Duration of post traumatic ammesia after mild head injury. I Clin Neuropisychol $2: 51 \cdot 60$.

35. Gronwall $\mathbb{D}$. Wrightson $P$ (1981) Memory and infomation processing capaciky after minor head injury. J Neurol Neurosurg Psychatry 44889-895.

36. Gullbrandsen GB (1984) Neuropsychology sequelae of light head injuries im older choldren 6 months after trame. ] Clin Neuropsychol, 6:257-268.

37. Guthkelch A (1980) Post-traumatic amnesie, postconcussional symptoms, and accident neurosis. Acta Neurochir 28: 120-123.

38. Haas DC, Lourie H 1988) Trauma-triggered migraine: an explanation for common neurological attacks after mild head injury. J Neurosurg 68: 181-188.

39. Healy GB (1982) Hearing loss and vertigo secondary to head injury. New Eng I Med 306: 1029-1031.

40. Hinkeldey NS, Corrigam ID (1990) The structure of head-injured patients neurobehavioral complaints: a preliminary study. Brain Injury $4: 115-133$. 
41. Hinoki M (1985) Vertigo due to whiplash injury: a newroblological approach. Acta Otolarymgol Suppl: 419. 9.29.

42. Holbourn AHS, (1943) Mechanics of head injuries. Lancet 2:438-441.

43. Horowitz MJ (1986) Stress-response symdromes; A review of post-tramatic stress aind adjustment disorders. Hosp Comm Psychiatry 37: 241-24:9.

44. Hugenholtz $\mathbb{H}$, Stuss DT, Stethem LL, Richard MT (1988) How long does it take to recover from and concussion? Neurosurgery 22,853858 .

45. Jacobson SA (1963) The post-traumatic synd rome following head injury. Springfield, IL: Charles C. Thomas CO.

46. Hacome DE (1987) EEG in whiplash: a reapprassal. Clin Electroencephalography 18: 41-45.

47. Jagger J, Levine Jl, Jane JA, Rimel RW (1984) Ephidemiologic foatures of head imjury in a predominantily rural population I Trauma 24: 40-44.

48. Jakobsen J, Baadsgaard SE, Thomsen S, Henriksen PB (1987) Prediction of post-concussional sequelae by reaction time rest. Acta Neurol Scand 75:341-345.

49. Johrison $R$, Gleave I (1987) Counting the people disabled by head injury Injury 18:7-9.

50. Jones RK (1974) Assessment of mininul head injuries" indication for in-hospital care. Surg Neurol 2 : $101-104$.

51. Jonsson $\mathrm{C}-\mathrm{O}$, Lidvall H, Mailhammer $\mathrm{G}$ (1967) An exploratory psychological study of the post-traumatic cerebral syndrome. Acta Neurol Scand 43; 158-166.

52. Keshavan MS, Channabasawannah SM1, Reddy GN (1981) Post-iraumatic psychiatric disturbances" patterns and predictors of outcome. Br ] Psychialt 138: 157-160.

53. Kozol HL (1946) Pretraumatic personality and peychiatric sequelae of head injury. Arch Neurol Psychiat 56: 245-275.

54. Kravs JF, Nourjah $P$ (1988) The epidemiology of mild, uncomplicated brain injury. I Trawma 28 : $1637-1643$.

55. Leininger BE, Gramling SE, Farrell AD, Kreutzer JS, Peck III EA (1990) Neturopsychological deficits in symptomatic minor head injury patients after concussion and mild concussion. I Neuroll Neurosing Psychiatisy 53: 293-296.

56. Levin HS, Benton AL, Grossmann RG (1982) Neurobehavioral consequences of dosed head injury. New York, Oxiord University Press.

57. Levin HS, Handel SF, Goldman AM, Eisenberg, HM, Guinto FC (1985) Magnetic resonance imaging after 'diffuse' nonmissile head injury. Arch Neurol 42: 963-968.

58. Lewin HS, Amparo E, Eisenberg HM, Williams DH, High WM, McArdle CB, Weiner RL (1987a) Magnetic resonance imaging and computerized tomography in relation to the neurobehavioral sequelae of mild and moderate head injury. J Neurosurg 66: 706-713.

59. Levin HS, Gary HE, High WM, Mattis S, Ruff RM, Eisenberg HM, Marshall LF, Tabad dor K (1987b) Minor head injury and the postconcussional syndrome: methodological issues in outcome studies. In HS Levin, I Grafmian and HM Eisenberg (eds). Neurobehavioral recovery from head injury. New York, Oxford University Press, pp. 262-275.

60. Levin HS, High WM, Goethe K, Sisson RA, Overall JE, Rhoades HM, Eisenberg HM, Kalisky ZVI, Gary $\mathrm{HE}$ (1987c) The neurobehavioral rating scale: assessment of the behavioural rating scale of head injury by the dinician. I Neurol Neurosurg Psychiatry 50: 183-193.

61. Levin HIS, Mattis S, Ruff RM, Essenberg HM, Marshall LF, Tabaddor K, High WM, Frankowski RF (1987d) Neurobehavierall outcome following minor head injury: a threecenter study. I Neurosurg 66:234-243.

62. Levin HS (1991) Pioneers in research on the behavioral sequelae of head injury. I Clin Exp Neuropsychology 13: 133-154.

63. Lishman WA (1988) Physlogenesis and psychogenesis in the "post-concussional syndrome'. Br J Psychiatry 153: 460-469.

64. Lidvall $\mathrm{FE}$, Linderoth B, Norlin B (1974) Causes of the postconcussional syndrome. Acta Neurol Scand $50($ Suppl 56$): 1-144$

65. Lishman WA (1973) The psychiatric sequelae of head injury: a review. Pychol Mad 3: 304-318.

66. Lishman WA 1988, Physiogenesis and psychogenesis in the 'post concussional syndrome. Br J Psychiatry 153: 460-469.

67. Lomg CI, Webb WL (1983) Psychological sequelae of head trauma. Psychiatr Med 1*35-71.

68. Long C], Novack TA (1986) Posticoncussion symptoms after head trauma.

69. MacFlynn G, Montgomery EA, Fenton GW, Rutherford W (1984) Measurement of reaction time following minor head injury. I Neurol Neurosurg Psychiatry 47:1326-1331.

70. Mahon D, Elger C (1989) Analysis of post-tramatic syndrone following a mild head injury. I Neurosci Nurs 21: 382-384.

71. McLean A, Temkin NR, Dikmen S, Wyler AR (1983) The behavioural sequelae of head injury. I Clin Neuropsychol 5: 361 .376.

72. McMillan TM (1985) Neuropsychological evaluation of mild head injury (letter). J Neurol Neurosurg Psychiatry 48: 847-848. 
73. MoMtilan IM, Glucksman EE (1987) The Neuropsychology of moderate head injury. II Nourol Neurosurg Psychiatry $50,393-397$.

74. Merskey $\mathrm{H}$, Woodforde 1 M (1972) Psychia tric sequelae of minor head injury. Brain 95: 521-528.

75. Michat DB; Guyot DR, Damody WR (1989) Coincidence of head and cervicall spine injury. I Neurctrauiriva 6: $177-189$.

76. Miller H (1961) Accident neurosis. Br Med I 15919-925.

77. Minderhowd JM, Boelens. MEM, Huizenga J, Satan RJ (1980) Treatment of minor head injuries. Clin Netral Neurosing $82: 127 \mathrm{~m} 140$

78. Minderhoud JM, van Zomeren AH (1984) Traumatische hersenletsels. Utrecht, Bohn, Scheltema Holkema.

79. Noseworthy IH, Miller J Muray TJ, Regan D (1981) Audutory brainstem responses in postconcussion syndrome. Arch Neurol 38:275-278.

80. Ommaya AK, Gennarelli TA (1974) Cerebral concussion and tramatic unconsciousness. Brain 97 : $633-654$

81. Oppenheimer DR (1968) Micorscopic lesions in the brain following head injury. I Neurol Neurosurg Psychiatry 31: 299-306.

82. Povlishock JT, Becker DP, Cheng CLY, Vaughan GW (1983) Axonal change in minor head injury. J Neuropesthol Exp Neurology $42: 225-242$.

83. Regler ) (1879) Uber die Folgen der Verletzung auf Eisenbahnen ins besondere der Verletzungen des Rúchemmarks. Berlin: G: Remes.

84. Rimel RW, Giordani B, Barth JT, Ball JT, Jane JA (1981) Disability caused by minor head injury. Nourosurgery $9: 221-228$.

85. Robertion A (1988) The posticoncussional syndrome then and now. A ust NZ J Psychiatry 22: $396-403$.

86. Rowe M), Carlson C (1980) Brainstem auditory evoked potentials in postconeussion dizziness. Arch Neurol 37:670-683.

87. Rune V. (1970) Acute head injuries in children. A retrospective, epidemiologic, and electroencephalographic study on primary school children in Umea. Acta Paediat Scand 209, 3-12.

88. Russell. WR (1932) Cerebral involvement in head injury. Brain 55: 5 49-603.

89. Russell WR (1971) The traumatic amnesias. Oxford: Oxford Umiversity Press.

90. Rutherford WH, Merrett JD, MCDonald $J \mathrm{R}$ (1977) Sequelae of concusstom caused by minor head injuries. Lancet i.: 1-4.

91. Rutherford WH, Merrett JD, McDonald JR (1979) Symptoms at one year following concussion from minor head injuries. Injury: 10: 225-230.

92. Rutherford WH (1989) Postooncussion symptomsi relationship to acute neurological indices, individual differences, and circumstances of injury. In HS Levin, HM Eisenberg and AL Benton (eds) Mild head injury. New York, Oxford University Press, PP. 217-228.

93. Schoenhuber R, Gentilini M (1986) Auditory brainstem responses in the prognosis of Iate postconcussional symptoms and neuropsychological dysfunction after minor head injury. Neurosurgery 19: 532-534.

94. Schoenhuber R, Gentilini M (1989) Neurophysiological assessment of mild head injury. In HS Levin, HM Eisenberg and AL. Benton (eds) Mild head injury. New York, Oxford University Press, pp. 142-150.

95. Sekino $\mathbb{H}$, Nakamura $N$, Muki $K$, Satoh J, Kikuchi $K$, Sanada $S$ (1981) Brain lesions detected by CT-scans in cases of minor head imjuries. Neurol Med Chir 21: 677-683.

96. Stead man ), Craham J (1970) Rehabilitation of the brain-jniured. Proc R Soc Med 63:23-27.

97. Strich (1961) Shearing of nerve fibers as a cause of brain damage due to head injury. Lancet 2 : $443-448$.

98. Stuss DT, stethem LL, Mugenholtz H, Picton T, Pivik J, Richard MT (1989) Reacton time after head injury: fatigua, divided and focused attention and consistency of perfornance. I Neurol Neurosurg Psychiertiry 52: $742-748$.

99. Symonds CP (1942) Discussion of differential diagnosis and treatment of postconcussional states. Proc $\mathrm{R}$ Soc Med 35: 601-607.

100. Taylor AR, Bell TK (1966) Slowing of cerebral circulation after concussional head injury. Lancet $178-180$.

101. Taylor AR (1967) Post-concussional sequelate. Br Med J 3: 67-71.

102. Trimble MR (1981) Post-tramatic neurosis: From railway spine to the whiplash. New York: John Wiley.

103. Van Hoof F (1973) Behandeling van patienten met een commotio cerebri. University of Utrecht, The Netherlands. Doctoral dissertation.

104. Van Zomeren AH, Van den Burg W (1985) Residual complaints of patients two year's after severe head injury. I Neurol Neurosurg Psychiatry 48:21-28\%

105. Waddell PA, Gronwall D. (1984) Sensitivity to light and sound following minor head injury. Acta Neurol Seand, $69: 270-276$.

106. Willson J17. Wiedmann KD, Hadley DM, Condon B, Teasdale G, Brooks DN (1988) Early and late mag netic resonance imaging and neuropsychological outcome after head injury, I Neurol Neursurg. 
Psychiatry 51: $391-396$.

107. Wrightson $P_{\text {s }}$ Gronwall $D$ (1980) Time off work and symptoms after minor head injury. Injury 12: 445454.

108. Yarnell PH, Rossie GV (1988) Minor whiplash head injury with major debilitation. Braln finj $2: 255-258$. 


\section{Questions Addressed in this Thesis}

It has been outlined above that studies on MHI are beset with methodological problems. Therefore, experimental methods designed to overcome some of the problems identified in previous studies were used in the studies described in this thesis. Moreover, the multifactorial pathogenesis of the postconcussion syndrome warrants a multidiagnostic approach with objective tests. MHII patients with evidence of a premorbid or traumatic compromising condition have to be excluded in order to focus on a homogeneous group of patients with a clearly defined uncomplicated MHI. In addition, both the patients and non-concussed control subjects were selected for the absence of evidence for neurobehavioral dysfunction, i.e. the absence of a history of preexisting emotional problems, allcoholism, epilepsy, birth trauma, centrall neurological deficits or disease, a systemic disease (e.g. SLE) or the use of psychoactive drugs.

Given these methodological and theoretical considerations, the thesis is organized to address the following groups of questions:

(Section A) Is it possible to evaluate objectively the outcome of MHI and PCS by tests that measure specific aspects of neurobehavioral functioning? Tests were developed to evaluate different aspects of neuropsychological and behavioral functions as well as of sensory hyperesthesia.

(Section B) What are the time-related characteristics of recovery from an uncomplicated MHI from a multidiagnostic perspective? In particular, what are the relationships between the outcome of certain diagnostic measures and the persistence of PCS after MHII?

(Section C) Is it possible to interpret the presence of PCS within the context of the coping hypothesis, which assigns a prominent role to the presence of post-traumatic stress reactions?

The following issues were addressed:

Assessment of visual and acoustic hyperesthesia after MHI (Chapters 2, 5 and 7)

Using a computerized psychophysical test that measures both maximal and submaximal levels of reduced tolerance, it was questioned firstly, whether $\mathrm{MHI}$ patients endure intense light and sound stimuli significantly less well than nonconcussed subjects (ch. 2); secondly, whether there is a significant recovery of these parameters in relation to recovery of behavioral complaints (ch. 5); and thirdly, whether symptomatic patients have a reduced tolerance to light and sound in comparison with asymptomatic patients and nonconcussed subjects 6 months after injury (ch. 7).

Post-traumatic cognitive deficits and complexity of the interference measure in the Stroop Color Word Interference test (Chapter 3)

It has become increasingly clear that even MHI can produce subtle cognitive deficits that selectively impair attention. The Stroop Color Word Interference test has been used to measure selective attention in head-injured patients. Generally, results indicate that head-injured patients do not perform the interference task less well than nonconcussed controls. It is possible that the Stroop Interference test is not sensitive enough to detect subtle changes in attentional performance after head injury. The aim of the work described in this chapter, therefore, was to test a newly developed subtask of the Stroop test which makes more demands on the subject by requiring them to shift between collor naming and word reading. The hypothesis was that MHI patients would have more difficulties with the more complex interference task than with the original task. 
Relationships between PCS and emotional complaints (Chapter 4)

There is much debate about whether $\mathbb{P C S}$ reflect emotional distress or primary post-traumatic brain dysfunction. This study describes a multivariate analysis of the inter-relationships between traditional postconcussite complaints and more emotional and vegetative symptoms so as to investigate which symptoms are related. In addition, it was investigated how ratings of the different symptoms differ between diflerent subgroups of MHI patients and nonconcussed volunteers.

\section{Persistence of PCS after uncomplicated MHI (Chapter 6)}

It was the aim of this study to examine prospectively a cohort of previously healthy subjects who had sustained an uncomplicated MHI that did not requite hospitalization. Postconcussive sequelae were recorded at each examination. Patients were also examined by using different objective tests and two belhavioral rating scales. The multidiagnostic and prospective nature of the study was chosen for a more comprehensive evaluation of the recovery and persistence of PCS to be investigated in a selected population of patients up to six months after an uncomplicated MHI.

\section{Cognitive deficits in relation to persisting PCS after MHI (Chapter 8)}

Most neuropsychological studies of MHI have compared head-injured patients with nonconcussed subjects instead of directly comparing MHI patients with and without PCS. It is possible that symptomatic patients may suffer from cognitive deficits in comparison with recovered MHI patients. The hypothesis was tested that six months after a MHI patients with PCS have cognitive dysfunctions in a selected battery of cognitive tests when compared with matched, symptom-free MHI patients and nonconcussed control subjects.

Stress, coping style, cognitive performance, and PCS (chapters 9-11)

In the last few decades evidence has accumulated that the stress response is not caused by the aversive or noxious nature of a stressor per se, but by an individual's ability to cope with the stressor. Salivary cortisol has been shown to be a sensitive measure of the stress response in man. Because of the striking similarity between stress symptoms and certain postconcussive symptoms, it has been suggested that PCS result from a chronic stress reaction as head-injured patients try to compensate for post-traumalic cognitive deficits by an enhanced mental effort. According to the coping hypothesis, PCS may represent the perceived post-traumatic stress, expressed as bodily symptoms, when a head-injured patient is not able to cope with environmental demands. The relationships between stress, coping abilities, and cognitive functions in healthy volunteers were studied first (ch. 9 and 10). This type of study was then extended to MHI patients to evaluate the coping hypothesis further in head-injured patients (ch. 11). 
CLUSTER A: Diagnostic Measures of Mild Head Injury and Postconcussive Symptoms

Difficultes in quantifying the subjective postconcussive complaints, which may persist in the absence of clear neurological or other abnormalities, led earlier workers to advance a psychogenic explanation of the development of the syndrome" (Waddell \& Gronwall, 1984)

2. A psychophysical method for assessing visual and acoustic hyperesthesia in patients with mild head injury.

3. Modification of Stroop Color Word test improves differentiation between patients with mild head injury and matched controls.

4. Post-traumatic and emotional symptoms in different subgroups of patients with mild head injury. 


\title{
Chapter 2
}

\section{A Psychophysical Method for Assessing Visual and Acoustic Hyperesthesia in Patients with Mild Head Injury}

\author{
N. Bohnen ${ }^{2}$. A. Twiphstra ${ }^{2}$ J. Kroeze ${ }^{3}$ and J. Jolles
}

1. Department of Neuropsychology \& Psychobiology, University of Limburg, Maastricht. The Netherlands.

2. Department of Neurology, University Hospital of Maastricht, The Netherlands.

3. Laboratory of Psychology, University of Utrecht, Utrecht, The Netherlands.

Br J Psychiat: in press

\section{Summary}

Although it is a well-known clinical observation that patients with mild head injury (MHI) are less able to endure intense light and sound stimuli than normal people, there are few psychophysical studies that have objectively measured this type of hyperesthesia. Moreover, these studies have only assessed the maximal or threshold level of reduced tolerance. It is still unclear to what extent patients with MHI have a lowered tolerance to light and sound at a submaximal level. In the present study, using a computerized rating scale technique, it was possible to assess both the maximal and submaximal levels of reduced tolerance to light and sound for a wide range of stimuli. We found that MHI patients $(\mathrm{N}=20)$ 3-6 days after the trauma were significantly less tolerant to stimuli of intensities from $71 \mathrm{~dB}$ and 500 lux levels than controls $(n=20)$. As these intensities are common in dally life, MHI patients may easily get disturbed by many daily life situations.

\section{Introduction}

The postconcussional syndrome (PCS) refers to a number of symptoms and signs that may occur singly or in combination after usually minor head trauma. These symptoms are a mixture of quasi-organic and subjective symptoms, such as headache, dizziness, easy fatiguability, insomnia, lowered tolerance to noise and light, irritability and difficulties with memory or concentration. There is disagreement in the literature between those who argue for a physiological pathogenesis and those who favour a psychological pathogenesis [2,7]. A subjective and invalidating symptom is the lowered tolerance to intense light and sound stimuli. There are few psychophysical studies that have studied this type of hyperesthesia $[6,11]$. As an example of so-called organic evidence, Waddell and Gronwall [11] tested tolerance to light and sound on a more objective basis and demonstrated that $\mathrm{MHI}$ patients had a significantly lower threshold of tolerance to light and a slightly decreased tolerance to sound 1.3 weeks after injury than healthy controls. In addition, they found no relationship between the subjective ratings and the objectively assessed levels of reduced tolerance. Moreover ${ }_{s}$ it appeared that the number of objectively demonstrated deficits was larger than the number of spontaneous complaints.

The physophysical studies performed so far $[6,11]$ did only measure the maximal level or threshold of reduced tolerance to an increasing intensity of sound and light, but did not provide information on submaximal levels of lowered tolerance. The present study describes another method of assessing tolerance to light and sound on a more objective basis. This method not only measures the maximal level of reduced tolerance, but can also be used to compare the submaximal levels of lowered tollerance by applying a graded tolerance scale for each stimulus. 
A major problem in the literature is the controversial use of psychophysical terms. Lowered tolerance has often been confused with sensitivity and hypersensitivity to light and sound. For reasons of clarity, only the term 'tolerance" will be used in this article and is defined as the subjective ability to endure higher intensities of light and sound stimuli. In contrast, sensitivity and hypersensitivity refer to absolute or nelative perception and thresholds of perception [3].

If was the aim of the present study to compare the maximal and submaximal levels of reduced tolerance to light and sound stimull of MHI patients with those of matched healthy controls.

It should be emphasized that the development of the test primarily aims at assessing neurobehavioral dysfunction, which in turn might contribute to an operationalization of the postconcussional syndrome.

\section{Materials and methods}

Method of rating the magnitude of tolerance.

Light and sound stimuli of 5 different intensithes were presented using a computer. A personal computer with a parallel interface controlled both a tone generator (calibrated for $1000 \mathrm{~Hz}$ ) with varying amplitude and a $50 \mathrm{~W}$ tungsten-halogen lamp (Osram, Halostar, AR 111, $50 \mathrm{~W}, 12 \mathrm{~V}$ ). The tone generator was connected to a pair of ATH-910 earphones (Audiotechnica) with noise reducing caps. The $50 \mathrm{~W}$ incandescant lamp was placed in round tube. The glass-covered aperture $(10 \mathrm{~cm}$ in diameter) was surrounded by a black ring and the tube was mounted on a mobile and adjustable stand.

Five intensities of sound (1000 Hz pure tone) and light were chosen on the empirical basis that they could be clearly distinguished by the human ear and eye $(57,71,81,89 \&$ $95 \mathrm{~dB}$-sound pressure level-for sound and 440,500,600, 1000 \& 1500 lux for light). The instrument was calibrated in a sound proof room $(3 \times 4 \mathrm{~m})$ with a background illumination of 300 lux by means of a sound pressure level $\mathrm{dB}$ and lux devices of measurement. Each of the five intensities was randomly presented 8 times; there were separate sessions for the two types of stimuli. Thus, a subject received a total of 40 stimuli for each sound and light session. Each stimulus was presented for 4 seconds, and was followed by a constant interval. The rise-fall time of the physical stimulus was greater than 10 msec. The interval was kept constant in order to achieve a relative constancy in individual habituation processess (for sound 6 seconds and for light 12 seconds; see also Stevens and Stevens, [9]; Bof et al, [3]). During this interval, the subject was asked to evaluate the preceding stimulus on a 7 point rating scale, ranging from totally bearable/tolerant (score: s0), via very mildly (s1), millly (s2), moderately (s3), moderately to severely ( $(44)$, severely (s5) to totally unbearable (s6). The response was given by pressing a button on a 7 point key board. After the session, the median. tolerance value was calculated for each intensity. These median values were used for statistical analysis.

\section{Sound}

The minimum lewels of nouse in the examination room were in the range 46 to $51 \mathrm{~dB}$. Before putting on the earphones, the subject received the following instructions:

'You will hear a series of sounds of varying intensity through your headphones. Each sound will be presented for 4 seconds. After the tone has finished, please press the buttton on the 7 point key board that corresponds to the degree of tolerance you have experienced. The left button means that you can tolerate the sound stimulus, the one of the extreme right means that you find the sound unbearable. The buttons in-between correspond to a decreasing scale of tolerance from left to right. A new stimulus will be presented automatically after 6 seconds. Forty stimuli of mixed intensity will be given at random.' 


\section{Light}

The average background illumination in the examination room was about 300 lux with dimmed windows. Each subject was seated so as to look into the centre of the light source at 1 metre distance from their eyes. The subjects received the following instructions:

Look into the centre of the lamp. The lamp will shine for 4 seconds. You will then have 12 seconds to press a button on this 7 point key board that corresponds to the degree of tolerance you have experienced. The left button means that you can tolerate the light stimulus, the one on the extreme right means that you find the light unbearable. The buttons in-between correspond to a decreasing scale of tolerance from left to right. Each new stimulus will be presented automatically after 12 seconds. Forty stimuli of different intensity will be given at random."

\section{Subjects}

Twenty patients with MHI, who were not selected on the basis of post-concussional symptoms, were recruited from the Accident and Emergency Department of the Universital Hospital of Maastricht. All subjects had been unconscious for a period ranging from some several seconds to 15 minutes; post-traumatic amnesia had lasted for less than 60 minutes. The EMV (Glasgow Coma) score for each patient on admission was 15. None of the patients had evidence of a focal neurological deficit, and none had evidence of a skull fracture. Patients were excluded if they had consumed alcohol at the time of the accident or if they had a history of pre-existing emotional problems. In addition, patients with hearing and visual problems were not eligible. The patients were tested 3-6 days after the trauma. The mean age was 26.4 11.2 (SD) years: 11 males and 9 females. Only 2 patients were totally free from symptoms (in terms of headache and dizziness) at the time of testing.

The patients were matched with paid control subjects for sex, age (plus or minus 3 years) and educational level (plus or minus 1 level). The educational level was assessed using the scale of Verhage [1.0], which has seven categories based on the nature and duration of education in the Netherlands. The control subjects $(n=20$; mean age $26.9 \pm 12.3$ years) had not been exposed to risk factors for brain dysfunction, such as brain tratuma or a neuropsychiatric history. Informed consent was obtained from all subjects.

\section{Statistical Analysis}

The first step in the analysis was to assess whether there was an overall difference between the two groups for all the five intensities of light and sound. Becausie of the ordinal level of the rating scale, the ranks over all observations per intensity were cilculated [4] and were analysed by multivariate analysis of vartance (MANOVA [8]). In the second step, separate analyses per intensity were carried out using Wilcoxon's rank sum test. A probability level of less than 0.05 defined a significant difference.

\section{Results}

There was an overall significant difference between the tolerance of MHI patients and controls to both sound (Wilk's Lambda: $F(5,34)=6.84, P<0.001$ ) and to light (Wilk's Lambda: $F(5,34)=6.64, P<0.001$ ), see also figure 1. Separate Wilcoxon tests per intensily indicated that the MHI patients tolerated the $71(z=2.1, \mathbb{P}<0.05), 81(z=3.1, \mathbb{P}<0.01), 89$ $(z=3.9, P<0.001)$ and $95(z=4.1, P<0.001) d B$, and the $500(z=2.6, P<0.01), 600(z=3.5, P<0.001)$, $1000(z=4.1, P<0.001)$ and $1500(z=4.3, P<0.001)$ lux levels significantly less well than the control subjects.

It was found that none of the controls demonstrated a severely to reduced level of tolerance (score 5-6) to any of the light and sound stimuli, In contrast, there were 13 patients $(\mathrm{N}=20)$ who had a severely to totally reduced level of tolerance ( $(5-6)$ to $95 \mathrm{~dB}$, and 9 patients to 1500 lux 
Tolerange to sound

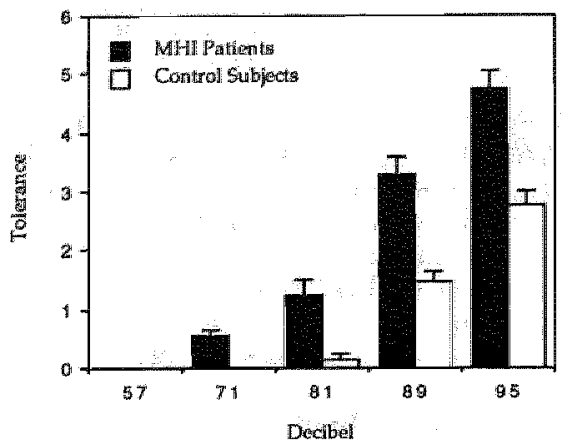

Tolerance to Higiht

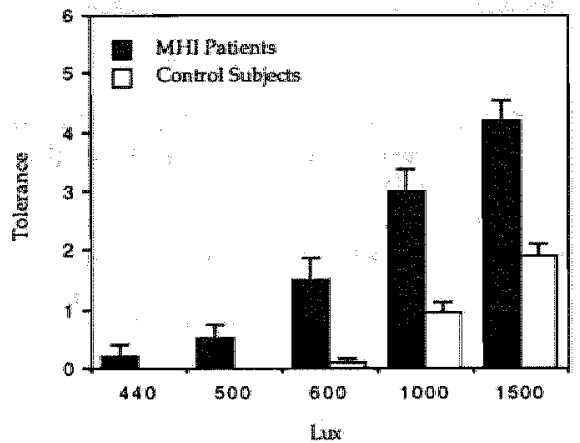

[Figure 1 Mean levels of tolerance of the patient and control group per intensity (means 4 SEMA) are presented ( 0 completely tolerant; $6=$ completely umbearable).

\section{Discussion}

Jonsson et al. [6] found that MHI patients with persistent postconcussional symptoms had a significanty lower ability to endure intense sound and light stimuli than heallhy controls. However, their results should be considered with some caution, as the study did not include MHI patients without postconcussional symptoms. Waddell and Gronwall [11] found that the mean luminance tolerated by an aselect group of MHI patients 1-3 weeks after the trauma was significantly lower than that tolerated by controls (1366 resp. 1783 lux). Although the mean sound intensity tolerated by the same patients was also lower than that tolerated by controls, this difference was not statistically significant (82 resp. $94 \mathrm{~dB}$ ).

Using the method described, we found that not only tolerance to light, but also tollerance to sound was significantly decreased in MHI patients compared with the tolerance of matched controls. With respect to sub-maximal levels of reduced tolerance to less intense stimuli, MHI patients were significantly less tolerant to low sound $(71$ $\mathrm{dB}$ ) and light intensities ( $500 \mathrm{lux}$ ) than healthy controls. This means that, for example the shining of a lamp or the noise of traffic could disturb a MHI patient. With respect to the presence of subjective postconcussional symptoms, it was striking that the two patients who had no subjective complaints at the time of testing were also more tolerant to the stimuli.

The finding of Waddell: and Gronwall [11] that subjectively reported lowered tolerance to light and sound was unrelated to objectively demonstrated deficits suggests that an objective basis for such complaints exists even though these symptoms are not always reported. Moreover, Jonsson et al. [6] found that in contrast to reported neurasthenic complaints, MHI patients with persistent symptoms 1-3 months after the trauma had a decreased tolerance to light and sound in comparison with neurotic control patients.

The experimental data available at present do not give a clear indication of how the visual and auditory system changes in MHI patients. Sensory data from receptors must be screened, filtered and evaluated under the control of higher cortical centres, including the prefrontal cortex and the limbic system. The reciprocal connectivity of the prefrontal cortex with several areas of the sensory and parasensory assiociation cortex is especially abundant in primates [5]. While traumatic brain injury mainly affects the brain diffusely [1], Walsh [12] has noted that the frontal and temporal lobes are particularly vulnerable because of the way they rest against the base of the skull. Taken together, it seems quite plausible that the changes in tolerance to light and sound are a 
manifestation of a lack of inhibitory control by orbital frontal cortex areas over sensory information processed by posterior brain areas and subcortical centres. More research is needed to evaluate this notion more fully. With respect to other concepts in psychophysics, there is no clear information at the moment about the relationships between tolerance versus (hyper/sensitivity and subjective loudness or brightmess.

The present results indicate that the tolerance of MHI patients to light and sound is a gradual rather than threshold phenomenon. Tolerance decreases with increasing intensity lewels. MHI patients may already be disturbed by intensity levels of sound or light common to daily life in an early phase after the trauma. Further research is aimed at investigating the tolerance of patients with persistent post-traumatic symptoms to light and sound in order to better evaluate the organic basis of the persistent postconcussional syndrome.

\section{References}

1. Alexander MP. (1982) Traumatic brain injury. In Psychiatric aspects of neurologic disease. Volume Ill. (eds Benson \& Blumer),pp. 219-250. New York: Grune \& Stratton.

2. Binder LM. (1986) Persisting symptoms after mild head injury: a review of the postconcussive synd rome TClin Exp Neuropsyrchol B,323-346.

3. Boff KR, Kaufman L. Thomas JP. (1986) Handbook of perception and human performance. Volume I: Sensory processes and perception. New York: John Wiley and sons.

4. Conover WI, Iman RL. (1981) Rank transformations as a bridge between parametric and nonparametric statistics. A.m Statistician, 35, 124-129.

5. Fuster JM. (1989) The prefrontal cortex (2nd edn). New York" Raven Press.

6. Jomsson C-O, Lidvall H, Malhammer G. (1967) An exploratory psychological study of the post-traumatic cerebral syndrome. Acta Neurolo 5cand 43,158-166.

7. Lishman WA (1988) Physiogenesis and psychogenesis in the "post-concussional syndrome". Br J Psychiatry, $153,460-469$.

8. SAS (1985) User's Guide. Statistics (Version 5 edn). North Carolina, Cary, SAS Institute Inc.

9. Stevens J C, Stevens SS. (1963) Brightness function: effects of adlaptation. J Opt Soc Am 55, 375-385.

10. Verhage R. (1964) Intelligentie en leeftijd. Dissertation. Assen, The Netherlands.

11. Waddell PA, Gronwall DMA. (1984) Sensitivity to light and sound following minor head injury. Acta Neurol Scand 69,270-276.

12. Walsh KW. (1987) Neuropsychology: a clinical approach. New York: Livingston. 
Chapter 3

\title{
Modification of the Stroop Color Word Test Improves Differentiation between Patients with Mild Head Injury and Matched Controls
}

\author{
N. Bohnen 1, J. Jolles1 \& A. Twijnistra2
}

1 Department of Neuropsychology \& Psychobiology, Uniwersity of Limburg, Maastricht, The Netherlands; 2 Department of Neurology, University Hospital Maastricht, The Netherlands.

\section{Submitted.}

\section{Summary}

Previous studies have indicated that patients with mild head injury have no specific deficits in selective attention as assessed with the Stroop Color Word Interference test. It has been reported that patients may be slower to name colors, but that they are not disproportionately slower on the subtask with color-word interference. The present study examined whether the performance of patients with mild head injury (MHI) was worse than that of nonconcussed controls on modified Stroop interference subtask of increased complexity. Patients $(n=44)$ were individually matched with controls for age, sex and education. It was found that MHI patients were significantly slower at this nodified subtask, whereas there was no significant difference between the two groups with the original interference subtask. The findings support the hypothesis that the cog* nitive disturbances of patients with mild head injury may be subtle and only demonstrable with more sensitive tests..

Key Words: attention, mild head injury, Stroop Color Word Test

\section{$\underline{\text { Introduction }}$}

Patients with mild head injury (MHI) may complain of a number of postconcussive symptoms, including headache, fatigue and cognitive problems [4]. There is circumstantial evidence that the cognitive difficulties are especially experienced when MHI patients have to perform different tasks under time pressure or stress. Evidence is accumulating to indicate that even mild to moderate head injury may produce subtle cognitive deficits. These deficits are not usually detected with traditional neuropsychological tests of intelligence or memory [8], but can only be demonstrated with more sensitive techniques of information processing and attention [3]. Studies on attention and head injury have usually focused on patients with moderate to severe injuries, and results indicate that deficits in divided attention are clearly present, whereas studies on selective or sustained attention yield conflicting results [13].

The Stroop Color Word Test [9] has been used to measure selective attention in patients with head injury [13]. Although the Stroop test consists in various forms, the essence of the test is that performance at several subtests is compared. The color-word interference subtask requires the subject to name a set of colors when they are printed as letters in a conflicting color (e.g., 'blue' printed in green ink). The performance of subtests on this subtask is compared with the performance on other subtasks in which the subjects read color words printed in black or in the appropriate colored ink. Stroop [9] found that subjects take longer to perform on the color word interference subtask than the other two subtasks. Generally, the difference in time needed is thought to be because the automatic reading response interferes with the response required by the task and can be taken as a measure of selective attention $[2,5]$.

So far, studies that have applied the Stroop Color Word Test to patients with head in- 
juries have yielded consistent results and indicate that subjects who are recovering from head injuries are slower than controls in the both color naming and color naming with interference subtasks, but that they are not disproportionately slower in the interference task $[1,10,11]$.

McLean et al. [7] found that patients with moderate to severe head injury differed from controls on all three measures of the Stroop Test three days after the injury. No differences were found between the two groups six months after the injury, although the authors commented that the difference in the interference measure just failed to reach statistical significance. This tendency to a difference between the two groups suggests that a subtle persistent deficit of selective attention as revealed by performance in the Stroop test might be present in patients with head injury. It is possible that the Stroop interference test is not sensitive enough to detect subtle changes in attentional performance after head injury. Moreover, the demands in terms of executive functions [6] in the Stroop Test are not very complex as the requirement of naming the colors of words is constant during the interference condition involving 100 words [13].

The aim of the present study was to test a newly developed subtask of the Stroop Test which makes more demands on the subject by requiring them to shift between color naming and word reading. We tested the hypothesis that patients about 10 days after a mild head injury are slower than matched healthy controls in performing a modified subtask of complex color-word interference. The demands of the new subtask are greater than those of the orthodox color-word interference subtask as flexibility is required for the naming and reading of the items depending on a speciall visual cue given with the words.

It should be emphasized that the development of the new subtask primarily aims at assessing neurobehavioral dysfunction, which in turn might contribute to an operationalization of the postconcussional syndrome.

\section{Subjects and Methods}

\section{Subjects}

Patients $(n=44)$ were selected from a larger group of patients who were participants in a comprehensive cohort study of patients with very mild to mild head injury. The criteria for inclusion in the study included a post-tratimatic interval of about 10 days (6-14 days), a post-traumatic amnesia not exceeding 60 minutes, a period of unconsciousness of less then 15 minutes, a Glasgow Coma Score of 15 on admission, no serious traumatic physical complication (including the absence of an orthopaedic injury) and willingness to participate. Patients who were intoxicated at the time of the trauma or who had a skull fracture were also exluded. None of the subjects were imvolved in litigation and none had a neuropsychiatric history. Patients were individually matched with healthy controls for age $(+/-4$ years), sex and educational level $(+/-1$ level [12]) in order to control for possible biasing effects. All patients and controls were younger than 45 years. None of the subjects were color blind. The causes of the injury were traffic (32), falls (5), fights (1), sports (5), and accident at work (1); $\mathbb{N}=44$.

The matched control subjects $(n=44)$ were selected from a pool of healthy nonconcussed volunteers. The mean age and educational level of these subjects are presented in table 1. All subjects gave their informed consent.

\section{Table 1}

Mean age and educational level [12] of the patient and control groups.

Age Educational Level

\begin{tabular}{lll}
\hline Patients & $24.5(8.9)$ & $5.0(0.9)$ \\
Controls & $23.4(8.1)$ & $4.9(0.8)$
\end{tabular}




\section{Test Material}

Stroop Test. The Stroop Color-Word Interference Test used in the present study is a version commercially avallable in the Netherlands (Swets \& Zeitlinger, Lisse, 1971). The test consists of three parts, with each part being presented on a $21 \times 29.5 \mathrm{~cm}$ sheet of paper. Ten lines are printed in each subtask with 10 items per line. The test examines the speed at which the namies of a 100 color (yellow, green, red and blue) are read (subtask I) and the speed at which 100 colored spots are named (subtask ID). Subtask III again involves 100 color names, but the naming of the printing ink of the words is taken as the test variable. The color-word interference score is obtained by subtraction of the time needed for subtask II from that of subtask III.

\section{New Subtask IV}

Twenty items from subtask III were randomly selected, and small rectangles $(0.8+2.0 \mathrm{~cm}$ ) were drawn around these words (see figure 1). The modiffed subtask (subtask 'IV') was further the same as subtask III, except that the subject was requested to read the printed word within the rectangles. Subtraction of the time needed for subtask II (color naming) from that for subtask IV (IV-II) was calculated as a measure of interference for subtask IV. All subjects were instructed to perform the task as quickly and as accurately as possible.

\section{Analysis}

The two measures of interference for subtask III (III-II) and subtask IV (IV-II) were used as the cognitive parameters in the present study. One-talled significance levels were applied corresponding to the unidirectional hypothesis.

\section{$\underline{\text { Results }}$}

The results for the four subtasks of the Stroop Test are presented in table 2. "T-tests (86 d.f.) indicated that there was no significant difference between the patients and controls for the original interference score (III-II): $30.07(11.10)$ and $28.73(9.51)$, respectively; $t=-0.6$ ns. In contrast, the interference score for the modified subtask (IV-II) was significantly different in patients and controls: $48.09(16.69)$ and $42.39(13.86)$, respectively; $t=-1.73$, $P<0.05$ (one-tailed). This indicates that there was only a significant effect at the modified interference measure.

\begin{tabular}{|c|c|c|c|c|c|c|c|c|c|}
\hline rigd & blü & yollow & grean & yellow & red & blua & red & red & red \\
\hline yolliow & bluia & yellow & rod & Yellow & grean & green & blue & rod & blute \\
\hline grem & graen & grean & gremn & red & green & green & red & yellow & yollow \\
\hline grawin & yollow & grean & green: & red & green & red & yellow & riod & red \\
\hline Yollow & groem & green: & blue & green & red & green & red & yellow & yellow \\
\hline yollow & green & gremon & groen & red & green & groen & yellow & ned & ingd \\
\hline nirid & rod & vellow & green & groen & bluie & green & blue & to & yellow \\
\hline biue & groen & bivo & red & grean & yellow & yellow & blue & blue & blue \\
\hline b) & yellow & yellow & yollow & yellow & blue & blue & yeltow & green & ried \\
\hline yellow & read & rod & green & 100 & red: & green & yellow & yollow & blue \\
\hline
\end{tabular}


Tablle 2

Results of the Stroop Color-Word Interference Test. Means are presented whith SD.

Patients

Controls

\begin{tabular}{lrlll}
\hline I & 43.22 & $(7.55)$ & 41.94 & $(5.27)$ \\
II & 57.96 & $(9.99)$ & 54.54 & $(9.01)$ \\
III & 88.03 & $(16.79)$ & 83.28 & $(1.4 .76)$ \\
M & 106.06 & $(22.84)$ & 96.93 & $(18.51)$
\end{tabular}

\section{Discussion}

Studies in which the Stroop Color Word.Test has been used with patients with head injuries have yielded consistent results indicating that the patients have no specific difficulty in focusing on the color dimension of the ambiguous stimuli $[1,10,11]$. The results of the present study confirm this finding in patients with mild head injury, as assessed by the standard Stroop-Color Word Interference Test. Scores for the modified subtask of increased complexity, however, indicated that the patients with MHIL were significantly slower than the controls. The extra mental flexibility and strategies needed in the modified subtask to direct attention to the different interference stimuli may have solely been responsible for this effect [5].

The present findings support the hypothesis that the cognitive deficits in patients with $\mathrm{MHI}$ are subtle and that the orthodox color-word interference test may not be sensitive enough to detect differences between concussed and nonconcussed subjects [7]. That the modified subtask requires more effort is consistent with circumstantial evidence that MHI patients especially experience their cognitive shortcomings when they have to deal with complexity or have to perform under time pressure. The patients appear to be able to cope with the demands of everyday life only when no time pressure is laid upon them or when they are allowed to do one thing at the time at their own tempo. Notwithstanding the significant difference between the two groups, the variability among subjects was high: statistical differentiation between groups does not mean individual prediction. Nevertheless, it is clear that a number of patients recover quickly after MHI and do not have problems, whereas others recover slowly and have problems. This could imply that the present series of pattients is heterogeneous and covers different subgroups of patients with varying degrees of post-traumatic brain dysfunction. The significant difference between the patients and controls found in the present experiments may thus be an underestimation of the sensitivity of the test to detect a post-traumatic cognitive deficit. Likewise, effects of age and education can be expected to play a role as well. Post hoc analysis indicated an even greater difference between more highly educated patients with MHI and matched controls: this is of interest as it indicates that the more difficult modified subtask 'tests the limits' of sub jects for whom the regular Stroop tests are not difficult enough and thus rather insensitive. When adjusted for other factors education may explain about one fourth of the total variance.

Further research is needed to investigate other factors, such as age and education, and to compare patients with and without postconcussive sequelae at more prolonged post-injury times to better assess the sensitivity of the modified subtask to detect post-traumatic brain dysfunction.

In summary, the present study provides evidence that subtle deficits in color word interference are demonstrable in patients with mild head injury only in a cognitively more demanding situation. 


\section{Reforences}

1. Chatwick $O$, Ruther M, Brown $G$, Shaffer D, Tratb M (1981) A prospective study of childrem with head unury: II Cognitive seguelae. Psychol Med, 11: $49-62$.

2. Dyer FN. (1973) The stroop phenomenon and its use in the study of perceptal, cognitive and response processes. Memory and Cognition, 1 : 106-120.

3. Hwgentioltz $\mathrm{H}_{\pi}$ stuss DT, Stethem BA Fuchard MT (1988) How long does il take to recover from a mald orncussion? Neurosurgery, $22,853-856$.

4. Lishman W. (1988) Physiogenesis and psychogenesis in the postt-cancussional syndrome', Br J Psychiatry, 153: 460-469.

5. Lowe DG,Mitterer JO. (1982) Selective and divided attention in a Stroop Task. Can J.Psychol, 36: $684-700$.

6. Luria A (1966) Higher corticall functions in man. London, Tavistock.

7. Mcleen A,Trmkin NR, Dikmen S, and A.R. Wyler A.R. (1983) The behavioural sequelae of head infury: J Clin Neuropsychol, 5: 361-376.

8. MelMillan TM. Glucksmian EE (1987) The neuropsychology of moderate head injury. I Neurol Neurosurg Psychiatry, 50:393-397.

9. Stroop IR (1935) Studies of interference in serial verbal reactions. I Exp Psychol, 18:643-662.

10. Skusis DT, Ely BA, Hugenholz H, Richard MT, LaRochelle S, Poirier CA, Bell L. (1985) Subtle newropisychological deficits in patients with good recovery aftar closed head injury. Neurosurgery, $17 ; 41-47$.

11. Thomals $C$ (1977), Deficits of memory and attention following closed head injury. M. Sc. Thesis, Oxford University.

12 Verhage R. (1964) Intelligentle en leatijd. Dissertation. Assen, The Netherlands.

13. Van Zomeren AH. Brouwer WH.(1987) Head injury and concepts of attention. In: Levin HS and Bisenberg HM (eds) Neurobehavioral recovery from head injury. Oxford Uniwersity Press, New York, pp. $398-415$. 


\title{
Chapter 4
}

\section{Post-traumatic and Emotional Symptoms in Different Subgroups of Patients with Mild Head Injury}

\author{
N. Bohnen ${ }^{\sharp}$ A. Twijnstra2 \& J. Jolles?
}

1 Department of Neuropsychology \& Psychobiology, University of Limburg, Maastricht;

2 Department of Neurology, University Hospital Maastricht, The Netherlands.

Submitted.

\section{Abstract}

Postconcussional symptoms, such as headache, dizziness and irritability, are thought to result from the emotional stress associated with decreased cognitive performance after a head injury. A questionnaire based investigation was carried out in 71 patients with nild head injury (MHI), using a heterogeneous item pool in order to study the interrelationships between traditional postconcussive complaints, cognitive problems, and more emotional and functional complaints. Factor analysis indicated that postconcussive symptoms loaded together with items on problems assoclated with decreased work performance and fatigability on a first factor, whereas psychovegetative and emotional complaints loaded together on a second factor. Two rating scales were constructed from the relevant items and were used to compare between subgroups of MHI patients and nonconcussed controls. Patients with uncomplicated MHI had significantly higher scores on the postconcussive-cognitive scale, but not on the emotional-vegetative scalle, than nonconcussed subjects. Patients with multiple head injuries or pre-existing emotional problems had higher scores on both the postconcussive/cognitive scale and the emotional-vegetative scale than $\mathrm{MHI}$ patients without a history of emotional problems. Reliable rating scales may be useful in multidiagnostic studies of MHI patients.

\section{Introduction}

In the past two decades there has been a plethora of studies examining the psychological sequelae of closed head injury (see also [1]). The focus of these studies was on patients with severe head injury, where post-traumatic amnesia exceeded $24 \mathrm{~h}$, and usually 1 week [2-4] . However, most of the neurobehavioral symptoms that are present in more severely head-injured patients, such as disturbed personality adjustment, psychomotor retardation, impulsivity and inaccurate self-apprailsal are generally absent in patients with mild head injury [2].

The so-called 'postconcussional syndrome' consists of subjective and quasi-organic complaints, such as headache, dizziness, fatigue, irritability, poor concentration, and sensitivity to external stimuli [5]. The aspecific and vague nature of postconcussional symptoms (PCS) cause researchers methodological difficulties when they try to quantify or conceptualize these complaints, and this has led to an ensuing controversy about the physiogenetic versus psychogenetic origin of the complaints $[5,6]$. Recently, factor analysis techniques have been used to identify different dimensions within the syndrome in populations of minor to severe head-injured patients. Results indicate that typical organic factors, ${ }_{r}$ such as severe memory deficits or frontal neurobehavioral symptoms, correlate with the severity of the trauma, but that patterns of so-called postconcussional symptoms do not $[3,4,7,8 \rrbracket$. The latter complaints have been interpreted as being secondary to the chronic emotional stress that patients experience when they are not able to cope with extra mental effort due to the post-traumatic cog- 
nitive deficits [3].

Because there are no studies that have focused solely on the postconcussive complaints of homogeneous population of patients with mild head injury (MHI), the present study was performed to investigate the interrelationstips between traditional postconcussive complaints and more emotional and functional symptoms. Therefore, questonnatre based investigation, using a heterogeneous item pool consisting of both traditional PCS and rather aspecific emotional and functional items, was comm pleted by MHI patients with a PTA of less than 60 minutes In addition, rating scales, derived by factor analysis were made to assess behavioral differences between subgroups of patients with uncomplicated and complicated MHI in comparison with nonconcussed controls.

It should be emphasized that the development of the tests primarily aims at assessing behavioral dysfunction, which in turn could contribute to an operationalization of the postconcussional syndrome.

\section{Subjects and methods}

\section{Subjects}

Patients were selected from a larger population $(\mathrm{N}=71)$ of consecutively admitted patients with mild head injury who were willing to participate in a study and who lived close enough to allow follow-up assessments. The criteria for inclusion in the study included a period of unconsciousness ranging from several seconds to 15 minutes, post-traumatic amnesia for less than 60 minutes, an EMV (Glasgow Coma) score for each patient on admission of 15 , and no evidence of a focal neurological deficit or of a skull fracture. Forty-six patients (23 females and 23 males; mean age $28.3+/-14.9 \mathrm{yr})$ appeared to have uncomplicated head injury without a prior history of complaints that could affect the study. The patients were initially examined within 6-14 days after injury, with a follow-up assessment 5 weeks after the trauma (4-6 weeks). There were 25 patients ( 7 femalles, 18 males; mean age $36.7+/-17.1 \mathrm{yr}$ ) who had complicated MHI because of the presence of one of the following conditions: a history of pre-existing emotional problems, the presence of a concomitant orthopedic injury, a previous head injury within the last 10 years, or the consumption of alcohol at the time of the trauma.

Pattents with uncomplicated MHI were matched for age, sex and educational level [9] with nonconcussed control subjects who were recruited from a pool of healthy volunteers ( $N=43$, mean age $29.2+/-14.2$ yr). All subjects gave their informed consent.

\section{Postconcussive Symptoms}

A checklist of postconcussive symptoms was completed, which included items such as headache, dizziness, nausea, difficulties with concentration and memory, fatigue, sleep disturbances and blurred vision. As these symptoms also occur in healthy individuals [10], the symptoms were scored for the absolutely or relatively increased appearance after the injury in comparison with the pretraumatic condition. All but three of the 46 patients with uncomplicated MHI complained of 1 or more PCS 10 days after the injury.

\section{Patterns of Behavioral Dysfunction}

A questlonnaire consisting of 26 ltems regarding a number of postconcussive and cognitive energetic complaints, as will as a series of emotional and vegetative complaints, was filled out by the total group of $\mathrm{MHI}$ patients $(\mathrm{N}=7 \mathrm{~J})$ about 10 days after the trauma in order to construct different rating scales. The first step was to select different subgroups of intercorrelated llems by means of factor analysis. The second step was to assess the internal consistency of each subgroup of items in order to construct reliable rating scales. This was done by principal components analysis (with varimax rotation [11]). Two factors were found (Table 1). To minimize miss-specification, factor loadings 
were considered relevant if they achieved value of $+/-0.45$ or more.

Factor I (postconcussive/cognitive complaints: eigenvalue $=6.44$ ) consisted of 11 high-loading items of typical postconcussional symptoms, such as headache, dizziness, intolerance to light, noise and other extermal stimuli, together with items indicating problems with decreased work capacity and efficiency, tiredness, difficulty doing things simultaneously, and diminished concentration.

Factor II (emotional/vegetative; eigenvalue $=5.09$ ) included 14 high loading items of rather aspecific psychovegetative functional symptoms, such as complaints of heart palpitations, wet hands, dyspnea, flushing, problems with digestion, and having a tense feeling on the chest, as well as items of depression, emotional lability (e.g., crying more easily, being easily defeated, loss of initiative and restlessness), and decreased libidlo. The 'irritability' item loaded on both factors, whereas the items on problems of falling asleep and waking up at night did not specifically load high on any factor.

According to the classical test theory of item analysis, the internal consistency of the two groups of high loading items on each factor were calculated (Cronbach's alpha). Cronbach's alpha for the first group (11 items) was 0.92 and 0.86 for the second group of 14 items. These two group of items may each be considered to form a scale [12]. Total scores were calculated by summing the original scores for the selected items of each scale. The response to each question was scored according to the severity or intensity of the complaint: $1=\mathrm{no}, 2=$ somewhat, $3=$ moderately or regulariy and $4=$ much or many/frequently.

Table 1

Principal components analysis with varimax rotation of the patient series. High loading items are shown in boldface print. ( $\mathrm{FI}=$ postconcussive/cognitive; $\mathrm{FII}=$ emotional/vegetative)

FI FII

\begin{tabular}{lrr}
\hline Headache & $\mathbf{0 . 6 8}$ & 0.27 \\
Falling asleep & 0.41 & 0.30 \\
Restless & 0.35 & 0.46 \\
Chest & -0.02 & 0.46 \\
Digest & -0.09 & $\mathbf{0 . 4 5}$ \\
Work & $\mathbf{0 . 7 6}$ & 0.11 \\
Light & $\mathbf{0 . 6 0}$ & 0.06 \\
Small Effort & $\mathbf{0 . 8 0}$ & 0.18 \\
Flushing & 0.31 & $\mathbf{0 . 5 2}$ \\
Concentration & $\mathbf{0 . 6 4}$ & 0.07 \\
Dyspnea & $\mathbf{0 . 3 3}$ & $\mathbf{0 . 5 9}$ \\
Trouble & $\mathbf{0 . 6 3}$ & 0.33 \\
Tired & $\mathbf{0 . 6 7}$ & 0.37
\end{tabular}

FI

FII

\begin{tabular}{lll}
\hline Fainting & 0.25 & 0.58 \\
Heart Palpit & 0.16 & 0.75 \\
Noise & 0.65 & 0.20 \\
Simul & 0.58 & 0.20 \\
Dizzy & 0.70 & 0.10 \\
Depr & 0.40 & 0.62 \\
Wet Hands & 0.09 & 0.50 \\
Crying & 0.20 & 0.53 \\
Libido & 0.30 & 0.60 \\
Irritable & 0.57 & 0.50 \\
Initiative & 0.44 & $\mathbf{0 . 5 1}$ \\
Awake at Night & 0.25 & 0.43 \\
Easily Defealed & 0.41 & 0.64
\end{tabular}

Chest=tense feeling on chest; Conc=trouble concentrating; Crying=cries more easily; Depr=depressed; Digest=problems with digestion; Dyspnea=feels short of breath; Easily Defeated $=$ easily overwhelmed by problems; Fainting =feels faint; Flushing $=$ flushes easily; Initiative=loss of initiative; Heart Palpit=heart palpitations; Libido=decreased libido; Light=intolerance to light; Noise=intolerance to noise; Simul= trouble doing things simuitaneously; Small Efforts=small effort requires much energy; Tired = tires easily; Trouble=has trouble being interrupted by others; Work=decreased work performance.

\section{Results}

Rating scale scores in patients with uncomplicated MHI and matched nonconcussed controls. 
Table 2 presents the mean scores on the two scales for the two groups. Patients with uncomplicated MHI complaimed of postconcussive and cognitive symptoms significantly more than controls (Wilcoxon $Z=3.38 ; P<0.001$ ). In contrast, there was no significant difference between the two groups on the emotional-vegetative scale ( $z=0.89 ; n s)$. As can be seen from figure 1, correlational data indicated that there was a positive relationship between the wo scales in both the concussed ( $R s=0.73 ; P<0.001)$ and the monconcussed group $(\mathrm{Rs}=0.69 \mathrm{P}<0.001)$.

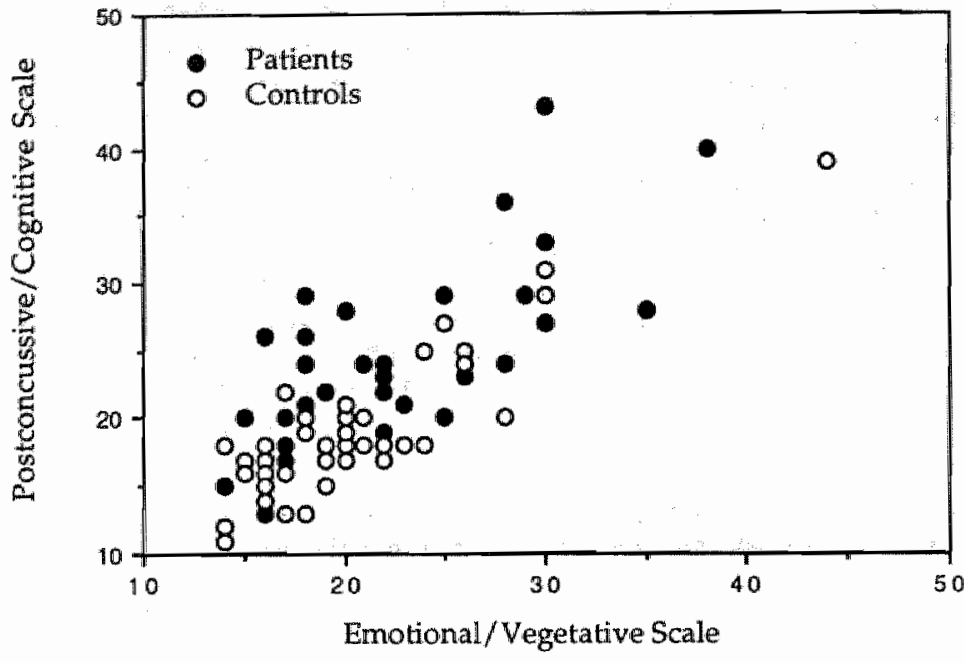

Filgure 1

Emotional/Vegetative Scale

Plot of postonncussive/cognitive complaints (Y-axis) and emotional/vegetative complaints (X-axis) for patients with uncomplicated MHI and nonconcussed controls.

\section{Recovery}

Mean scores on the two scales decreased significantly 5 weeks after an uncomplicated head injury (scalle I-postconcussive/cognitive scale: -3.02 (SD 5.61); $t=-3.28, \mathrm{P}<0.01$; for scale II-emotional/vegetative scale: $-1.28(\mathrm{SD} 3.18), \mathrm{t}=-2.28, \mathrm{P}<0.05)$.

In order to study more specifically the trammatic contribution to the correlational pattern between the postconcussive/cognitive and emotional/vegetative scales, the difference scores ( 5 weeks minus 10 days) for each scale were used for a correlation analysils. A significant relationship between time after injury and the two scales was not found $(\mathrm{Rs}=0.26, \mathrm{~ns})$. This indicates that recovery from postconcussive/cognitive complaints does not significantly parallel recovery from emotional/vegetative complaints.

Rating scale scores in different subgroups of MHI patients with a compromising condition. Mean data for each scale of each subgroup are presented in table 2. Subgroups of patients with a particular condition were compared with the group of uncomplicated MHI patients. Analysis of covariance was used in order to adjust for age and sex.

Pathents who had a previous head trauma within the last 10 years $(n=9)$ had higher scores on both the postconcussive/cognitive sicale $(F(1,51)=3.99 ; \mathbb{P}<0.05)$ and the emotional/vegetative scale $(=$ scale $I)(F(1,51)=5,63 ; \mathrm{P}<0.05)$ than the control patients. Patients with pre-existing emotional problems $(n=5)$ also scored higher on the postconcussive/cognitive scale $(=$ scale II $)(\mathrm{F}(1,47)=4.48, \mathrm{P}<0.05)$ but had even disproportionally higher scores on the emotional/vegetative scale $(F(1,47)=11.84 ; \mathrm{P}<0.01)$. Patients who had sustained MHI together with an orthopedic injury $(n=5)$ did not differ significantly on either scale (scale I: $F(1,47)<1, n s)$; scale II: $F(1,47)=1.49$;ns), but tended to have higher scores on the emotional/vegetative scale (Table 2 ). 
Table 2

Mean scores on the two scales for different groups (SD are preserted within brackets). Scala I is the postoon cussive/cognitive scale, scale II is the emotional/ vegative scalle.

\begin{tabular}{lccc} 
& $\mathrm{N}$ & Scale I & Scale II \\
\hline $\begin{array}{l}\text { uncomplicated MHI patients } \\
\text { nonconcussed controls }\end{array}$ & 46 & $23.6(7.1)$ & $21.6(6.2)$ \\
& 43 & $18.9(4.8)$ & $20.5(5.3)$ \\
$\begin{array}{l}\text { patients with a previous } \\
\text { head injury }\end{array}$ & 9 & $32.2(5.2)$ & $32.4(4.8)$ \\
$\begin{array}{l}\text { patients with pre-existing } \\
\text { emotional problems } \\
\text { patients with an orthopedic } \\
\text { injury }\end{array}$ & 5 & $32.2(5.2)$ & $32.4(4.8)$ \\
& 5 & $23.2(9.1)$ & $26.0(7.7)$
\end{tabular}

\section{Discussion}

Principal components analysis with varimax rotation yielded two clearly distinct factors in a general population of $\mathrm{MHI}$ patients. The first factor indicated that postconcussive symptoms of headache, dizziness and intolerance to environmental stimuli loaded together with items of decreased cognitive and work performance. In contrast, items of emotional lability and depression loaded together with rather aspecific vegetative symptoms. These results provide evidence that, even in a population of MHI patients, postconcussive sequelae can be distinguished from more emotional and functional complaints.

The scores on the two scales correllated with each other in both the patient and the control group. However, further analysis of the differences between the two groups indicated that MHI patients without a prewious history complained significantly more about postconcussive and cognitive problems, but did not complain disproportionally more about emotional and functional symptoms, than the nonconcussed controls. The decrease in postconcussive and cognitive complaints did not parallel the decrease in emotional and vegetative complaints. Therefore, it appears that the emotional and vegetative complaints may reflect an aspecific correlate of the postconcussive sequelae. According to the coping hypothesis $[3,8]$, postconcussive complaints may result from the chronic effort of patients to compensate for their cognitive deficits that may lead to a chronic stress reaction. This notion is supported by data reported by Bornstein [13] who found a positive relationship between emotional disturbance and cognitive deficits in patients with minor head injury. Although Hinkeldey and Corrigan [8] suggested that traditional postconcussive complaints may represent an (hypothesized) increase in emotional distress expressed through bodily symptoms, the present data indicate that this may be true for the vegetative symptoms. The complaints of headache, dizziness and intolerance to external stimuli did not load together with the vegative and emotional complaints and may therefore represient a distinct subgroup of post-traumatic complaints. In addition, Barth et al. [14] found that selected symptoms of headache, nausea, dizziness and memory problems were rather unique to head-injured patients in comparison with nonconcussed patients with an orthopedic injury or healthy subjects. It might be possible that emotional and vegetatiwe complaints are more related to a patient's reduced ability to cope with environmental stress than to post-traumatic brain dysfunction per se.

Analysis of the data of different subgroups of MHI patients with a compromising condition support previous reports that multiple concussions may have a cumulative and aggravating effect [15], and that patients with pre-existing emotional problems report disproportionally more emotional and functional symptoms than control patients 
with uncomplicated MHI [7]. Dikmen el al. [10] reported that patients with system and orthopedic injuries had more limitations in psychosocial functioning than patients with head injury alone. Although we did not find a significant difference on the two scales between MHI patients with a concomitant orthopedic injury and controls, the former group of patients lended to have higher scores on the emotional/vegetative scale. Moreover, the small number of subjects in the present study and the fact that hospitalized patients with more serious orthopedic problems were exluded do not allow usi to draw firm conclusions.

It needs to be stressed that this study of postcommotional complaints was confined to MHI patients in an early phase after the trauma. It is to be expected that patients at more prolonged post-injury times, and especially those with persistent symptoms, may develop symptoms of anxiety or depression [5]. Accordingly, the constellation of the syadrome may be different in these patients compared to the 'subacute' patients investigated in the present paper.

In summary the present findings indicate that patients with uncomplicated MHI complain more of postconcussive and cognilive complaints, but not disproportionally more of emotional and vegetative complaints, than nonconcussed controls. Associated emotional and vegetative complaints form a distinct subgroup of symptoms and appear to be of a secondary nature. Subgroups of patients with a compromising condition fend to report both more postconcussive and emotional complaints than uncomplicated control patients and may therefore bias studies of MHI. Further research is needed to apply the two scales to subgroups of patients with objectively demonstrated deficits on neurobehavioral and cognitive tests in order to further explore the somatic, cognitive, and emotional post-traumatic symptoms in patients with MHI.

\section{Refieriences}

1. Ponsford JL. Psychological sequelae of closed head injury: time to redress the imbalance. Brain Injury, 4: $111-114,1990$.

2. Levin HS, Grossman RG. Behaviozal sequelae of closed head injury. A quantitative study. Arch Neurol 35:720-727, 1978 .

3. Van Zomeren AH, Van den Burg W. Residual complaints of patients two years after severe head injury. I Neurol Neurosurg Psychiatry, 48:21-28, 1985.

4. Levin HS, High WM, Goethe KE.Sisson RA, Overall JE, Rhoades HM, Eisenberg HM, Kalisky ZVI, Gary HE. (1987b) The neurobehavioral rating scale: assessment of the behawiaural sequelae of head injury by the clinician. I Neurol Neurosurg Psychiatry, 50: 183-193.

5. Lishman WA. (1988) Physiogenesis and psychogenesis in the 'post-concussional syndrome'. $\mathrm{Br} J$ Psychiatry, 153: 460-469.

6. Binder LM. (1986) Persisting symptomis after mild head injury: a review of the postconcussive syndrome. J Clin Exp Neuropsychol 8: 323-346.

7. Levin HS, Gary Jr HE, High WM, Mattis S, Ruff RM, Eisenberg HM, Marshall LF; Tabaddor K. (1987a) Mimor head injury and the postconcussional syndrome: methodological issues in outcome studies; In: HS Levin, I Grafman, HM Eisenberg (eds). Neurobehavioral recovery from head injury $(\mathrm{Ox}$ lord University Press, New York), pp. 262-275.

8. Hinkeldey $\mathbb{N S}$, Corrigan JD. (1990) The structure of head-injured patients' neurobehawioral complatints: a preliminary study. Brain Injury 4: 115-133.

9. Verthage R. (1964) Intelligentie en leeftijd. Thesis. Assen, The Netherlands.

10. Dikinen S, McLean A, Temkin N. (1986) Neuropsychological and psychosocial consequences of minor head injury. I Neurol Neurosurg Psychiatry, 49: 1227-1232.

11. SAS (1985) User's Guide: Statistics Version 5 Volume. Cary, N.C. SAS Institute linc.

12. Novick MR. (1966) The axtoms and principle results of classical test theory. I Math Psychol 3: 1-18.

13. Bornstein RA, Miller HB, Van Schoor JT. (1989) Neuropsychological deficit and emotional disturbance in head-injured pattents: J Neurosurg 70:509-513.

14. Barth JT, Alves WM, Ryan ThV, Macciocchi SN, Rimell RW, Jane JA, Nelson WE. (1989) Mild thead injury in sport: neuropsychological sequelae and recovery of function. In: HS Levin, HM. Eisenberg, AL Benton (eds). Mild Head Injury. (Oxford University Press, New York), pp.257-275.

15. Gronwall D, Wrightson P. (1981) Memory and information processing capacity after minor head injury. INeurol, Neurosurg Psychiatry, 44: 889-895. 
CLUSTER B: Recovery and Persistence of Symtoms up to Six Months after an Uncomplicated Mild Head Injury

'Ideally, all etiological factors should be measured simultaneously, and at repeated intervals during recovery, to gain a just appreciation of their relative values, and most importantly, of how they might sometimes operate in conjunction with one and another" (Lishman, 1988)

5. Recovery from visual and acoustic hyperesthesia following mild head injury in relation to patterns of behavioral dysfunction.

6. Persistence of postconcussive symptoms in uncomplicated mild head-injured patients: a prospective cohort study.

7. Tolerance to light and sound of patients with persistent postconcussionall symptoms six months after mild head injury.

8. Neuropsychological deficits in patients with persistent symptoms six months after mild head injury. 


\title{
Chapter 5
}

\section{Recovery from Visual and Acoustic Hyperesthesia Following Mild Head In- jury in Relation to Patterns of Behavioral Dysfunction}

\author{
N. Bolmen 1, A. Twijnstra2, G. Wignen 1 \&. Jolles
}

1. Department of Neuropsychology \& Psychoblology, University of Limburg; Maastricht;

2 Department of Neurology, University Hospital Maastricht. The Netherlands.

Parts of this paper will be published in: ] Neurol Neurosurg Psychiatry

\section{Summary}

Patients with head injuries frequently complain of a decreased ability to endure intense light and sound stimuli. The few psychophysical studies that have objectively studied this type of visual and acoustic hyperesthesia have not assessed to what extent patlents recover from this lnyperesthesia following mild head injury (MHI). In addition, there are no data available about whether the decreased tolerance to light and sound is related to a particular pattern of behavioral symptoms. A computerized rating technique was used to assess both the maximal and submaximal levels of tolerance to intense sound (95 dB) and light (1500 Lux) stimuli in selected patients with an uncomplicated MHI. Tolerance to light and sound was tested 10 days and 5 weeks after the injury. Generally, an overall recovery from both visual and acoustic hyperesthesia was found; however, $25 \%$ of the patients were still not able to endure intense stimuli by 5 weeks. In addition, patients with persistent postconcussive symptoms 5 weeks after injury tolerated the light and sound stimuli less well than patients without persistent symptoms. Analysis of data obtained with two newly developed behavioral rating scales (one with postconcussive/cognitive complaints and a second with emotional/vegetative complaints) indicated that visual hyperesthesia was specifically related to the postconcussive/cognitive complaints scale. Assessment of visual and acoustic hyperesthesia may be used as objective criteria for the evaluation of patients with post-concussional symptoms.

Key words: light, sound, mild head injury, hyperesthesia.

\section{Introduction}

Postconcussional symptoms (PCS) occur in a high proportion of patients with mild head injury [1, 2], and include headache, dizziness, easy fatiguability, insomnia, irritability and difficulties with memory or concentration. Rutherford et al. [3] found that $51 \%$ of MHI patients still reported PCS 6 weeks after the trauma. There is continuing controversy about the physiogenetic versus psychogenetic origin of the persistent postconcussive syndrome [1]. As an example of somcalled organic evidence, Waddell and Gronwall [4] demonstrated that MHI patients had a significantly lower thres hold tolerance to light and a slightly decreased tolerance to sound 1-3 weeks after injury than healthy controls. Using a computerized method that measures both maximall and submaximal levels of reduced tolerance by applying a graded tolerance scale for each stimulus, we found recently that MHI patients 3-6 days after injury had a significantly decreased tolerance to sound stimuli over $71 \mathrm{~dB}$ and to light stimuli over 600 Iux (see Chapter 1). With respect to the relationship between this intolerance and postconcussive symptoms, Jonsson et al. [5] found that MHI patients with persistent symptoms 3 months after the trauma had a decreased tolerance to light and sound in comparison with both neurotic patients and normal control subjects. 
Unfortunately, no psychophysical studies have measured the recovery from visual and acoustic hyperesthesia following MHI. In addition, there are no empirical data available about the relationship between hyperesthesia and different patterns of behavioral symptoms in terms of postconcussive symptoms, such as headache, fatigue and dizziness; or emotional and functional complaints. It was therefore the aim of the present study to investigate 1) whether there is significant recovery from visual and acoustic hyperesthesia following $\mathrm{MHI}_{;}$2) whether patients with PCS tolerate light and sound stimuli less well than symptom-free patients 5 weeks after the trauma; and 3) whether visual or acoustic hyperesthesia is related to a particular pattern of post-traumatic behavioral dysfunction.

\section{Materials and Methods}

\section{Subjects}

The criteria for inclusion in the study included a period of unconsciousness ranging from some several seconds to 15 minutes, post-traumatic amnesia for less than 60 minutes, and an EMV (Glasgow Coma Scale) score for each patient on admission of 15. None of the patients had evidence of a focal neurological deficit or of a skull fracture. Seventy-one patients were selected from a larger population of consecutively admitted patients with mild head injury. These patients were willing to participate in the study and lived close enough to allow follow-up assessment. Twenty-five patients with complicated MHI were excluded. MHI was considered complicated when patients had consumed alcohol at the time of the accident, had a concomitant orthopedic injury, had previously sustained a head injury or had a history of emotional problems. In addition, patients with hearing or visual problems were not eligible. Forty-six patients (23 females and 23 males; mean age $28.3+/-14.9 \mathrm{yr}$ ) had simple $\mathrm{MHI}$ and were selected. The patients were examined within 6-14 days after injury. Three patients did not return to the follow-up assessment 5 weeks after injury (4-6 weeks) and were also excluded.

The 43 patients were individually matched for age and sex with nonconcussed control subjects who were recruited from a pool of healthy volunteers (mean age $29.2+1-14.2$ yr). The study was approved by the medical ethical council of the University Hospital and all subjects gave their informed consent.

\section{Postconcussive Symptoms}

A checklist of postconcussive symptoms was completed, which included items such as headache, dizziness, nausea, difficulties with concentration and memory, fatigue, sleep disturbances and blurred vision. As these symptoms may also occur in healtly individuals [6], the symptoms were scored for the absolutely or relatively or increased appearance after the injury in comparison with before the injury.

Five weeks after injury the patients were divided into a group with persistent PCS and a group without PCS. Inclusion in the first group was based on the presence of at lleast one symptom from the postconcussive checklist.

Procedure of Rating the Magnitude of Tolerance.

Light and sound stimuli of different intensities were presented using an IBM-XT personal computer. The computer contained a parallel interface and controlled both a tome generator (calibrated for $1000 \mathrm{~Hz}$ ) with varying amplitude and a $50 \mathrm{~W}$ tungsten-halogen lamp (Ostam, Halostar, AR 111, 50 W, 12V). The tone generator was connected to a pair of ATH-910 earphones (Audiotechnica) with noise reducing caps. The 50-W incandescant lamp was placed on a round tube. The glass-covered aperture (10 $\mathrm{cm}$ in diameter) was surrounded by a black ring, and the tube was mounted on a mobile and adjustable stand.

Five intensities of sound (1000 $\mathrm{Hz}$ pure tone) and light were chosen on the empirical basis that they could be clearly distinguished by the human ear and eye $(57,71,81,89 \&$ 
95 dB -sownd pressure levels- for sound and 440,500,600, 1000 \& 1500 lux for light). Each of the tive intensities was randomly presented 8 times; there were separate sesslons for the rwo types of stimuli: Thus, a subject received a total of 40 sound stimuli and 40 light stimuli. Each stimulus was presented for 4 seconds and was followed by a constant interval. The rise fall time of the physical stimulus was greater than $10 \mathrm{msec}$. The interval was kept constant to achleve a relative constancy in individual habituation processess (for sound 6 seconds and for light 12 seconds, 7,8 ). During this interval, the subject was asked to evaluate the preceding stimulus on a 7 -point rating scale, ranging from totally tolerant/bearable (score; s0), via very milly (sil), mildly (s2), moderately (s3), moderately to severely (s4), severely (s5), to totally unbearable (s6).. The response was given by pressing a button on a 7 -point keyboard. After the session, the median tolerance value per subject was calculated for each intensity level. These median values were used for statistical analysis.

The background levels of noise in the examination room ranged from 46 to $51 \mathrm{~dB}$. The average background illumimation in the examination room was about 300 lux.. The room had dimmed windows. Fach subject was seated so as to look into the centre of the light source, which was 1 meter from their eyes.

\section{Patterns of Behavioral Dysfunction}

The 71 consecutively admitted MHI patients who were willing to participate in the study filled in a questionnaire within 10 days (6-14 days) after the trauma. There were 26 questions covering postconcussive, cognitive-energetic, emational and psychovegetative complaints. This information was used to draw up different rating scales. The first step was to select subgroups of intercorrelated items by factor analysis. The second step was to assess the internal consistency of the selected tems in order to construct a reliable scale. Further details on the construction of the scales will be reported elsewhere.

A principal components analysis (with varimax rotation [9] on the total item pool revealed that there were two factors (see Chapter 4 for further details). To minimize miss-specification, factor loadings were considered relevant if they achieved a value of $+/-0.45$ or higher.

Factor I (postconcussive/cognitive complaints) consisted of 11 items evaluating cognitive-energetic and habitual postconcussive symptoms, such as headache, dizziness, fatigue and problems with decreased work performance. Factor II (emotional/ vegetative complaints) included 14 items of rather aspecific psychovegetative functional symptoms as well as iterns of depression and emotional lability (see Chapter 4).

Since the aim of the study was to correlate different patterns of behavioral symptoms with objectively assessed tolerance to light and sound, the two ltems of factor I referring to subjectively experienced hyperesthesia ('light" and "noise') were removed to avolid bias of partial autocorrelation. The internal consistency of the two groups of ttems was calculated according to the classical test theory of item analysis (Cronbach's alpha). Cronbach"s alpha for the first group ( 9 items) was 0.88 and 0.86 for the second group. These two group of items thus both form a scale [10]. Total scores were calculated by summing the original scores for the selected items per factor. The response to each question was scored according to the severity and intensity of the endorsed complaints: $1=$ no, $2=$ somewhat, $3=$ moderately or regularly, and $4=$ much or very often.

\section{Statistical Analysis}

The two highest intensities of sound and light (95 dB for sound; 1500 Lux for light) were chosen as the principal parameters in the present study. Because of the ordinal level of the tolerance scale, data were analysed with non-parametric tests (Friedman two way analysis of variance, Wilcoxon's rank sum test and Spearman's rank correlation coefficients: $R s$ ). 


\section{Results}

Ten days after the injury, MHI patients $(\mathrm{N}=43)$ had a significantly lower tolerance for both $95 \mathrm{~dB}$ sound $(z=3.1, \mathrm{P}<0.01)$ and 1500 lux light $(z=4.30, \mathrm{P}<0.001)$ than the nonconcussed controls (figure 1). There was significant recovery from the reduced tolerance to light (Friedman Chi square $=5.75, \mathrm{~d} f 1, \mathrm{P}<0.05$ ) and sound (Chi square $=9.25$, df 1 , $\mathrm{P}<0.01$ ) (fig 1). Nevertheless, the proportion of patients with considerable to completely reduced tolerance (scores 5-6) to $95 \mathrm{~dB}$

were $17 / 43$ at 10 days and $11 / 43$ at 5 weeks (compared with $1 / 43$ in the nonconcussed controls). For 1500 lux light, these proportions were $18 / 43$ and $10 / 43$ at the same time points, as compared with $2 / 43$ in the controls.

Only three patients were totally free of postconcussive symptoms 10 days after injury whereas this number increased to 12 after 5 weeks. As can be seen from table 1 , it was found that patients with PCS at 5 weeks $(n=31)$ had a significantly decreased tolerance to light (Wilcoxon's $z=-1.78, P<0.05)$ and sound $(z=-2.76, P<0.01)$ in comparison with the patients without PCS.

Table 1

Mean levils of tolerance to $95 \mathrm{~dB}$ sound and 1500 lux light levels in MHI patients with and without persistent post+concussion symptoms (PCS) 5 weeks after injury (meanst SD).

\section{$\mathrm{N} \quad 95 \mathrm{~dB} \quad 1500$ lux}

\begin{tabular}{lllll}
\hline patients with PCS & 31 & $3.63(1.63)^{* *}$ & $3.38(1.62)^{*}$ & $*: P<0.05$ \\
patients without PCS & 12 & $2.05(1.39)$ & $2.36(1.86)$ & $*: P<0.01$
\end{tabular}
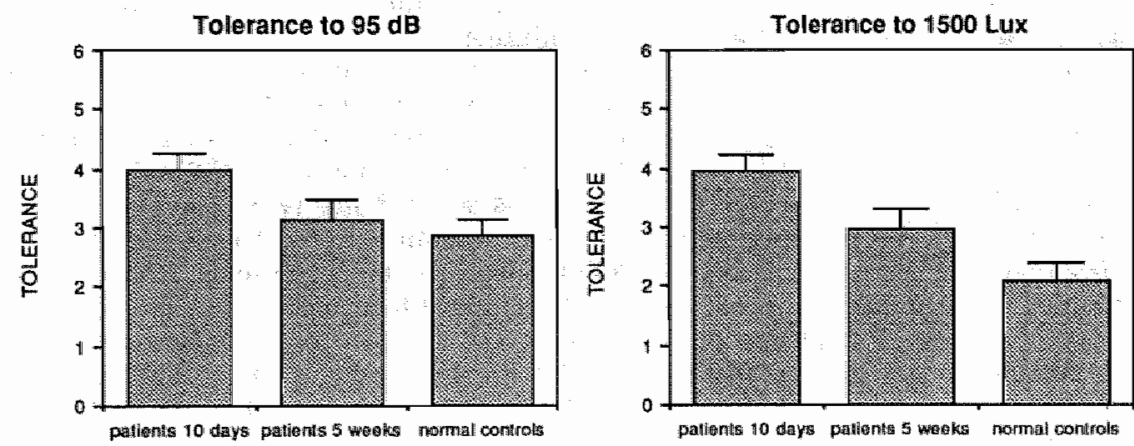

Fugure 1

Mean levels of tolerance of the patient group and noncomeussed group assessed 10 days and 5 weeks after the trauma (means+SEM). [0=completely bearable; $6=$ completely uribearable]

The scores on the two behavioral rating scalles were compared with the magnitude of the visual and acoustic hyperesthesia in the total group of patients with uncomplicated MHI $(n=43)$. Correlational data indicated that reduced tolerance to sound 10 days after the trauma was significantly correlated with higher scores on both the postconcussive/cognitive scale ( $R s=0.52, P<0.001)$ and the emotional/vegetative scale $(R s=0.43$, $P<0.01$ ) . Reduced tolerance to light was only significantly correlated with higher scores on the postconcussive/cognitive scale $(R s=0.44, \mathrm{P}<0.01)$, and not with the scores on the emotional/vegetative scale ( $R s=0.18$, ns).

Lastly, we investigated whether there. was a relationship between the extent of recovery from visual and acoustic hyperesthesia (scores at 5 weeks relative to those at 10 days) and the scores obtained with the two behavioral rating scales att the two time points. Therefore, difference scores (5 weeks munus 10 days) were calculated for each parameter (tolerance to light and sound, postconcussive/cognitive scale and 
emotional/ vegetative scale) and used for correlational analysis. It was found that there was no significant correlation between the differences in tolerance to sound with the difference scores for either of the two scales (RS $=0.24$, ns for the postconcussive/cog: nitive scale; $R s=0.08$ for the emotional/vegetative scale). In contrast, differences in tolerance to light were significantly correlated with the differences in scores measured with the postconcussive/cognitive scale ( $\mathrm{Rs}=0.36, \mathrm{P} \times 0.05)$ but not with the changes measured with the emotional/vegetative scale ( $\mathrm{Rs}=0.24, \mathrm{~ns})$.

\section{Discussion}

Patients with persistent sequelae after the first weeks of recovery following MHI have been the source of controversy regarding an organic versus psychogenic etiology [1]. By definition, MHI patients show no objective neurological deficits. Therefore, cognitive measures have been used mostly for the evaluation of the validity of persistent postconcussive sequelae $[6,11]$. This approach may have shorteomings as cognitive tests may not be sensitive enough to detect subtle post-traumatic brain dysfunction $[12,13]$. The extent of the visual and acoustic hyperesthesia can be used to objectively assess post-traumatic brain dysfunction (4). In the present, although we found that most patients recovered from their decreased tolerance to intense light and sound stimuli, 25 percent of the patients with MHI still demonstrated a considerable to completely reduced tolerance to $95 \mathrm{db}$ sound or $1500 \mathrm{lux}$ light at 5 weeks. In addition, patients who still complained of persisting post-traumatic symptoms tolerated the intense light and sound stimuli less well than those patients who had no PCS. This is in accordance with the findings of Jonsson et al. $[5]$ who found that MHI patients with persistent post-concussional symptoms 3 months after injury had a significanty lower ability to endure intense sound and light stimuli than controls.

Waddell and Gronwall [4] found that all their MHI patients with decreased tolerance to sound and light had evidence of reduced information processing. Moreover, the observation that the proportion of patients who subjectively reported a decreased tolerance to light or sound was smaller than the proportion of patients with objectively demonstrated deficits also favours an organic explanation of this type of hyperesthesia. It is possible that the post-traumatic changes in tolerance to light and sound are a manifestation of a lack of inhibitory control by orbital frontal cortex areas over sensory information processed by posterior brain areas and subcortical centres [14,15].

In the present study, it appeared that the more organic pattern of postconcussive/cognitive symptoms was particularly associated with the extent of the visual hyperesthesia but not with the pattern of emotional/vegetative complaints. Whether assessment of visual hyperesthesia reflects recovery from post-traumatic brain dysfunction better than assessment of acoustic hyperesthesia cannot be concluded from the present study. Further research is needed to investigate this interesting notion more fully.

In summary, a selected population of patients with uncomplicated MHI who had no premorbid abnormalities or acute traumatic complications recovered from visual and acoustic hyperesthesia but 1 in 4 patients were still severely troubled by this intolerance 5 weeks after injury. The extent of visual and acoustic hyperesthesia can be assessed as an objective parameter for the evaluation of the recovery of MHI patients.

\section{References}

1. Lishman WA. (1988) Physiogenesis and psychogenesis in the 'post-concussional syndrome'. Br I Psychiatry 153:460-9.

2. Lowdon IMR, Briggs M, Cockin J. (1989) Post-concussional symptoms following minor head injury. Injury $20: 193: 4$.

3. Rutherford WH, Merrett ID, McDonald JR (1977) Sequelae of concussion caused by minor head injuries. Lancet i:1-4.

4. Waddell PA, Gronwall DMA. (1984) Sensitivity to light and sound following minor head injury. Acta 
Neurol Scand $69: 2 \% 0-6$

5. Jonsson $\mathrm{C}-\mathrm{O}$, Lidvall $\mathrm{H}$, Mathammer $\mathrm{G}, 1967)$ An exploratory psychological study of the post-tramatic cerebral syndrome. Acta Neurol Scand 43:158-66.

6. Dikmen S, McLean A, Temkin N. (1986) Neuropsychological and psychosocial conseguences of minor head infiry. I Neurol Neurosurg Psychiatry 49:1227-32.

7. Stevens JC, Stevens SS. (1963) Brightmess function: effects of adaptation J Opt Soc Arr $55: 375-85$.

8. Bolf KR, Kaufman $L_{;}$Thomas JP, (1986) Handbook of perception and thuman performance. Volume l: Sensory processes and perception. New York John Wiley and Sons.

9. SAS (1985) User's Guide: Statistics Version 5 Wolume. Cary, N.C. Sas Institute Inc.

10. Novick MR (1966) The axioms and principal results of dassical test theory. I Mathematical Psychol 3:1-18

11. Levin HS, Mattis S, Ruff RM, Eisenberg HM, Marshall LF, Tabaddor K, High WM, Frankowski RF. (1987) Neurobehavional outcome following minor head injury: a three center study. INeurosurg 66:234-43.

12. Stuss DT, Ely P, Hugenholtz H, Richard MT, La Rochelle S, Poiriet CA, Bell I, (1985) Subthe neuropsychological deficits in patients with good recovery after closed head injury. Neurosurgery 17:41-7.

13. Hugenholtz, H., Stuss, DT, Stethem, LL and Richard, MT, (1988) How long does ill take to recovery from a mild concussion? Neurosingery $228853-8$.

14. Walsh KW. (1987) Neuropsychology: a clinical approach. New York: Livingstor.

15. Fuster IM. (1989) The prefrontal cortex (2nd edition). New York: Raven Press. 
Chapter 6

Persistence of Postconcussive Symptoms in Uncomplicated, Mild HeadInjured Patients: A Prospective Cohort Study

N. Bohnen1, A. Twijnstra2 \& 1. Jolles1

1. Department of Neuropsychology \& Psychobiology, University of Limburg, Maiastricht;

2 Department of Neurology, University Hospital Maastricht, The Netherlands.

Parts of this paper will be published in:

Neuropsychiat Neuropsychol Behaw Neurology

Abstract

We report the follow-up of 41 ambulant subjects with uncomplicated mild head injury (MHI) and no premorbid compromising condition. At three months after the trauma 22 patients still complained of at least 1 postconcussional symptom (PCS) and 10 patients had 3 or more PCS. At 6 months 12 patients complained of at least 1 PCS, whereas 9 patients still had 3 symptoms or more. Patients with persistent PCS complained more of emotional symptoms. Results obtained with objective tests indicated that this group was characterized by a decreased performance on the Stroop Color Word interference test and a reduced tolerance to light and sound stimuli in comparison with patients with only few or no PCS. Although most patients may substantially recover after $M H I$, a relevant number of patients may persist with a residue of neurobehavioral deficits. Patients with persistent PCS should be evaluated in a multidiagnostic and objective way in order to gain a better understanding of the nature and origin of the subjective symptoms.

Key Words: MHI, postconcussive symptoms, Stroop Color Word Test, light, sound.

\section{Introduction}

It has been reported that post-traumatic symptoms and impaired performance, termed the positconcussion syndrome, may persist for weeks after MHI [19]. However, estimates of the frequency of the persistent syndrome vary widely from 20 up to 80 percent [20]. This discrepancy may be due to methodological differences, such as the heterogeneity of the patient group, the definition of mild head injury and the duration of the post-injury time $[9,20]$. Moreover, there are a considerable number of patients with mild concussions who are never seen by medical personnel or who are examined but not admitted to hospital. Apart from the disagreement about the frequency of postconcussive sequelae, there has been much debate over the years as to whether minor head injuries result in significant and persistent cerebral damage, and if present, whether it is demonstrable by objective tests.

By definition, MHI patients have no neurological deficits. Therefore, neuropsychological measures have usually been used as objective criteria for the evaluation of patients with persistent postconcussive sequelae $[14,16]$. Persistent cognitive deficits $3-6$ months after MHI have been reported by Barth et al. [2] and Hugenholtz et al. [11]. The results of several other studies, however, do not indicate decreased cognitive functioning. about 1 month after MHI $[8,14]$. It is clear that cognitive criteria are arbitrary and depend on the selection of a particular neuropsychological task. Moreover, it has been demonstratted that the cognitive deficits following MHI may be subtle and may be better detected with more demanding tasks of attention and information processing [11]. For example, Levin, et al. [14] found that memory deficits were mainly resolved by 1-3 
months in minor head-injured patients, but that $47 \%$ of the patients stil complained of headache 3 months after the injury.

Taken together, it is clear that studies on mild head-injured patients are beset with methodological problems. There are not onlly differences with respect to the definition of the patient population in terms of selection criteria and post-injury time, but there is also a lack of uniform and objective diagnostic criteria for defining a postconcussion syndrome. Moreover, the multifactorial pathogenesis of the postconcussion syndrome warrants a multidiagnostic approach with objective tests [15]. MHI patients with evidence of a premorbid or traumatic compromising condition have to be excluded in order to focus on a homogeneous group of patients with clearly defined, uncomplicated MHL.

It was therefore the aim of the present study to prospectively examine a cohort of previously healthy subjects who sustained an uncomplicated MHI that did not require hospitalization. Postconcussive sequelae were recorded at each examination. In addition, patients were examined by using a psychophysical measure of visual and acoustic hyperesthesia, a cognitive measure and two behavioral rating scales (a postconcussive/cognitive scale and an emotional/vegetative scale).

\section{Materials and Methods}

\section{Subjects}

Patients seeking medical attention within an hour of a mild head injury and who did not require hospital admission were invited to participate in the study. On admission all patients were investigated neurologically and an $X$-ray of the skull was made. The criteria for inclusion in the study included a period of unconsciousness ranging from some several seconds to 15 minutes, post-traumatic amnesia of less than 60 minutes, an EMV (Glasgow Coma) score on admission of 15 , no evidence of a focal neurological deficit or of a skull fracture. From consecutive series of 131 patients aged 15 and older, 31 patients did not live close enough to allow follow-up assessments, and 29 patients were not willing to participate in the study. The seventy-one patients who were willing to participate in the study were divided into two groups ( $A$ \& $B)$. Group $A(N=46$; 23 females and 23 males) consisted of patients with uncomplicated MHI without a premorbid compromising condition. Patients in group $B(N=25 ; 7$ females and 18 males) were characterized by the presence of a premorbid or traumatic compromising condition, for example, patients who were intoxicated at the time of the accident, had sustained a previous head injury or had a history of pre-existing emotional problems. Patients from group $A$ were assessed 4 times after the injury. The initial examination was performed within 6-14 days after the injury. with follow-up assesments at 5 (4-6) weeks, 3 months (13-15 w) and 6 months (22-28 weeks). Three patients dropped out at 5 weeks, and two patients at 3 months: 41 patients completed the study.

The causes of the injury were traffic (33), falls (6), fights (1), sports (5), and accident at work $(1) ; N=46$.

Patients with uncomplicated $\mathrm{MHI}$ were matched for age and sex with 43 nonconcussed control subjects who were recruited from a pool of thealthy volunteers in order to obtain normative data. Table 1 summarizes the major demographic characteristics of the patient groups. From the 29 patients who refused to participate, 21 were males and the majority $(n=18)$ were intoxicated at the time of the trauma. In comparison with the participating patients, this group was less educated $(4.1+/-0.5$ levels [23]) and were somewhat younger $(23.5 t /-8.5 \mathrm{yr})$. In addition, fighting was the cause of the trauma in 14 cases. Some of the data obtained with the specific diagnostic tests at 10 days and 5 weeks will be reported elsewhere [5]. The study was approved by the ethical council of the University Hospital and all subjects gave their informed consent.

At each assessment the concussed subjects completed two rating scales, one consisting 
of postconcusive/cognitive and the other of emotional/vegetative complaints. In addition, patients were examined by using an objective test of wisual and acoustic hyperesthesia and a cognitive measure (Stroop Color Word Test).

Table 1

Age and educational level [23] of the different patient groups. Mean data are presented $(+/-S D)$.

\begin{tabular}{lccl} 
& N & Age & Education \\
\hline Uncomplicated MHI & 46 & $28.3(1.4 .9)$ & $5.0(0.8)$ \\
Control subjects & 43 & $29.2(14.2)$ & $4.7(0.9)$ \\
Complicated MHI & 25 & $36.7(17.1)$ & $4.9(0.9)$ \\
$\begin{array}{l}\text { Uncomplicated MHI } \\
\text { with at least 3 PCS at 3 m }\end{array}$ & 10 & $29.9(12.3)$ & $4.7(0.5)$ \\
$\begin{array}{l}\text { Uncomplicated MHI } \\
\text { with at least 3 PCS at 6.m }\end{array}$ & 8 & $31.2(11.7)$ & $4.5(0.6)$
\end{tabular}

Postconcussive Symptoms

A checklist of postconcussive symptoms (PCS) was completed, which included items such as headache, dizziness, nausea, difficulties with concentration and memory, fatigue, sleep disturbances, and blurred vision. As these symptoms also occur in healty individuals [8], the symptoms were sicored for the absolutely or relatively increased appearance after the injury in comparison with the pretraumatic condition.

Patients with persistent PCS are usually characterized by the presence of a number of symptoms. Generally, headache is the most frequently reported symptom [14]. We divided the patients into three groups at each assessment: a group who still complained of at least 3 PCS (often a combination of headache, fatigue, cognitive problems or dizziness), a group with only 1 2 PCS (mainly headache), and a group that had no symptoms at all.

Assessment of the Magnitude of Tolerance for Light and Sound.

Light and sound stimuli of different intensities were presented by using an IBM-XT personal computer [5]. The computer contained a parallel interface and controlled both a tome generator (calibrated for $1000 \mathrm{~Hz}$ ) with varying amplitude and a $50 \mathrm{~W}$ tungsten-halogen lamp (Osram, Halostar, AR 111,50 W, 12 V). The tone generator was connected to a pair of ATH-910 earphones (Audiotechnica) with noise reducing caps. The lamp was placed on a round tube. Each subject was seated so as to look into the centre of the light source at 1 metre distance from their eyes. Five intensities of sound (1000 Hz pure tone) and light were chosen on the empirical basts that they could be distinguished clearly by the human ear and eye $(57,71,81,89 \& 95 \mathrm{~dB}$-sound pressure level- for sound, and $440,500,600,1000$ \& 1500 lux for light). Each of the five intensities was randomly presented 8 times; there were separate sessions for the two types of stimuli. Each stimulus was presented for 4 seconds, and was followed by a constant interval. The rise-fall time of the physical stimulus was longer than $10 \mathrm{msec}$. The interval was kept constant in order to achieve a relative constancy in individual habituathon processess (for sound 6 seconds and for light 12 seconds; see also Boff et all. [4]). During this interval, the subject was asked to evaluate the preceding stimulus on a 7 point rating scale, ranging from totally tolerant/bearable (score: 50 ), via very mildly (s1), mildly (s2), moderately ( 33 ), moderately to severely ( 44 ), severely (s5), to totally unbearable (s6). The response was given by pressing a button on a 7 point key board. After the session, the median tolerance value per subject was calculated for each intensity level.

Patterns of Behavioral Dysfunction

A 26-item questionnaire that consisted of questions about a number of postconcussive 
and cognitive-energetic complaints as well as of a sieries of emotional and psychovegetative complaints was filled in by 71 consecutively admitted MHI patients who were willing to participate in the prospective study about 10 days after the trauma. These data were used for the construction of rating scales. The first step was to select different subgroups of intercorrelated variables by means of factor analysis. The second step was to assess the internal consistency of the items in order to construct a reliable scale. Consequently, principal components analysis (with varimax rotation [21]) was performed on the total item pool and rewealed two factors (see Chapter 4 for more details). To minimize miss-specification, factor loadings were considered relevant if they had achieved a value of $+/-0.45$ or more.

Factor I (postconcussive/cognitive complaints) consisted of 11 items evaluating cognitive-energetic and traditional postconcussive symptoms. Factor II (emotional/ vegetative complaints) included 14 items of rather aspecific psychoyegetative functional symptoms as well as items of depression and emotional lability (see also Chapter 4). The internal consistency of the two groups of items was calculated according to the classical test theory of item analysis (Cronbach's alpha). Cronbach's alpha for the first group (11 items) was 0.92 and was 0.86 for the second group of 14 items. Therefore, these two group of items may both be considered to form a scale [18]. Total scores were calculated by summing the original scores on the selected items per factor. "The response to each question was scored according to the severity and intensity of the complaints: $1=$ no, $2=$ somewhat, $3=$ moderately or regularly and $4=$ much or very often.

\section{Test Material}

Stroop Test [22]. The Stroop Color Word Interference Test used in the present study is a version commercially available in The Netherlands (Swets \& Zeitlinger, Lisse, 1971). The test consisits of three parts with each part being presented on a $21 \times 29.5 \mathrm{~cm}$ sheet of paper. Ten lines are printed in each subtask with 10 items per line. The test examines the speed at which 100 color names (yellow, green, red and blue) are read (subtask I) and the speed at which 100 colored spots are named (subtask II). Subtask III again involves 100 color names, but the color names are printed in inappropriately colored ink. The naming of the printing ink of the words is taken as the test variable. The Color Word interference score is obtained by subtraction of the time needed for subtask II from the time needed for subtask III (III - II) and was used as the cognitive parameter in the present study. This interference measure can be taken as a measure of selective attention [10].

\section{Statistical Analysis}

The two highest intensities (95 dB for sound; 1500 Lux for light) were chosen as the principal parameters in the present study. Because of the ordinal level of the tolerance scale, ranks over all observations were calculated [7] and analyzed by ANOVA with the factor 'group' (patients with no, 1-2 or 3 or more PCS at 3 or 6 months). Duncan's multiple range tests were used as post hoc tests [21]. The data on the Stroop test were analyzed with an analysis of covariance with the factor 'group', and age and education were used as covariates in order to adjust for these two variables. Chil square tests were performed between prognostic variables such as sex, education, and the persistence of PCS at 3 and 6 months after the trauma. Normative data for tolerance to light and sound, performance on the Stroop test, and scores on the two rating scales were obtained from nonconcussed subjects.

\section{$\underline{\text { Results }}$}

Persistent postconcussional symptoms in patients with uncomplicated $\mathrm{MHI}$

The results are set out in table 2. The proportion of patients with PCS at 3 months was 22/41 (54\%); 12 subjects had 1-2 symptoms and 10 had 3 symptoms or more. Headache 
was the mosit common symptom reported, followed by fatigue, dizziness, and problems with concentration. Twelve patients had symptoms 6 months after the trauma $(N=41)$. Three patients had 1-2 symptoms and 9 patients had at least 3 symptoms. Headache was again the most frequently mentioned symptom, followed by problems with concentration and dizziness. The mean time off work in the group was 3.2 weeks $(+/-1.7)$, with a maximum of 8 weeks. Although 9 patients with more than 3 PCS at 3 months had resumed their work, all of them experienced problems, with one pattent being forced stop working for a second time. There was no significant relation between the incidence of PCS and the factors sex, age, educational level and duration of PTA (shorter or longer than 15 minutes).

\section{Table 2}

Frequemcy distribution of postconcussive symptoms for the group of wncomplicated MHI patients at the four follow w sleep=distubed sleep. Absolute numbers are given with percentages between brackets.

\begin{tabular}{|c|c|c|c|c|c|c|c|c|}
\hline \multirow[b]{2}{*}{ headache } & \multicolumn{2}{|c|}{$\begin{array}{l}10 \text { days } \\
N=46\end{array}$} & \multicolumn{2}{|c|}{$\begin{array}{l}5 \text { weeks } \\
N=43\end{array}$} & \multicolumn{2}{|c|}{$\begin{array}{l}3 \text { months } \\
N=41\end{array}$} & \multicolumn{2}{|c|}{$\begin{array}{l}6 \text { months } \\
N=41\end{array}$} \\
\hline & 34 & (74) & 24 & (56) & 17 & $(41)$ & 12 & (29) \\
\hline nausea & 9 & $(20)$ & 4 & (9) & 3 & $(7)$ & 2 & (5) \\
\hline fatigue & 33 & $(72)$ & 24 & $(56)$ & 16 & (39) & 8 & $(20)$ \\
\hline dizziness & 28 & (61) & 19 & (44) & 12 & (29) & 9 & (22) \\
\hline memory & 20 & (43) & 16 & $(37)$ & 10 & (24) & 8 & $(20)$ \\
\hline concentration & & (54) & 18 & (42) & 11 & $(27)$ & 10 & (24) \\
\hline sleep & 19 & (41) & 14 & (33) & 8 & $(20)$ & 8 & $(20)$ \\
\hline blurred vision & 6 & (13) & 3 & (7) & 0 & $(0)$ & 1 & (2) \\
\hline
\end{tabular}

The scores on the two behaviorally rating scales are depicted in figure 1 . The data of the group as a whole revealed a steady decline on the two scales with the passage of time post-injury. It was striking that patients who had at leasit 3 persistent symptoms at each time point tended to have higher scores on the emotional/vegetative scale as the time post-injury increased.

Results on the different tests in relation to the presence of symptoms at 3 and 6 months.

Mean data for each test per group and time point are presented in table 3 together with ANOVA F-values for overall "group' effects. Significant "group' effects were found for tolerance to sound both at 3 months and at 6 months as well as for tolerance to light at these two time points (Table 3). Post hoc testing indicated that patients with 3 or more PCS at 3 and 6 months had a significantly decreased tolerance to light and sound in comparison with patients with 1-2 or no PCS at the same time points. In contrast, there were no significant differences in tolerance to light or sound between patients with $1-2$ PCS and patients without symptoms, except at 3 months when the patients with 1-2 PCS had a lowered tolerance to sound than the patients without PCS (Table 3). With respect to the levels of tolerance to light and sound in nonconcussed subjects, the proportion of patients with a considerable to complete lack of tolerance (score 5-6) for $95 \mathrm{~dB}$ was $18 / 46$ at 10 days, $11 / 43$ at 5 weeks, $7 / 41$ at 3 months, and $6 / 41$ at 6 months versus $1 / 43$ of nonconcussed controls. For 1500 lux light these proportions were $18 / 46$, $10 / 43,8 / 41$ and $6 / 41$ at the same time points, against $2 / 43$ of the controls.

Analysis of covariance of the Stroop color word interference measure revealed a significant group effect at both 3 and 6 months (Table 3). Patients with 3 PCS or more were significantlty more susceptible to interference than patients with no or less PCS. With respect to normative data in nonconcussed subjects, there were 7 of the 10 patients with 3 PCS or more at three months post-injury who had scores lower than the 10th percentile in healthy volunteers of similar age and educational level. This figure was 6 
out of 9 patients at 6 months after the injury. In contrast, there was only 1 patient with a similarly decreased level of performance in the group with $1-2$ or no PCS

Table 3

Mean data of the levels of tolerance to sound (95 dB) and light (150oL), and performance on the Stroop Color Word test. The difference score (III-II) represent the Color Wond Interference measure. Meams are presented with SD. (ANOWA F"values with significance levels are presented in the last column). Common letters indicate a significant differenco between the two groups, als assessed by post hoc testing.

Patients with uncomplicated MHI 3 months after the trauma

$$
\text { no } 1-2 \mathrm{PCS} \quad 3 \mathrm{PCS} \text { or more }
$$

\begin{tabular}{lllll}
\hline $95 \mathrm{~dB}$ & $2.22 / 1.26 \mathrm{ab}$ & $3.25 / 1.73 \mathrm{~b}$ & $3.95 / 1.36 \mathrm{a}$ & $F=5.0^{*}$ \\
$1500 \mathrm{Lux}$ & $2.23 / 1.48 \mathrm{a}$ & $2.75 / 1.42 \mathrm{~b}$ & $4.15 / 1.73 \mathrm{ab}$ & $F=4.7^{*}$
\end{tabular}

Stroop test:

$\begin{array}{lllll}\text { Subtask I } & 40.75 / 5.78 & 41.02 / 10.12 & 49.00 / 9.43 \\ \text { Subtask II } & 50.36 / 7.74 & 54.32 / 12.11 & 60.84 / 12.18 & \\ \text { Subtask III } & 72.82 / 14.01 & 76.12 / 14.63 & 99.49 / 19.81 & \\ \text { III - II } & 21.81 / 9.98 \mathrm{a} & 21.72 / 8.23 \mathrm{~b} & 38.52 / 12.71 \mathrm{ab} & \mathrm{F}=6.5^{* * *}\end{array}$

Patients with uncomplicated MHI 6 months after the trauma

\section{no PCS $1-2$ PCS}

\section{$95 \mathrm{~dB}$}

1500 Lux

Stroop test:

Subtask I

Subtask II

Subtask III

III - II

$\begin{array}{ll}2.10 / 1.03 \mathrm{a} & 2.00 / 1.84 \mathrm{~b} \\ 2.18 / 1.27 \mathrm{a} & 2.00 / 1.56 \mathrm{~b}\end{array}$

$38.61 / 4.99$

$48.59 / 6 / 38$

$69.11 / 10.47$

$20.25 / 7.14 a$
$38.40 / 4.20$

$52.55 / 7.74$

$75.51 / 12.86$

$22.04 / 10.11 \mathrm{~b}$
3 PCS or more

$\begin{array}{ll}4,62 / 1.69 \mathrm{ab} & \mathrm{F}=9.2^{* * *} \\ 4.56 / 1.68 \mathrm{ab} & \mathrm{F}=9.3^{* * *}\end{array}$

$53.75 / 1.3 .88$

$62.83 / 10.02$

$100.77 / 19.88$

$35.56 / 12.44 a b \quad F=6.3^{* * *}$

* $P<0.05 ; * * P<0.01 ; * * \mathbb{P}<0.001$
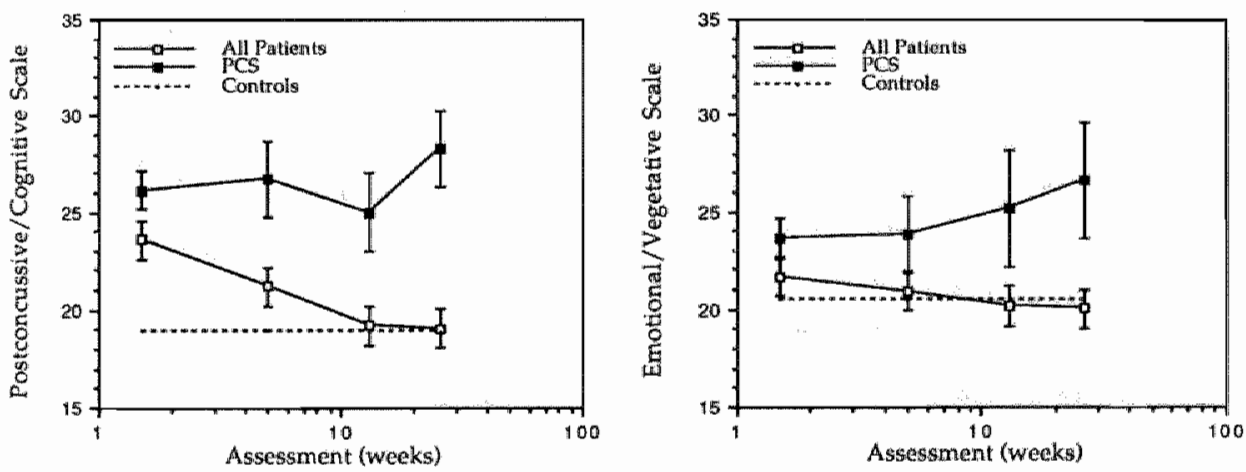

Figure 1

Mean scores on the two rating scales alt the 4 follow-up assessments $(1.5,5,13$, and 26 weeks) for the thotal group of patients with uncomplicated MHI, patients with 3 or more PCS att each time point and normative data for of nonconcussed subjects (normative reference line: dashed line), Mean values are presertied with SEM. X-axis is presented logarithmically. 


\section{Discussion}

Patients with persistent sequelae after the first weeks of recovery following MHI have been the source of controversy regarding the organic versus psychogenic etiology of thetr sequelae [15]. Recent reports favor multifactorial explanation, in which persistent PCS would result from an interaction between organic and psychological factors $[9$, 15]. Nevertheless, studies on MHI patients performed so far have mostly been limited to the study of angle diagnostic measure, and few studies have reported the serial testing of patients with MHI $[11,14,16]$. Consequently, our knowledge in this area is sill quite fragmentary and not adequate to reconcile certain points of contradictory information that have to begun to emerge [9]. Ideally, all diagnostic tests should be measured simultaneouslly, and at repeated intervals during recovery to gain a just appreciation of their relative values [15].

Dikmen, et al. [8] suggested that a single minor head injury in persons with no prior compromising condition is associated with mild but probably clinically non-significant difficulties 1 month after injury. However, we found that about one-fourth of our non-hospitalized patients with uncomplicated MHI who did not have a premorbid compromising condition had 3 or more PCS at 3 and 6 months. The patients with 3 or more persistent PCS complained significantly more of aspecific emotional and vegetalive symptoms than patients with fewer or no symptoms. Results obtained with objective tests in the present study indicated that the patients with 3 or more persistent PCS tolerated intense sound and light stimuli significantly less well than control. patients and nonconcussed subjects. This is in accordance with the findings of Jonsson et al. [13] who found that MHI patients with persistent symptoms 3 months after injury had a reduced ability to endure intense light and sound stimuli. Although Waddell and Gronwall [24] suggested an organic etiology for this type of visual and acoustic hyperesthesia, this hypothesis needs to be further established.

The Stroop Color Word Interference test has been used to measure selective attenition in patients with head injury [10]. Results consistently indicate that head-injured patients have no specific difficulty in focusing on the color dimension of the ambiguous stimuli when data are aggregated at a group level without reference to the persistence of PCS $[1,6]$. In contrast, McLean, et al. [17] found a significant interference effect on the Stroop test only in the subacute stage post-injury. These studies have compared head-injured patients with nonconcussed subjects instead of directly comparing patients with and without PCS. We found that patients with 3 PCS or more at 3 and 6 months after MHI were disproportionally slower at the interference task than the patients with no or fewer PCS. The critical question is whether or not the lower cognitive performance of these patients was caused by the injury or was already present before the injury. Given the lack of premorbid cognitive information we cannot draw a firm conclusion. However, patients with a neuropsychiatric history were excluded from the study, and none of the patients developed symptoms of a post-traumatic stress disorder. In addition, 4 of the 10 patients with 3 PCS or more at 3 months after the injury were working in responsible jobs, wo patients were successful high school students, 2 persons performed semj-skilled work and the remaining two subjects were active housewives. Lastly, given the duration of the follow-up (6 months), the structure of the Dutch Social Security system is such that the results are unlikely to be affected by considerations of compensation.

As in olher studies, we were not able to predict the persistence of PCS on the basis of age, sex, PTA, or educational level [11, 12]. Although there are reports that older patients are at greater risk [20], the absence of a significant difference in the present study could be due, in part, to the small number of patients involved. The duration of time off work in the Netherlands is not a good parameter to assess morbidity in MHI patients as these patients are readily advised to take off up to 2-4 weeks from work.

It needs to be stressed that the present results conceri a well-defined population of uncomplicated and unhospitalized MHI patients. Hospitalized patients, including 
patients with more systemic injuries, alcohol intoxication or neurological deficits, were not included. The group of patients that refused to participate consisted mainly of younger intoxicated males. This means that this group of young males is uriderrepresented in the present study.

It can be summarized that about $25 \%$ of the patients with uncomplicated MHI and without premorbid abnormalities or acute traumatic complications were still subjectively disabled 3 and 6 months after the injury. The findings indicate that patients with subjective impairments may have demonstrable deficits on neurobehavioral tests.

\section{References:}

1. Acker MB, Davis JR. (1989) Psychology scores associated with late outcome in head injury. Nauropsychology $3,123-133$.

2. Barth JT, Macciocchi SN, Giordani B., et al. (1983) Neuropsychological secuelae of minor head injury. Neurosurgery $13,529.533$.

3. Binder LM. (1986) Persisting symptoms after mild head injury: a review of the postconcussive symarome. J Clin Exp Neuropsychal $8,323-346$.


Sensory processes and perception. John Wiley \& Sons, New York, 1986.

5, Bohnen N, Twijnstra A, Kroeze J. Jolles J. (1991) A psychophysical method for assessing visual and acoustic hyperesthesia in patients with mild head injury. Br. J. Psychat. (in press).

6. Chadwick $\mathrm{O}$, Rutter $\mathrm{M}$, Brown $\mathrm{G}$, Shaffer D. Traub M. (1981) A prospective study of children with head injury: Il Cognitive sequelae. Psychol. Med. 11: 49-62.

7. Conover W]. Iman RL. (1981) Rank tranformations as a bric ge between paranataic and non parametric statistics. Am Statist 35, 124-129.

8. Dikmen SS, McLean A. Temkin N. (1986) Neuropsychologicall and psychosocial consequences of mimor head injury. J Neuro Neurosurg Psychiatry $49,1227-1232$.

9. Dikmen SS, Temkin $\mathrm{N}_{*}$ Armsden $\mathrm{C}_{\text {. }}$ (1989) Neuropsychological recovery: relationship to psychosocia! functioning and postconcussional complaints. In: HS Levin, HM Eisenberg. AL Benton (Eds.) Mild head injury. Oxford University Press, New York, 229-241.

10. Gronwall D. (1987) Advances in the assessment off attention and information processing after head imjury. In: HS Levin, J Grafman, HM Eisenberg (Eds,): Neurobehavioral recovery from head injury. Oxford University Press, New York, 355-371.

11. Hugenholtz H, Stuss DT, Stethem BA, Richard MT. (1988) How long does if take to recover from a mild concussion? Neurosurgery $22,853-858$.

12. Jakobsen J, Batadsgaard SE, Thomsen S, Henriksen PB. (1987) Prediction of postconcussional sequelae by reaction time test. Acta Neurol Scand 75, 341-345.

13. Jonsson C-O, Lidvall H, Malhammer G. (1967) An exploratory psychological study of the past-traumatic cerebral symarome. Acta Neurol Scand 43, 158-166.

14. Levin HS, Mattis S, Ruff RM, et al. (1987) Neurobelvavioral outcome following mimor head injury: a three-center study. I Neurosurgery $66,234-243$.

15. Lishman WA. (1988) Physiogemesis and psychogenesis in the "postaconcussional syndrome'. Br J Psychiat 153, 460-469.

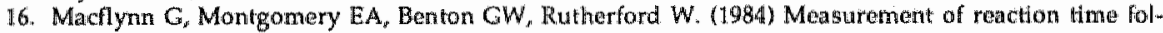
lowing minor head injury. I Neuno Neurosurg P'sychiatry 47, 1326-1331.

17. McLean A, Temkin NR, Dikmen S, Wyler AR. (1983) The behavioural sequelate of head injury, I Cllin Newropsychology $5,361-376$.

18. Novick MR. (1966) The axioms and principal results of classical hest theory. I Math Psychology 3, $1 \sim 18$.

19. Rutherford WH, Merrett JD, MCDonald JR. (1977) Sequelate of concussion caused by minor head injuties. Lancet i, 1-4.

20. Rutherford WH, (1989) Postconcussion symptoms: relationships to acute neurological indices, individual differences, and crcumstances of injury. In: HS Levin, MM Eisenberg, AL Bentorn (Eds.). Mild head Injury. Oxford Uniwersilly Pres, New York, 217-228.

21. SAS (1985) U'ser's Cutde: Statistics. Versfom 5 Edition. SAS Institute, Ine. Cary NC.

22. Stroop JR (1935) Studies of interference in serial werbal reactions J Exp Psychology 18, 643-662.

23. Verhage R. (1964) Intelligentie en leetijd. Dissertaton. Assen, The Netherlands.

24. Waddell PA, Gronwall DMA. (1984) Sensitivity to light and sound following minor head injury. Acta Neurol Scand $69,270-276$. 


\title{
Chapter 7
}

\section{Tolerance for light and Sound of Patients with persistent Postconcussional Symptoms Six Months after Mild Head Injury}

\author{
N. Bohnen1, A. Twijnstra2, G. WijnenI \& Jolles 1 \\ 1 Department of Neuropsychology \& Psychobiology, University of Limburg, \\ Maastricht; \\ 2 Department of Neurology, University Hospital Maastricht, The Netherlands.
}

Neurol: accepted for publication

\section{Summary}

The present study examined whether patients with postconcussive symptoms (PCS) about 6 months after a mild head injury (MHI) had a decreased tolerance for light and sound in comparison with concussed patients without PCS and nonconcussed healthy controls. MHI patients with PCS were individually matched with subjects from the two control groups for the time elapsed from the injury, age and sex. Using a computerized rating technique, we could assess both the maximal and submaximal levels of lowered tolerance for light and sound over a wide range of stimuli. We found that the MHI patients with PCS 6 months after the trauma $(n=11)$ tolerated significantly less well stimuli of intensities of $71 \mathrm{~dB}$ and 500 lux than MHI patients without PCS $(\mathrm{n}=11)$ and nonconcussed controls $(n=11)$. There were no significant differences in tolerance for light and sound between MHI patients without PCS and the non-injured controls. Decreased tolerance for light and sound may contribute to the persistence of symptoms up to six months after a mild head injury. The psychophysical method provides an objective measure for the evaluation of the late persistent post-concussion syndrome.

Key Words: light, sound, postconcussional syndrome.

\section{Introduction}

Postconcussional symptoms (PCS) occur in many patients with mild head injury [11,

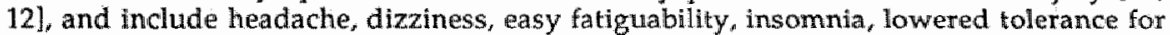
noise and light, irritability and difficulties with memory or concentration. Although patients may recover completely within some weeks, there is a fairly high number of patients that report symptoms after the first weeks of recovery [13]. Because there is often litigation when personal injuries are involved, especially when the complaints persist, the validity of a patient's persistent post-concussional symptoms comes under guestion. Both organic and psychological factors have been considered to explain the occurrence of persistent PCS [11]. Neuropsychological investigations to assess cognitive deficits after MHI have indicated that subtle impairments in the rate of information processing and in reaction time are inilially present but may disappear within a couple of months $[1,9,10]$. Although repeated neuropsychological testing has, up till now, not allowed straightforward interpretation of whether or not significant cognitive disability is present, evidence indicates that a fairly high proportion of MHI patients (over $20-50 \%$ ) still complain of belavioral dysfunction up to $3-6$ months after injury $[1 ; 9 ; 10]$. The fact that a clear-cut organic or neuropsychological dysfunction cannot be found leads to a more psychogenic interpretation of the persistent subjective symptoms $[5,9]$.

The objective testing of tolerance for light and sound has been proposed as a procedure to obtain evidence of an underlying organic dysfunction. Waddell \& Gronwall [16] 
demonstrated that $\mathrm{MHI}$ patients had a significantly lower threshold tolerance for light and a slightly decreased tolerance for sound $1-3$ weeks after injury than healthy controls. In addition, Jonsson et al. (1967) found that MHI patients with persistent symptoms on average 3 months after the trama had a decreased tolerance for light and sound in comparison with both neurotic patients and normal control subjects.

Unfortunately, there are no psychophysical studies that have objectively assessed the tolerance for light and sound of MHI patients at more prolonged post-injury times or compared MHI patients with and without PCS.

The aim of the present study was, therefore, to compare the maximal and submaximal levels of reduced tolerance for light and sound stimuli of MHI patients with PCS with those of matched patients without PCS and healthy nonconcussed controls. We also investigated whether patients without $P C S$ had a different tolerance for light and sound than nonconcussed controls.

We used an objective method of assessing tolerance for light and sound that not only measures the maximal level of lowered tolerance, but than can also be used to compare the submaximal levels of lowered tolerance by applying a graded tolerance scale for each stimulus. Recently, we found that MHI patients 3-6 days after injury tolerated intense light and sound stimuli both at maximal and at submaximal levels of reduced tolerance less well than controls.

Non-uniform criteria for defining MHI have undoubtedly contributed to conflicting results obtained in studies on the postconcussion syndrome. Clearly defined eligibility criteria were applied in the present study, i.e. patients with an uncomplicated MHI, a post-traumatic amnesia of less than 60 mimutes, a loss of consciousness of less than 15 minutes and a Glasgow Coma Score of 15 on admission and the absience of a focal neurological deficit.

\section{Materials and Methods}

\section{Subjects}

Patients were selected for postconcussive behavioral dysfunction from a larger group of patients who had participated in a comprehensive study of patients with mild head injury. The criteria for inclusion in the study included an elapsed time after the injury of about 6 months, a period of unconsciousness ranging from some several seconds to 15 minutes, post-traumatic amnesia for less than 60 minutes, and an EMV (Glasgow Coma) score on admission of 15 . None of the patients had evidence of a focal neurological deficit, or of a skull fracture. Patients were excluded if they had consumed alcohol at the time of the accident or if they had a history of pre-existing emotional problems. In addition, patients with hearing and visual problems were not eligible. Eleven patients with persistent PCS were selected and individually matched with both a patient without PCS and a nonconcussed control subject for sex, age $(+/-5 y+)$ and time elapsed after injury ( $+/-1-2$ months). Normally, younger males are overrepresented in a head-injured population. The application of strict eligibility criteria, especially the exclusion of intoxicated subjects, may have reduced the maleto-femalle sex ratio in the present study of patients with an uncomplicated MHI. The nonconcussed control subjects were recruited from a pool of healthy volunteers. Data on sex, age and post-injury time for each group are presented in table 1 . The study was approved by the ethical council of the University Hospital and all subjects gave heir informed consent.

\section{Posticoncussive Symptoms}

A checklist of postconcussive symptoms was completed, which included items such as headache, dizziness and irratibility. As these symptoms may also occur in healthy individuals [5], the symptoms were scored for the absolute or relatively increased appearance after the injury in comparison with the pre-traumatic condition. All patients 
with PCS complained of 3 or more symptoms. The frequency of the reported symptoms in the symptomatic patient group $(\mathrm{N}=11)$ was as following: headache ( $\mathrm{n}=7$ ), rausea $(n=1)$, latigue $(n=9)$, dizziness $(n=6)$, forgetfulness $(n=7)$, problems with concentration ( $n=8)$, intolerant to light $(n=5)$, intolerant to noise $(n=7)$, and blurred vision $(\mathrm{n}=2)$.

\section{Table 1}

Sex, age (years) and time (months) elapsed after injury. Group I MHII patients with persistent postconcussional symptoms; Group II: MHI patients without symptoms; Group IIt nonconcussed heal thy subjects.

\begin{tabular}{lllllllllll}
\multicolumn{3}{c}{ GROUP II } & \multicolumn{9}{c}{ GROUP II } & \multicolumn{4}{c}{ GROUP III } \\
nr & sex & age & time & nr & sex & age & time & nr & sex & age \\
\hline 1 & $\mathrm{~F}$ & 24 & 6.0 & 1 & $\mathrm{~F}$ & 22 & 5.0 & 1 & $\mathrm{~F}$ & 22 \\
2 & $\mathrm{M}$ & 34 & 6.5 & 2 & $\mathrm{M}$ & 36 & 6.5 & 2 & $\mathrm{M}$ & 29 \\
3 & $\mathrm{M}$ & 24 & 6.0 & 3 & $\mathrm{M}$ & 24 & 7.0 & 3 & $\mathrm{M}$ & 26 \\
4 & $\mathrm{~F}$ & 23 & 6.0 & 4 & $\mathrm{~F}$ & 25 & 5.0 & 4 & $\mathrm{~F}$ & 22 \\
5 & $\mathrm{~F}$ & 47 & 6.5 & 5 & $\mathrm{~F}$ & 42 & 8.5 & 5 & $\mathrm{~F}$ & 47 \\
6 & $\mathrm{~F}$ & 18 & 6.0 & 6 & $\mathrm{~F}$ & 18 & 6.0 & 6 & $\mathrm{~F}$ & 18 \\
7 & $\mathrm{M}$ & 44 & 6.0 & 7 & $\mathrm{M}$ & 39 & 6.0 & 7 & $\mathrm{M}$ & 43 \\
8 & $\mathrm{M}$ & 27 & 5.0 & 8 & $\mathrm{M}$ & 22 & 6.0 & 8 & $\mathrm{M}$ & 30 \\
9 & $\mathbb{F}$ & 20 & 7.0 & 9 & $\mathrm{~F}$ & 16 & 5.5 & 9 & $\mathrm{~F}$ & 19 \\
10 & $\mathrm{M}$ & 35 & 6.5 & 10 & $\mathrm{M}$ & 36 & 6.0 & 10 & $\mathrm{M}$ & 38 \\
11 & $\mathrm{~F}$ & 51 & 7.0 & $\mathbb{1 1}$ & $\mathrm{F}$ & 49 & 6.5 & 11 & $\mathrm{~F}$ & 54 \\
mean & 31.5 & 6.2 & & & 29.9 & 6.2 & & & 31.6 \\
$(+/ /$ SD) & 11.4 & 0.6 & & & 10.9 & 1.0 & & & 12.1
\end{tabular}

Procedure for rating the magnitude of tolerance.

Light and sound stimuli of 5 different intensities were presented using an IBM-XT personal computer. The computer contained a parallel interface and controlled both a tone generator (calibrated for $1000 \mathrm{~Hz}$ ) with varying amplitude and a $50 \mathrm{~W}$ tungsten-halogen lamp (Osram, Halostar, AR 111, $50 \mathrm{~W}, 12 \mathrm{~V}$ ). The tone generator was connected to a pair of ATH-910 earphones (Audiotechnica) with noise reducing caps. A $50 \mathrm{~W}$ incandescant lamp was placed on a round tube. The glass-covered aperture (10 $\mathrm{cm}$ in diameter) was surrounded by a black ring and the tube was mounted on a mobile and adjustable stand, so as to adjust the height to the individual patient. The intensities were calibrated at 1 meter distance of the lamp in a room with a background illumination of 300 lux.

Five intensities of sound (1000 $\mathrm{Hz}$ pure tone) and light were chosen on the empirical basis that they could be distinguished clearly by the human ear and eye $(57,71,81,89$ \& $95 \mathrm{~dB}$-sound pressure level- for sound and 440,500,600, 1000 \& 1500 lux for light). Each of the five intensities was randomly presented 8 times; there were separate sessions for the two types of stimuli. Thus, a subject received a total of 40 sound stimuli and 40 light stimuli. Each stimulus was presented for 4 seconds and was followed by a constant interval. The rise-fall time of the physical stimulus was greater than $10 \mathrm{msec}$. The interval was kept constant in order to achieve a relative constancy in individual habituation processes (for sound 6 seconds and for light 12 seconds; see also ref. [3, 15]). During this interval, the subject was asked to evaluate the preceding stimulus on a 7 point rating scale, ranging from totally tolerant/bearable (score: $s 0$ ), via very mildly (s1), milldly (s2), moderately (s3), moderately to severely (s4), severely (s.5), to totally unbearable/reduced tolerance ( $(\mathrm{s} 6$ ). The response was given by pressing a button on a 7 point key board. After the session, the median tolerance value per subject was calculated for each intensity level. These median values were used for statistical analysis. 


\section{Sound}

The background levels of noise in the examination room ranged from 46 to $51 \mathrm{~dB}$. Before putting on the earphones, the subject recelved the following instructions:

'You will hear a series of sounds of varying intensity through your headphones. Each sound will be presented for 4 seconds. After the tone has finished, please press the button on the 7 point key board that corresponds to the degree of tolerance you have ex perienced. The left button means that you can tolerate the sound stimulus, the one of the extreme right means that you find the sound unbearable. The buttons in-between correspond to a decreasing scale of tolerance from left to right. A new stimulus will be presented automatically after 6 seconds. Forty stimuli of mixed intensity will be given at random.'

\section{Light}

The average background illumination in the examination room was about 300 "lux. The room had dimmed windows. Each subject was seated so as to look into the centre of the light source at $1 \mathrm{~m}$ distance from their eyes. The subjects received the following instructions:

'Look into the centre of the lamp. The lamp will shine for 4 seconds. You will then have 12 seconds to press a buttom on the 7 point key board that corresponds to the degree of tolerance you have experienced. The left button means that you can tolerate the light stimulus, the one on the extreme right means that you find the light unbearable. The buttons in-between correspond to a decreasing scale of tolerance from left to right. Each new stimulus will be presented automatically after 12 seconds. Forty stimuli of different intensity will be given at random."

\section{Statistical Analysis}

We first assessed whether there was an overall difference over the three groups for all the five intensities of light and sound. Because of the ordinal level of the rating scale, the ranks over all observations per intensity were calculated [4] and were analysed by multivariate analysis of variance (SAS), [14]. Then separate analyses per intensity were carried out using Duncan's multiple range test as a post-hoc test to evalluate between-group differences for significant overall effects. A probability level of less than 0.05 defined a significant difference.

\section{$\underline{\text { Results }}$}

Multivariate analysis of variance yielded a significant overall effect for tolerance for both sound (Wilk's Lambda: $F(5,25)=2.75$, $P<0.05$ ) and light (Wilk"s Lambda: $\mathrm{F}(5,25)=4.10, \mathrm{P}<0.001)$. Post hoc testing indicated that the MHI patients with PCS tolerated the 71, 81, $89 \& 95 \mathrm{~dB}$, and the $500,600,1000 \& 1500$ lux levels significantly less well than the patients without PCS and the nonconcussed controls (siee also figure 1). The patients without PCS did not have a significantly different tolerance from that of the non-injured healthy controls for any of the intensities, except for a decreased tolerance to the 600 lux light stimulus.

At an individual level, there were seven MHI patients with PCS that demonstrated a severely to totally reduced level of tolerance (tolerance scores of 5-6) to $95 \mathrm{~dB}$ compared with one patient without PCS and none of the nonconcussed control subjects. Five patients with PCS compared with one patient wilthout PCS and none of the nonconcussed control subjects showed severely to totally reduced tolerance to $1500 \mathrm{lux}$.

\section{Discussion}

There has been much debate over the years as to whether minor head injuries result in significant and persistent cerebral damage, and if present, whether it is 
demonstrable by objective methods. Experimental studies and human autopsy data have shown that even mild head injuries may lead to anatomical abnormalities [2]. However, other patients may recover quickly and be without symptoms after a mild head injury. Althowgh it has been reported that persistent behavioral dysfunction after a MHI is not explicitly associated with cognitive disabilify $[9,10]$, Ewing et al. [6] provided evidence that perstiting cognitive effects may still be present after a $\mathrm{MHI}$, but only emerge under the effects of stress.
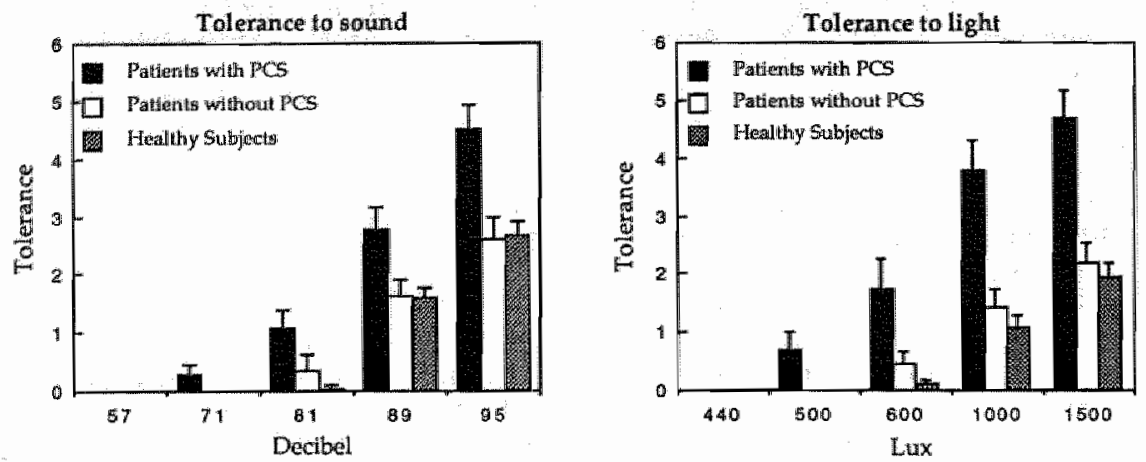

Figure 1

Mean levels of tolerance of the patient and comtrol group per intensity (means 5 SM are presented). The 7 point rating scale ranged from totally tolerant/bearable (score: s0), via very mildly (s1), mild(y (s2), moderately ( 53 ), moderately to severely (sh), severely (s5), to totally unbearable/treduced tolerance (s6).

Jonsson et al. [8] found that MHI patients with persistent post-concussional symptoms at an average of 3 months after injury had a significanty lower abllity to endure intense sound and light stimuli thar control subjects. The present results indicate that tolerance for light and sound is significantly decreased in MHI patients with persistent symptoms six months after injury compared with the tolerance of matched patients without PCS and nonconcussed controls. With respect to sub maximal levels of tolerance to less intense stimuli, MHI patients wilh PCS were significantly less tolerant to low sound $(71 \mathrm{~dB})$ and light intensities (500 lux) compared to patients from the two control groups. This means that, for example, the shining of a lamp or the noise of a lively conversation could disturb a MHI patient who has persistent symptoms. Although patients without PCS did not differ significantly from the healthy control subjects in their tolerance for light and sound, there was a very slight tendency to a decreased tolerance for light.

Waddell \& Gronwall [16] found that, in their study all MHI patients with decreased tolerance for sound and light had evidence of reduced functions of information processing. Additionally, Jonsson et al. [8] reported that symptomatic patients had a lowered tolerance for light and sound stimuli after a mild head injury than symptomatic nonconcussed neurotic patients. These findings may provide evidence for the hypothesis that there is an organic basis for this type of hyperesthesia. Nevertheless, further studies are needed to establish this hypothesis.

It is possible that the postmtraumatic changes in tollerance for light and sound are a manifestation of a lack of inhibitory control by orbital frontal cortex areas over sensory information processed by posterior brain areas and subcortical centres [7, 17]. The changes in the wisual and acoustic system following mild head injury may persist together with subjective symptoms.

It can be summarized that MHI patients with PCS may already be disturbed by sound or light intensities common to daily life up to 6 months after injury, whereas patients without PCS can normally tolerate more intense stimuli of sound and light. The present study provides an objective measure for the assessment of persistent postcon- 
cussional symptoms in uncomplicated MHI patients with no pre-morbid abnormalities.

\section{Refierences}

1. Barth JT, Macciochi SN, Giordani B, Rimel R, Jane JA, Boll Th J (1983) Neuropsychological sequelae of minor head injury. Neurosurgery 13:529-533.

2. Binder LM (1986) Persisting symptoms after mild head injury: a review of the postconcussive syndrome. J Clin Exp Neuropsychol 8:323-346.

3. Boff KR, Kaufman $L_{r}$ Thomas JP (1986) Handbook of perception and human performance. Volutule I: Sensory processes and perception. John. Willey and sons, New York.

4. Conover W], Iman RL (1981) Rank transformations as a bridge between parametric and nonparametric statistics. Am Statistician 35:124-129.

5. Dikmen $S_{\text {, }}$ MeLean A, Temkin N (1986) Neuropsychological and psychosocial consequences of minor head injury. I Neurol Neurosurg Psychiatry 49:1227-1232.

6. Ewing R, McCarthy D, Gronwall D, Wrightson $\mathbb{P}$ (1980) Persisting effects of minor head injury obserwable during hypoxic stress. J Clin Neuropsychol 2:147-155.

7. Fuster IM (1989) The prefrontal cortex (2nd edn). Raven Press, New York.

8. Jonsson $C_{-} \mathrm{O}$, Lidvall $H$, Mälhammer $G$ (1967) An exploratory psychological study of the post-traumatic cerebral syndrome. Acta Neurol Scand 43:158-166.

9. MacFlymn G, Montgomery EA, Fenton GW, Rutherford W (1984) Measurement of reaction time following minor head injury. I Neurol Neurosurg Psychatry 47:1326-1331.

10. Levin HS, Mattis S, Ruff RM, Eisenberg HM, Marshall LF, Tabaddor K, High WM, Frankowskỉ RF (1987) Neurobehavioral outcome following mimor head injury: a three center study. I Nevrosuris $66: 234-243$.

11. Lishman WA (1988) Physiogenesis and psychogenesis in the 'posttconcussional syndrome'. Br I Psychiatry $153: 460-469$.

12. Lowdon MMR, Briggs $M$, Cockin ] (1989) Post-concussional symptoms following minor head injury. Injury 20:193-194:

13. Rutherford WH, Merrett JD, MCDonald JR (1977) Sequelae of concussion caused by minor head injuries, Lancet $1: 1-4$

14. SAS User"s Guide (1985) Statistics (Version 5 edn). SAS Institute Inc, North Carolina, Cary.

15. Stevens JC, Stevens SS (1963) Brightness function: effects of adaptation. J Opt Soc Am 55.375-385.

16. Waddell PA, Gronwall DMA (1984) Sensitivity to light and sound following minor head injury. Acta Neurol Scand 69:270-276.

17. Walsh KW (1987) Neuropsychology: a clinicall approach. Livingston, New York. 


\title{
Neuropsychological Deficits in Patients with Persistent Symptoms Six Months after Mild Head Injury
}

\author{
N. Bohnen, J. Jolles $1:$ A. Twijnstra 2
}

1 Department of Neuropsychology \& Psychobiology, University of Limburg, Maastricht;

2 Department of Neurology, University Hospital Maastricht, The Netherlands.

Neurosurgery: accepted for publication

\section{Abstract}

There is much debate on the nature and duration of cognitive deficits and postconcussive symptoms (PCS) after milld head injury (MHI). Most studies performed so far have compared head-injured patients with nonconcussed subjects instead of directly comparing patients with and without persistent PCS. The present study examined whether patients with $P C S(N=11)$ about 6 months after an uncomplicated mild head injury performed less well on selected neuropsychological tests than MHII patients without PCS $(\mathbb{N}=11)$ and healthy controls $(\mathbb{N}=11)$. Patients with PCS were individually matched with controls for the time elapsed after the injury, age, sex and edvcation. We found that patients with PCS performed less well on tests of divided and selective attention than patients without PCS and nonconcussed subjects. It is concluded that cognitive deficits may be present up to six months after mild head injury when symptoms persist. The findings indicate that MHI patients with subjective symptoms may manifest demonstrable cognitive deficits.

Key Words: Attention, Mild head injury, Postconcussive symptoms

\section{Introduction}

The cognitive deficits and postconcussive sequelae caused by severe head injury are well established [5]. Mild head injuries (MHI) are much more common than severe head injuries, and many patients have subjective impairments as a result of their head injury [3]. There has been much debate over the years as to whether minor head injuries result in significant persistent cerebral damage, and if present, whether it is demonstrable by objective methods. Neuropsychological investigations thave been carried out over the past twenly years to evaluate behavioral and cognitive dysfunctions in patients with MHI. Whereas gross deficits in intelligence or memory have not been reported in minor head injury $[8,10,18]$, subtle impairments in the rate of information processing and attention have been found $[12,13,15,22]$. An important question is how long these cognitive deficits will persist. Persistent neuropsychological and psychosocial difficulties 3-6 months after minor head injury have been reported $[2,17,26]$. The results of several other studies, however, do not indicate decreased cognitive functioning about 1 month after minor head injury $[8,10,18]$. The conflicting results may be because of the heterogeneity of the subjects, the different time intervals after injury, the sensitivity of the selected cognitive tests to detect post-traumatic brain dysfunction, and the appropriateness of the control group. Most studies performed so far have compared head-injured patients with nonconcussed subjects instead of directly comparing patients with and without persistent postconcussive symptoms [20]. Evidence is growing to indicate that cognitive deficits may be limited to a subgroup of MHII patients, for instance those with subjective complaints $\llbracket 9,10,17\rceil$.

The aim of the present study, therefore, was to test the hypothesis that pathents with 
postconcussive symptoms six months after mild head injury have cognitive dysfunctions in comparison with matched, symptom-free MHI patients and nonconcussed control subjects. A specific impairment of attention after MHI has been shown by a number of studies $[10,11,15]$. Therefore, tests that measure different aspects of attention were included in the test battery.

\section{Subjects and Methods}

\section{Subjects}

Patients $(n=11)$ with persistent PCS were selected from a larger population of patients with mild head injury. This population refers to a consecutive series of seventy-one MHI patients who were willing to participate in a prospective cohort study with a follow-up time of six months (unpublished data). The criteria for inclusion in the study included a post-traumatic interval time of about 6 months, a post-traumatic amnesia not exceeding 60 minutes, a period of unconsciousness of less then 15 minutes, a Glasgow Coma Score [28] of 15 on admission, and no serious traumatic physical complication (including the absence of orthopaedic injury). Patients who had drunk alcohol at the time of the trauma or who had a skull fracture were excluded. None of the subjects were involved in litigation-compensation affairs and none had a history of neuropsychiatric disorder. Consequently, 25 patients ( 7 females, 18 males) were excluded from the study. Fourty-six patients (23 gemales, 23 males) with an uncomplicated MHI without a premorbid compromising condition were selected. The causes of the injury were traffic (33), falls (6), fights (1), sports (5) and accident at work (1). Six patients were lost during the follow-up evaluation. There were 9 patients with persistent PCS at 6 months after the uncomplicated MHI (i.e. 22\%). Two patients with persistent PCS, who were not initially seen by us at the time of their uncomplicated MHI, were also included in the present study (one male aged $33 \mathrm{yr}$ and one female of $23 \mathrm{yr}$ ). Both had an educational level of 5 on the scale of Verhage [29]. The mean age and educational level of the 9 PCS patients were 30.4 yr (SD 11.7) with an educational level of $4.7(0.6)$. The causes of the injury within the PCS group were traffic (9), fights (1) and sports (1). The 7 points scale of Verhage [29] represents 7 different levels of educational achievements based upon the particular system of the Dutch scholastic system.

The MHI patients $(n=11)$, who had recovered completely and had no PCS 6 months post-injury; were selected from the same cohort population on the basis of matching criteria with the patients with persistent PCS. The uninjured group $(n=11)$ was selected from a pool of nonconcussed healthy volunteers. Both the MHI patients without PCS and the healthy volunteers were individually matched with the patients with PCS for age $(+/-6$ years), sex and education $(+/-1$ level; 29$)$. Each group consisted of 6 males and 5 females. Mean age, time elapsed after the trauma, and the educational level are presented in table $\mathbb{1}$. All subjects gave their informed consent.

Tablie 1

Mean age (years) , time after the trauma (months), and educational level 2291 of patients with persistent $\mathrm{PCS}_{s}$ patients without PCS and nonconcussed subjects. Means are presented with SD.

\begin{tabular}{lllll} 
& $\begin{array}{l}\text { Patients } \\
\text { with PCS } \\
(\mathrm{N}=11)\end{array}$ & $\begin{array}{l}\text { Patients } \\
\text { without PCS } \\
(\mathrm{N}=11)\end{array}$ & $\begin{array}{l}\text { Nonconcussed } \\
\text { Controls } \\
(\mathrm{N}=11)\end{array}$ \\
\hline $\begin{array}{lccccc}\text { age } \\
\text { education }\end{array}$ & $29.7 \pm 10.8$ & $28.0 \quad \pm 11.0$ & $30.0 \quad \pm 11.5$ \\
time postinjury & 4.9 & \pm 0.7 & $5.0 \quad \pm 0.9$ & $5.2 \pm \pm 1.3$
\end{tabular}


Postconcussive symptoms

A checklist of postconcussive symptoms was completed, which included ittens of headache, nausiea, dizziness, difficulties with concentration and memory, fatigue, and sleep disturbances. As these symptoms also occur in healthy individualls [8], the symptoms were scored for the absolutely or relatively increased appearance after the injury in comparison with the pretraumatic condition. Ten patients with persistent PCS $(\mathbb{N}=11)$ complained of 3 symptoms or more, and one patient complained of 2 symptoms. By definition, patients without PCS did not report any symptom 6 months after the injury.

\section{Psychometric tests}

The following tests were used:

(1) Memory task. A visual, computer assisted version of the Auditory Verbal Learning Test (AVLT; see Lezak, 19) was presented on a portable microcomputer [4]. The test consists of a list of 15 monosyllabic meaningful words, which are presented for 1 second at 1 second intervals. Ak the end of the trial the subjects recall the words. Five trials were carried out. The variable used in this study was the total number of correct words over all trials.

(2) The Stroop Color Word Interference Test [see Lezak, 19] consists of three subtasks. The tests examines the speed at which 100 color names (yellow, green, red and blue) are read (subtask I) and the speed at which 100 colored spots are named (subtask II). Subtask III again involves 100 color names, but the printing ink is different from the color name; the speed at which the color of the printing ink of the words is named is taken as the test variable. The color word interference score - which can be taken as a measure of selective attention [14]- results from the subtraction of the time needed for subtask II from that of subtask III (III-II), and was used as the cognitive parameter.

(3) In the computerized divided attention task, dots were presented at irregular time intervals within a fixed $6 \times 10$ rectangular matrix on a monitor screen of $20 \times 28 \mathrm{~cm}$ (Vienna test system, Schuhfried GmbH, Austria). The subject was instructed to press a button when 4 dots formed a square (=the signal). Each square was illuminated for 3 seconds, while other dots appeared and disappeared. The maximum number of different points 'moving' simultaneously was three. Sixty signals were presented in the total testing time of 12.5 minutes. The mean reaction time and the number of omissions were recorded and used as the cognitive measures.

\section{Statistical Analysis}

The first step in the analysis was to assess whether there was an overall difference between the two groups for all cognitive parameters together by MANOVA [27]. This multivariate approach is particularly suitable for analyzing differences between groups when subjects are examined by more than one parameter, in that the same degree of protection against type-1 errors as that for the general analysis is maintained for each comparison. In the second, separate univariate analyses per cognitive parameter were carried out. Duncan's multiple range test was used as a post hoc test to evaluate significant main effects [27]. Probabilities greater than 0.05 were considered non-significant. Ranks over all observations were calculated for scores that did not ap* proximate a normal distribution [7].

\section{Results}

Multivariate analysis yielded a significant "group" effect [Wilks lambda of 0.52 equivalent multivariate $F(8,54)=2.60, \mathrm{P}<0.05]$. Therefore, separate univariate tests per cognitive parameter were carried out. Mean data and $F_{*}$ values are presented in table 2 . With respect to the verbal learning test the ANOVA just failed to achieve a significant 
difference between groups $(\mathrm{P}<0.06)$.

There was a significant overall group effect of the Stroop Color Word Interference Score (III-II). Post hoc tests indicated that patients with PCS had significantly higher interference times than both control groups.

Anallysis of the scores for the divided attention task revealed an overall significant group effect for the mean reaction time. Post hoc tests indicated that the patients with PCS were significantly slower than the patients without PCS and the nonconcussed controls. In contrast; there were no significant differences between the patients without PCS and the nonconcussed control subjects. In order to check the possible biasing effects of fatigue, the mean reaction time of subjects in the first half of the test was compared with that in the second half. ANOVA revealed no significant group effect $[\mathrm{F}(1.32)=1.3, \mathrm{~ns}]$ indicating that each group had about the same reaction times in both halves of the test. Although patients with PCS tended to make more omissions, there was no significant overall difference between the three groups for this parameter (table 2).

\section{Table 2}

Results of the neuropsychological tesis (Means \pm SD) together with $F(1,32$ ) wallues (ANOVA).

A common letter signifies a statistically significant difference according to the Duncan Multiple Range Test.

$\begin{array}{lll}\text { Patients } & \text { Patients } & \text { Nonconcussed } \\ \text { with PCS }(\mathrm{N}=11) & \text { without PCS }(\mathrm{N}=11) & \text { Controls }(\mathrm{N}=11)\end{array}$

\begin{tabular}{clll}
\hline Divided Attention Task: & & & \\
Omissions $[\mathrm{F}=1,24 \mathrm{~ns}]$ & $15.4+/-8.8$ & $12.1+/-7.2$ & $10.7+/-4.7$ \\
Reaction time $\left[\mathrm{F}=4.68^{*}\right]$ & $1.45+/-0.21 \mathrm{ab}$ & $1.17+/-0.35 \mathrm{a}$ & $1.16+/-0.14 \mathrm{~b}$
\end{tabular}

Stroop Color Word Interference Test:

$\begin{array}{llll}\text { SI } & 50.17+/-17.42 & 36.66+/-5.12 & 39.22+/-3.88 \\ \text { SII } & 61.51+/-17.19 & 45.91+/-5.46 & 46.37+/-4.59 \\ \text { SIII } & 103.32+/-35.44 & 66.05+/-10.33 & 77.85+/-10.82 \\ \text { SIII-II }\left[F=7.77^{* *}\right] & 41.80+/-20.37 \mathrm{ab} & 20.14+/-6.05 \mathrm{a} & 26.48+/-8.67 \mathrm{~b}\end{array}$

Verbal Memory Test:

Total score $[\mathrm{F}=3,16 ; \mathrm{P}<0.06] 43.55+/-8.74 \quad 50.91+/-12.44 \quad 53.00+/-5.20$

$* \mathrm{P}<0.05 ; * * *: \mathrm{P}<0.001$

\section{Discussion}

There has been considerable debate about the question whether minor head injuries result in significant persistent cerebrall damage and, if present, whether this damage can be demonstrated by using psychometric tests. There is accumulating evidence to indicate that even mild head injury may produce subtle cognitive deficits [15]. These deficits appear to selectively impair functions of attention and information processing and are most consistently seen with more complex and demanding tasks $[11,15,22,24]$. Studies in patients with MHI cover a heterogeneous population as there are subgroups of patients who recover quickly, within days, whereas others have persistent PCS after the first weeks of recovery. It is possible that these subgroups represent varying degrees of post-traumatic brain dysfunction. It is important to compare a group of MHI patients experiencing PCS with both MHI patients without PCS and nonconcussed subjects when seeking to establish meaningful relationships. The present study indicates that patients with persistent PCS 6 months after an uncomplicated MHI had neuropsychological deficits in comparison with MHI patients without PCS and non- 
concussed subjects. The present results are in accordance with those of Dikmen et al. [8] and Leininger al. [17], and indicate that symptomatic MHI patients displayed significanty poorer performance than controls on several neuropsychological tests. Deficits were most evident on tests of divided and selective attention.

Although we only found a trend towards decreased performance on the verbal memory tests, Leininger et al. [17] found that symptomatic MHI patients 1-22 months after injury had decreased scores on a werbal memory test. The Stroop collor word interference test has been used to measure selective attention in patients with head injury [14]. Results consistently indicate that head-injured patients have no specific difficulty in focusing on the color dimension of the ambiguous stimuli when data are aggregated at a group level without reference to the persistence of PCS [1,6]. In contrast, McLean et al. [23! found a significant interference effect on the Stroop test only in the subacute stage after injury. We found that patients with persistent PCS at 6 months had more difficulties with the Stroop Color Word Interference measure than asymptomatic patients and nonconcussed controls. Recently, Gentilini et al. [11] reported further evidence for deficits in selective attention in mildly head-injured patients.

Patients with PCS reacted significantly more slowly on the divided attention task than the asymptomatic patients and nonconcussed controls. Fatigue can be discarded as a causative factor because the cognitive deficits were already present in the first half of the task. Although these attentional impairments may appear to be subtle, they may have very disabling consequences. Impaired attention and information processing may adversely affect performance in a vocation that entails decision making or stress [15]. Patients are less efficient in the processing of information under time pressure and in demanding situations. Moreover, the demands placed on a mildly head-injured patient at a give point in time post-injury are greater than that placed on a wictim of severe head injury [25]. The real-life consequences of slight disturbances in complex information processing in MHI patients have not been investigated as yet.

With respect to the persistence of symptoms following MHI, Gronwall and Wrightson [12] reported that information processing functions were impaired during the first weeks, with recovery occurring by 35 days unless the post-traumatic symptoms persisted. These authors suggested that a reduction in the rate of information processing is an important factor in the genesis of the postconcussion syndrome. Similarly, Jakobson et al. [16] were able to predict behavioral recovery 1 month after minor head injury by using a reaction time task. In contrask, MacF]ynn et al. [22] found no relationship between measires of reaction time and behavioral sequelae. Whether cognitive deficits underlie or contribute to the behavioral sequelae has to be considered in the perspective of different factors, stuch as the selection of a particular cognitive test, the environmental demands placed upon a pattent [21], and the nature of particular postconcussive symptoms. For example, MacFlym et al. [22] demonstrated that patients with a symptom cluster of vomiting, vertigo and diplopia had neurophysiological abnormalities, but did not differ in mean reaction time from patients without this symptom cluster.

The critical question is whether or not the lower neuropsychological performance of symptomatic patients was caused by the injury or whether neuropsychological dysfunc tions were already present before the injury. Given the small sample size and lack of premorbid information no firm conclusion can be drawn. However, patients were strictly matched on educational level. In addition, none of the patients was unemployed because of the trauma. The presence of symptoms was scored for their appearance after the injury in comparison with the pretraumatic condition. Despite the persistence of symptoms 10 out of 11 patients had resumed their work within 3 months after the injury, with one patient being forced stop working for a second time. Although none of the patients experienced a symptom-free interval within the first period after the trauma, the resumption of work was a common cause of aggravation of their symptoms. None of the patients developed symptoms of a post-traumatic stress disorder 
It can be summarized that the subgroup of MHI patients who report PCS at 6 months after an uncomplicated MHI may demonstrate deficits on tests of attention and information processing. The present findings provide an objectiveable basis for the sometimes vague and "crocky" complaints and symptoms of patients some time after an uncomplicated mild head injury. In contrast, patients who had recovered from an uncomplicated MHI did not differ in cognitive functioning from nonconcussed control subjects. The less adequate neuropsychological functioning of symptomatic patients is important and warrants further establishment. Further research should be aimed at a more integrated approach using a combination of cognitive and neurophysiological or neuroimaging measures, to investigate whether MHI patients with persisting PCS may have evidence of structural brain damage.

\section{References:}

1. Acker MB, Dawis JR. (1989) Psychology test scores associated with lake outcome in head injury. Neuropsychology 3:123-133.

2. Barth JT, Macciocchi SN, Giordani B, Rimel R, Jane JA, Boll I. (1983) Neuropsychological sequelae of minor head injury. Neurosurgery 13:529-533.

3. Binder LM. (1986) Persisting symptoms after mild head injury: a review of the postconcussive syndrome. J Clin Exp Neuropsychology 8:323-346.

4. Brand $\mathrm{N}$, Jolles J. (1985) Learning and retrieval of words presented auditorilly and visually. J Gen Psychology 112:201-210.

5. Brooks DN, Aughton ME, Bond MR, Jones B, Rivzz S, (1986) Cognitive sequelae in relationship to early indices of severity of brain damage after severe blunt head injury. I Neurol Neurosurg Psychiatry 43: $529 \cdot 534$

6. Chadwick O, Rutter M, Brown G, Shaffer D. Traub M. (1981) A prospective study of children with head injury: II Cognitive sequelae. Psychol Med 11: 49-62.

7. Conover WJ, Iman RL. (1981) Rank transformations as a bridge between parametric and non-parametric statistics. Am Statist 35:124-129.

8. Dikmen S, McLean A, Temkin N. (1986) Netaropsychological and psychosocial consequences of minor head injury. J Neurol Neurosurg Psychuatry 49:1227-1232.

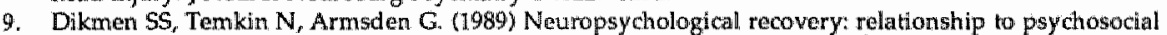
functioning and postconcussional complaints, in Levin HS, Eisenberg HM, Benton AL (eds): Mild head injury. New York, Oxford Uniwersity Press, pp 229-24\%.

10. Gentilini $M_{*}$ Nichelli $P$, Schoenhuber $R$, Bortolotti P, Tonelli L, Falasca A, Merli GA. (1985) Neuropsychological evaluation of mild head injury. J Neurol Neurosurg Psychiatry 48:137-140.

11. Gentilini $M_{r}$ Nichelli $P$, Schoenhuber $\mathbb{R}$. (1989) Assessment of attention in mild head injury. In Levin HS, Eisenberg HM, Benton AL (eds): Mild head injury. New York, Oxford University Press, pp 163-175.

12. Gronwall $\mathrm{D}$, Wrighison $\mathrm{P}$. (1974) Delayed recovery of intellectual function after minor head injury. Lancet 2:605-609.

13. Gronwall D, Wrightson P. (1981) Memory and information processing capacity after minor head injury. J Neurol Neurosurg Psyctiatry 44:889-895.

14. Gronwall D. (1987) Advances in the assessment of attention and information processing after houd

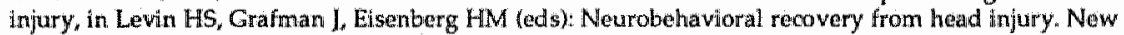
York, Oxford University Press, , pp 355-371.

15. Hugenhol tz $\mathrm{H}_{\epsilon}$ Stuss DT, Stethem LL, Richard MT. (1988) How long does it take to recover from a mild concussion? Neurosurgery 22:853-858.

16. Jakobsen I, Baadsgaard SE, Thomsen S, Henriksen PB. (1987) Prediction of post-concussional sequelae by reaction time test. Acta Neurol Scand 75:341-345.

17. Leininger BE, Gramling, SE, Farrell AD, Kreutzer IS, Peck EA III: (1990) Neuropsychological deficits in symptomatic minor head injury patients after concussion and mild concussion. I Neurol Neurosurg Psychiatry $53: 293-296$.

18. Levin HS, Mattis S, Ruff RM, Eisenberg HM, Marshall LF, Tabaddor K, High WM, Frankowski RF. (1987) Neurobehavioral outcome following minor head injury: a three-center study. I Neurosurg $66: 234-243$.

19. Lezak MD. (1983) Neuropsychological assessment. New York, Oxford Uniwersity Press, ed 4.

20. Lishman WA. (1988) Physiogenesis and psychogenesis in the "post-concussional syridirome". Br I Psychiatry 153:460-469.

21. Long Cl, Novack TA. (1986) Postcancussion symptons after head trauma: Interpretation and treatment. South Med I 79:728-732.

22. MacFlynn $G_{v}$ Monigomery EA, Fenton GW, Rutherford W. (1984) Measurement of reaction time following minor head injury. J Neurol Neurosurg Psychiatry 47:1326-1331. 
23. McLean A, Temkin MR, Dikmen S, Wyler AR. (1983) The behavioural sequelae of head inifury. I Clin Netropsychol 5,361-376.

24. McMllin TM, Glucksman EE. (1987) The neuropsychobgy of moderate head injury I Neurol Neurosurg Pischiatry 50:3913-397.

25. Ponsford ). (1990) Psychological sequela of closed head jnjury: timue to redress he imbalance. Brain linjury $4111-114$.

26. Rinal सW, Ciordan Barth JT, Ball JT, Jame JA (1981) Disabllity caused by minor head injury. Neurosurgery $9: 221 \% 228$.

27. SAS (1985) User: Guide. Statistics, Version 5 Edition North Carolina, Cary, SAS Institute lnc.

28. Teasdale $G$, Jennett B. (1974) Assessment of coma and impaired consciousness A praictical scale. The Lancet 2,81, 84 .

29. Verhatge R. (1964) Intelligentie en leeftijd. Dissertation. Assen, The Netherlands. 


\section{CLUSTER C: The Coping Hypothesis, Stress, Cognitive Performance and Postconcussive Symptoms}

'As a general rule, postconcussive symptoms will occur whenever environmental demands exceed cognitive capacity for dealing effectively with the denands' (Long \& Novack, 1986)

9. Coping style, trait anxiety, and cortisol reactivity during mental stress.

10. Cortisol reactivity and cognitive performance in a mental task paradigm.

11. Coping styles, cortisol reactivity, and performance in a vigilance task of patients with persistent postconcussive symptoms after a mildhead injury. 


\title{
Chapter 9
}

\section{Coping Style, Trait Anxiety and Cortisol Reactivity during Mental Stress}

\author{
N. Bohnent, N. Nicolsonl, J. Sulon'z \& J. Jolles
}

1 Deparment of Neuropsychology \& Psychobiology, University of Limburg, Maastricht, The Natherlands.

2 Laboratoire de Steroides, Centre Hospitalier Universitaire Sart Tilman, Liege, Belgium.

J Psychosom Res 1991: 35: 141-147.

\section{Abstract}

The present study examined whether salivary cortisol secretion as an index of stress reactivity to continuous mental task performance reflected individual differences in coping styles. During 4 hours of continuous mental tasks significantly higher cortisol levels were found in comparison with a control session. However, individual variability in the cortisol response was high. Correlational data indicate a significant negative relationship between the coping style 'comforting cognitions.' and the individual cortisiol response during mental stress. During this particular type of cognitive stress, where the subject has no control over the experimental situation, comforting and emotion-focused coping may be effective because of the subject's efforts of trying to reframe the inevitable situation in a positive and self-encouraging way. In contrast, there was no significant relationship between trait anxiety and individual glucocorticoid susceptibility to mental stress.

Keywords: coping, salivary cortisol, anxiety, mental stress

\section{Introduction}

Organisms are continuously exposed to stressful events or stressors which can affect the homeostasis. Any biochemical or physiological change in response to such a stressor is ustally called stress or stress response. For example, increases in plasma epinephrine and cortisol levels are typical biochemical signs of stress. In the last decade evidence has accumulated that the stress response is not caused by the aversive or moxious nature of the stressor per se, but by the ability of the organism to deal with the stressor. If an individual can cope successfully with the environmental challenge, little or no stress is experienced. Thus, coping strategies rather than the nature of the stressor will determine whether or not stress is experienced by an individual $[1,2]$.

It has been stated that where there is little or no elevation in circulating corticosteroids the individual is effectively coping with the stressor [3]. For example, it has been found that persons with ineffective defences have higher cortisol excretion during psychosocial stress (see Vickers for review, 4). Baade et al. [5] demonstrated a clear relationship between high levels of cortisol and low performance in parachutist trainees.

Studies on personality traits and coping styles as determinants of interindividual differences in neuroendocrine responses to stress have not yet yielded conclusive results $[6,7]$. Bossert et al. [8] could not predict the interindividual differences in the frequency of cortisol responses to laboratory stress tests by any of the psychometric variables (personality traits and coping styles) they had investigated. They question whether psychological factors actually contribute to the neuroendocrine stress response. On the other hand, it can be stated that in most studies relating psychological measures to cortisol secretion, urinary free cortisol was used. However, it is questionable whether the stressors are of suffictent magnitude or duration to cause measurable changes in 
uminary cortisol excretion [9,10]. Another way of sampling cortisol is by means of saliva [11]. which has the advantage of easy and repeated stress-free sampling.

It was the aim of the present study to investigate salivary cortisol secretion during a mental task paradigm in relationship to psychometric measures of coping style and trail anxiety in order to address two questions. Firstly, is the stress related to 4 hours of continuous mental tasks of sufficient magnitude to induce increased cortisol reactivity? Secondly, if so, are subjects characterized by less-effective coping styles or increased trait anxiety more susceptible to increased cortisol reactivity?

\section{Subjects and Methods}

\section{Subjects}

The study was conducted with 24 female volunteers in good physical and mental condition. The subjects were drawn from the following age groups: $41-49$ years $(n=12)$, and 61-69 years $(n=12)$. Each subject was paid and gave her informed consent.

\section{Procedure}

The study consisted of two sessions separated by an interval of 6 days. Each subject participated both in a continuous mental task session during 4 consecutive hours and in a control session. Saliva samples for determination of cortisol. were taken at 6 times in each session $(10.20,12.40,14.10,14.45,15.00$ and 15.30$)$. Each day started at 10.15 with instructions and assessment of cognitive functions, followed by a 4 -hour experimental period (11.45-15.45).

Together with the instructions at the beginning a Spielberger Trait Anxiety Inventory [12] and a 47-item Coping List (UCL) were completed [13]. During the experimental period the subjects abstained from smoking and drinking coffee or tea. At lunch time (noon), 13.10 and 14.40 each subject received $150 \mathrm{ml}$ of lemonade. The experimental session was only interrupted for 10 minutes for a quick lunch. In order to control for possible sequence effects the subjects were assigned at random either to a schedule of starting with the continuous session followed one week later by the control session, or to a schedule with a reverse order.

\section{Continuous mental tasks for 4 hours}

The rationale behind this program was based on the application of sielf-paced, motivating cognitive tasks, partly in combination with environmental noise of $65-70$ $\mathrm{dB}$, in order to enhance fatiguing or stress effects [14].

The experimental session included the following activities:

Activity $1(11.45-12.10)$ : repetitive performance of a psychometric test (memory comparison task; paper and pencil version), interrupted for a short $\mathbb{L}$ unch.

Activity 2 (12.15-12.45): self-paced computerised geometrical recognition task (Vienna Test System, Schuhfrtied GMBH, Austria).

Activity 3 (12.45-13.10): Diwided attention test.

Activity 4 (13.15-13.45): Bourdon-Wiersma concentration task [15].

Activity 5 (13.45-14.15): self-paced computerised arithmetic (Vienna Test System, Schuhfried GMBH, Austria) with environmental noise.

Activity 6 (14.15-14.40): Divided attention test.

Activity 7 (14.45-15.05): sham video-recorded speech task, in which the subject was requested to speak about her own positive personality traits. Subjects were allowed 10 minutes of preparation and then had to talk for 5 minutes.

Activity 8 (15.05-15.30): self-paced computerised reaction time task with envirommental noise.

\section{Control session}

Except for the administrations of the divided attention test (12.45-13.10 and 14.15-14.40) the subject was free from 11.45 to 15.45 in the choice of the following activities: reading 
popular family fournals, listening to soft music or watching short segments of amusement videa. The subject was left alone in a separate room:

\section{Trait Anxiety Inventory}

The trait anxiety inventory of Spielberger in an adapted version for the Dutch language [12] was used in order to assess general susceptibility to stress .

\section{Utrecht Coping List}

The Utrecht Coping List is a 47 -iten questionnaire describing 7 styles of coping, which have been factor-analytically derived [13]. Sum scores are calculated for each of the seven subscales. Subscale 1 (7 items) "active problem solving" describes a direct and rational approach towards problem situations. Subscale 2 (8 items) 'palliative response" includes items of seeking distraction, trying to feel better by smoking, drinking, or relaxing. Subscale 3 ( 8 items) 'avoidance and passive expectancy" involves items of problem avoiding or awaiting the consequences. Subscale 4 (6 items) 'seeking social support' includes items of seeking help from others. Subscale 5 ( 7 items) 'depressive reaction involves items of being overwhelmed by the problem and of being pessimistic about the outcome. Subscale 6 (3 items) 'expression of emotion and anger' defines an emotional expressive reaction towards problems. Finally, subscale 7 (5 items) 'comforting cognitions' includes items of considering the problem in a rellative way, of self-encouragement and of a positive reframing of the situation.

\section{Salivary cortisol}

Saliva was collected by holding an absorbent cotton roll in the mouth for 1-2 minutes. The roll was then placed in a capped plastic vial ('Salivette', Sarstedt B.V.). By the end of each session the samples were stored at $-200 \mathrm{C}$ until analysis. Experiments in our laboratory have demonstrated that cortisol levels in saliva collected with the Salivette cotton rolls do not differ from levels in matched samples collected in plain tubes (Sulon, pers. comm.). Salivary cortisol was determined by direct radioimmunoassay [16], using 125I-cortisol (Farmos diagnostica, Fimland) and anticortisol antiserum (made against the 3-CMO-BSA conjugate), in duplicate, by dr. J. Sulon of the Steroid Laboratory, University Hospital Liège Belgium. Saliwa cortisol was measured from nonextracted saliva $(25 \mu \mathrm{l})$, as we have found wery high correlation between extracted (with ethylacetate) and nonextracted saliva $(r=0.99, \mathrm{n}=20, \mathrm{P}<0.001)$, confirming the absence of corticosteroid binding protein in saliva. The lower detection limit of the assay was $0.69 \mathrm{nmol} / 1$, with an intra-assay coefficient of $4.4 \%$. All samples were analyzed in the same assay.

\section{Analysis}

The 4 afternoon cortisol samples were compared for each session by repeated measures analysis of variance; paired t-tests were used for comparisons between sessions at each sampling time. In addition, individual difference scores were calculated (continuous task session minus control session). Difference scores for the three latest afternoon cortisol samples were highly intercorrelated, therefore the mean of these three differences was calculated as an index of cortisol reactivity. In addition, Spearman rank correlation coefficients (two-tailed tests) were calculated between the individual cortisol response and the scores on the coping list and trait anxiety inventory.

\section{Results}

The effects of stress on cognitive performance are reported elsewhere.

As can be seen from figure 1, following the expected diurnal decline in cortisol secretion in the moming hours there was a significant increase in the four mid-afternoon cortisol samples during the continuous task session compared to the control session $(\mathrm{F}(1,20)=27.47 ; \mathrm{p}<0.0011$, with an average increase of $76 \%, 39 \%, 46 \%$ and $99 \%$ at the 
respective time points (see also table 1 ).

There were no significant relations between the averaged difference scores from the three latest aftemoon cortisol samples and either the factor sequence $(t=1.05$, ns) or age $(\mathrm{t}=-0.01, \mathrm{~ns})$.

\section{Table 1}

Mean difference scores for the five afternoon cortisol samples (continuous bask session minus control session). Data are presented together with $\mathrm{SD}_{*} \mathrm{SEM}_{v} \mathrm{t}$-values and significance levels.

Time $\underset{\substack{\text { Mean Difference } \\(\mathrm{nmol} / \mathrm{l})}}{\mathrm{SD}} \quad \mathrm{SEM} \quad \mathrm{T}$

\begin{tabular}{llllll}
\hline 12.40 & -0.06 & 1.91 & 0.41 & -0.14 & $\overline{n s}$ \\
14.10 & 0.91 & 0.91 & 0.20 & 4.58 & $\mathbb{P}<0.001$ \\
14.45 & 0.66 & 1.14 & 0.24 & 2.77 & $\mathbb{P}<0.05$ \\
15.00 & 0.95 & 0.93 & 0.19 & 5.00 & $\mathbb{P}<0.001$ \\
15.30 & 1.16 & 1.69 & 0.35 & 3.35 & $\mathbb{P}<0.01$
\end{tabular}

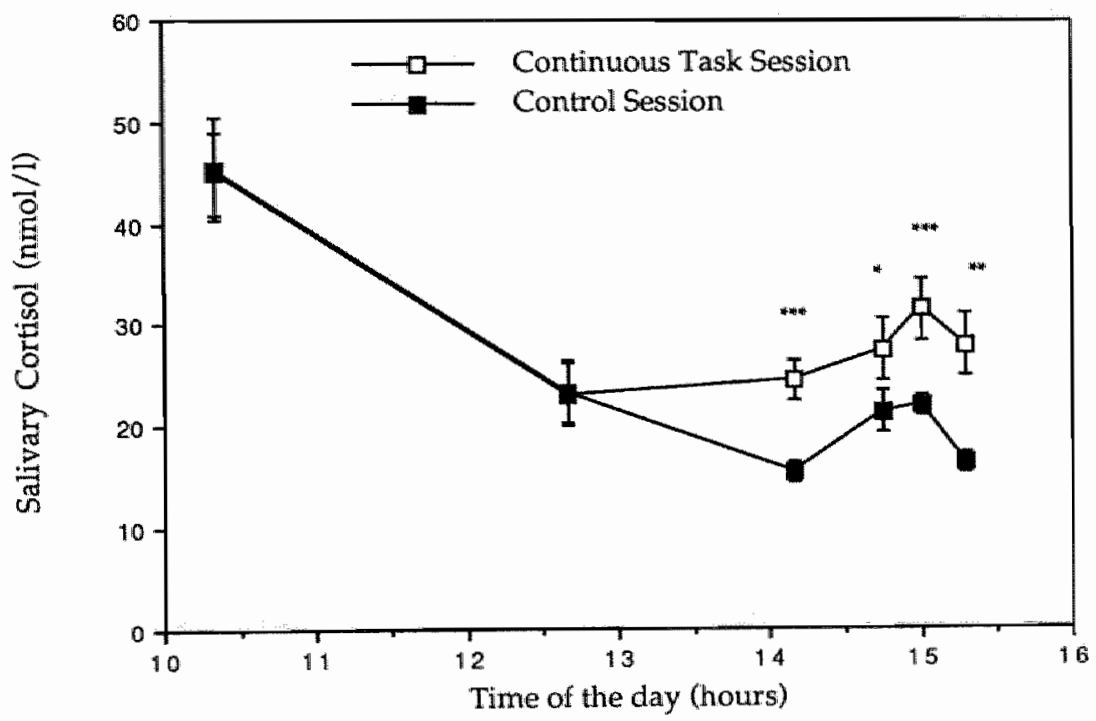

Figure 1

Mear cortisol levels $(+S E M)$ in the continuous task session and in the control session ( $n=24)$. The two-tatled significance levels of the paired $t$-tests for the 4 mid-atternoon samplas between the two sessionstare marked with asterisks $(* ; \mathrm{p}<0,05 ; * * ;<<0.01 ; * *: \mathrm{p}<0.001)$.

The correlational data between the psychological variables and the cortisoll response are presented in table 2 . The data indicate a significant negative correlation between the coping style 'comforting cognition' and the cortisol response ( $r s=-0.41, p<0.05)$. In addition, there was a non-significant negative relationship between the coping style "seeking social support" and the cortisol response $(\mathrm{rs}=-0.36, \mathrm{p}<0.1)$. There was no significant relationship between trait anxiety and saliva cortisol response ( $r_{s}=0.17$, ns). 
Tiable 2

Correlational dat between individul cortisol reactivity, trat anxtery and coping style subscales are presinted logether with the mean scores $(4 \mathrm{SD})$

Cortisol Response

Mean Sicores

(continuous-task-session minus control-session)

\begin{tabular}{lll}
\hline Trait Anxiety & 0.17 & $37.0 \pm 11.2$ \\
1: Active Problem Solving & -0.32 & $19.0 \pm 3.6$ \\
2. Palliative Response & -0.26 & $17.9 \pm 3.4$ \\
3: Avoidance and Passive Expectancy & -0.17 & $15.7 \pm 3.4$ \\
4: Seeking Social Support & -0.36 & $10.8 \pm 3.1$ \\
5: Depressive Reaction & 0.13 & $11.6 \pm 3.1$ \\
6: Expression of Emotion and Anger & -0.20 & $6.6 \pm 2.1$ \\
7: Comforting Cognitions & $-0.41 *$ & $13.8 \pm 2.1$ \\
& &
\end{tabular}

\section{Discussion}

Measurement of salivary cortisol levels, as well as providing a simple, stress-free, noninvasive collection procedure, closely reflects in time the changes in plasma levels of the hormone, not suffering from the large lag-time involved with urinary hormone measurements [17]. In the present study it was found that the stress related to 4 hours of continuous mental tasks elicited a significant increase in corkisol secretion. Salivary cortisol proved to be a sensitive and useful index of mental stress, in that rather small percentual increases were shown by a large percentage of the subjects. In addition, the administration of the divided attention test in the control session (eg 14.15-14.40) induced a short-lasting pronounced increase in salivary cortisol levels. From an individual point of view, it was found that salivary cortisol sampling revealed fairly large differences in cortisol reactivity between subjects after 4 hours of continuous mental tasks.

Individual coping variables have been hypothesized as important factors in the stress process [1]. Coping responses or strategies represent the specific actions that people take in order to deal with a given problem or stressor, for example by talking it over with others, ignoring the situation or taking direct action to solve the problem [18]. In addition, there has been a growing conviction that beliefs about personal control over situational demands play an important role in stress and coping [19]. Beliefs about control can alter the extent to which an encounter is appraised as threatening and can influence coping.

"The present results indicate that the coping style 'comforting cognitions' was most powerful in predicting the cortisol response during this particular type of cognitive stress, in which subjects had to perform superimposed tasks under strict instructions without having any control over the allocation of experimental time. Coping may have two major functions: the regulation of emotion or distress (emotion-focussed coping) and the management of the problem that is causing the distress (problem-focussed coping; 19). Folkman et al. [20] have shown that both forms of coping are used in most stressful encounters. The use and effectiveness of coping behaviors have found to be dependent on the appraisal of the situation's amenability to change. For example, in the present experiment emotion-focussed coping could be used to alter the meaning of a situation and thereby enhance the individual's sense of control over her distress. When there is no possibility to change the superimposed tasks, an adequate adaptation may be to acknowledge the tasks as being inevitable and to try to comfort oneself as much as possible given the temporary stressful condition. The other coping styles were not associated in a specific way to individual cortisol variability in our experimental paradigm. However, it is possible that these types of coping behavior could give rise to an increased or decreased cortisol secretion during exposure to other types of stress, such as examination stress [21] or lecturing stress [22]. 
Houston [23] found a relationship between trait anxiety and cognitive coping behaviors. Highly trait-anxious individuals tended to respond with maladaptive cog nitive coping behavior to stress. With respect to cortisol reactivity, Hubert et al. [7] found no correlation between trait anxiety and salivary cortisol release in response to a suspense film. The present findings also falled to demonstrate a significant relationship between levels of trait anxiety and individual glucocorticoid susceptiblity to stress. In summary, the present results indicate that 4 hours of continuous mental tasks significantly elevated cortisol levels in saliva in comparison with a control session, and that a psychometric measure of coping was significantly related to salivary cortisol reactivity under these particular conditions.

\section{References}

1. Holroyd KA, Lazarus RS. (1982) Stress, coping and somatic adaptation. In Handbook of stress: theoretical and clinical aspects (Edited by Goldberger L, Breznitz S.). New York, Free Press.

2. Vogel WH. (1985) Coping, stress, stressors and health consequences. Neuropsychobiology 13: 129-135.

3. Levine S. (1978) Cortisol changes following repeated experiences with parachute training In

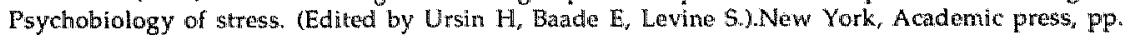
51-56.

4. Vickers RR Jr. (1988) Effectiveness of defenses: a significant predictor of cortisol excretion under stress. J Psychoson Res 32, 21-29.

5. Baade E, Ellertsen B, Johnsen TB, Ursin H. (1978) Physiology, psychology and performatnce. In Psychobiology of stress. (Edited by Ursin H, Balade E, Levine S.). New Yark "Acadenic press, pp. $163-182$.

6. Herbert J. Moore GF, de la Riva $C_{r}$ Watts FN. (1986) Endocrine responses and examination anxiety. Biol Psychology 22, 215-226.

7. Hubert W, de Jong-Meyer R. (1989) Emotional stress and saliva cortisol response. J Clin Chem Clin Blochem 27; 235-237.

8. Bossert $S$, Berger $M$, Krieg JC, Schreiber $W$, Junker $M$, von Zerssen D. (1985) Cortisol response to various stressful situations: relationship to personality variables and coping styles. Neuropswchobiology 20,36-42.

9. Kathol RG, Noyes $\mathrm{R}_{k}$ Lopez A (1988) Similarities In hypothalanic-pituitary-adrenal axis between patients with panic disorder and those experiencing external stresses. Psychiatr. Clin North-Am 11, 335-348.

10. Semple CG, Gray CE, Borland W, Espie CA, Beastall GH. (1988) Endocrine effects of examination stress. Clin Sci 74, 255-259.

11. Vining RF, MoGinley RA. (1986) Hormones in sali wa. Crit Rev Clin Laboratory Scí 23, 95-146.

12. Van der Ploeg HM, Defares PB, Spielberger CD. (1981) Handleiding bij de zelf-beoordelings-vragenlijst. Lisse, The Netherlands: Swets \& Zeitlinger.

13. Sehreurs PJG, wan de Willige $G$, Tellegen $B$, Brosschot JF. (1987) De Utrechtse Coping Lijst: UCL. Lisse, The Netherlands: Swets \& Zeitlinger.

14. Brandenberger $G$, Follenius $M$, Wittersheim $G$. Salame P. (1980) Plasma catecholamines and pituitary adrenal hormones rellated to mental task demand under quiet andi noise conditions. Biol Psychology 10, 239-252.

15. De Zeeuw, J. Algemene psychodiagnostiek I- Tesmethoden. Lisse, The Netherlands: Swets Zeitlinger, 1981 .

16. Ansseau M, Sulon J. Doumont A, Cerfontaine JL, Legros J, Sodoyez JC, Derney, Ponusart E. (1984) The use af saliva cortisol in the dexamethasone siuppression test. Psychiatry Res 13, 201-211.

17. Bassett JR, Marshall PM, Spillane R. (1987) The physiological measurement of acute stress (public speaking) in bank employees. Int I P'sychophywiology 5, 265-273.

18. Menaghan EG. (1982) Measuring coping exfectiveness: a panwal analysis of marital problems and coping efforts. I Health Soc Behav 23, 220-234.

19. Folkman, S. (1984, Personal control and stress and coping processes; a theoretical analysis. J Pers Soc Psychology 46, 839-852.

20. Folkman S, Lazarus RS, Dunkel-Schether C, DeLongis A, Gruen $\mathbb{R}$ (1986) The dynamics of astressful encounter. cognitive appraisal, coping and encounter outcomes. I Pers Soc Psychology 50, 992-4003.

21. Hellhammer DH, Heib C. Hubert W, Rolf R. (1985) Relationships between salivary cortisol release and behavioral coping under examination stress. IRCS Med Se 13, 1179 1180.

22. Houtman ILD. (1990) Stress and coping in lecturing. Thesis Free University Amstterdam.

23. Houston BK (1982) Trailt anxiety and cogritive coping behavior. In: Achievernent, stress and anxiety. (Edited by Krohne HW, Laux L.). Washingtom: Hemisphere Publishing Corporation pp. 195-206. 


\title{
Chapter 10
}

\section{Cortisol Reactivity and Cognitive Performance in a Continuous Mental Task Paradigm}

\author{
N. Bohnen, P. Hou*, N. Nicolson \& J. Jolles
}

Department of Neuropsychology \& Psychobiology, University of Limburg Maastricht. The Netherlands.

Biol Psychol: in press

\section{Abstract}

The after-effects of fatigue or stress on the performance of cognitive tests have been particularly difficult to demonstrate. In this study we examined whether salivary cortisol, used as an index of stress evoked by the continuous performance of mental tasks, reflected individual differences in cognitive performance. In a within-subject experiment in which 24 subjects were exposed to 4 hours of continuous mental activity and to a control session, significantly higher cortisol levels were found during the continuous task session. Cognitive performance was assessed before and after each session. The relevant test parameters involved aspects of werbal memory, concept shifting and divided attention. When subjects were divided into two groups based on the magnittude of individual cortisol responses to the continuous tasks, it was found that the subgroup with higher cortisol responses decreased in attention compared with their attention after the control session. In contrast, the perfarmance of the subgroup with no or lower cortisol responses did not differ between the two sessions. There was no evidence of similar effects on verbal memory or concept shifting.

\section{Introduction}

Organisms are continuously exposed to stressful events or stressors that can affect homeostasis. Cortisol and catecholamine levels in urine or plasma are often used as measures of the biochemical response to stress. In the last decade evidence has accumulated that the stress response is not caused by the aversive or noxious nature of the stressor per se, but by the ability of the subject to cope with the stressor. If an individual can cope successfully with the environmental challenge, little or no stress is experienced. Levine [12] suggested that there is little or no elevation of circulating corticosteroids when an individual copes with a stressful situation effectively.

Apart from blological mechanisms, recent research has prowided considerable insight into the psychological mechanisms involved in the impairment of human performance caused by stressors, such as sleep loss, noise and mental fatigue [8]. Much of this research has focused on models of cognitive processes during or after exposure to various stressors, especially within the framework of the information processing theory [7]. Most before-after studies done so far have failed to demonstrate significant aftereffects of prolonged work on cognitive measures when data are aggregated at the group level [9].

With respect to biological processes and human performance during stress, Frankenhaeuser [6] has reported a relationship between sympathetic adrenal-medullary activation and successful performance on the one hand, and between activation of the pituitary-adrenocortical system and distress on the other. Similarily, Baade, et al. [3] found that poor performance in parachutist trainees was associated with high cortisol levels, whereas good performance was associated with high levels of catecholamines and blood glucose. Because individwals differ in their susceptibility to stressors, it may be useful to measure individual cortisol responses in studies of stress and human per- 


\section{formance.}

The present investigation was designed to assess whether individual differences in susceptibility to stress are reflected in cognitive performance. We first examined whether the stress related to 4 hours of continuous mental activity is sulficient to induce increased cortisol levels. We then tested the hypothesis that individuals with the largest increases in salivary cortisol levels in response to stress are more likelly to display a negative cognitive after-effect than subjects with a small cortisol response.

Because saliva can be collected repeatedly and without stress, salivary cortisol has been found to be a powerful tool in psychoneuroendocrinological research [10]. Cortisol concentrations in saliva are highly correlated with the plasma "free' fraction, which is considered to be the biologically active hormone, and are independent of the flow rate of saliva [20].

\section{Subjects and Methods}

\section{Subjects}

Subjects were 24 healthy female volunteers drawn from two age groups: 41-49 years $(n=12)$ and $61-69$ years $(n=12)$. The educational level of the subjects ranged from low to average [19]. Each subject was paid and gave her informed consent.

\section{Procedure}

The study consisted of two sessions separated by an interval of 6 days. Each subject participated in a continuous mental task session lasting 4 hours and in a control session. Cognitive performance was assessed before and after each session with tests of verbal memory, concept shifting ability and divided attention. Salivat samples for determination of cortisol were taken 6 times in each session $(10.20,12.40,14.10,14.45,15.00$ and 15.30). Each session started at 10.15. The 'before' assessment of cognitive performance took 1 hour (from 10.45 - 11.45), and was followed by the experimental period from 11.45 to 15.45 ; the 'after' cognitive performance was assessed from 15.45 to 16.45 . During the experimental period, the subjects abstained from smoking and drinking coffee or tea. The experimental session was only interrupted for 10 minutes for a quick lunch. Each subject received $150 \mathrm{ml}$ of lemonade at lunch time $12.00,13.10$ and 14.40 . In order to control for possible sequence effects, the subjects were randomly assigned to a group in which the continuous session was followed one week later by the control session, or to a group with the reverse schedule. In a pretest assessment the day before the first session, each person was subjected to the complete neuropsychological test battery in order to reduce effects of novelty, practice effects and procedural learning. Finally, a questionnaire rating personality traits was completed.

\section{Continuous mental activity for 4 hours}

The rationale behind this program was based on the application of self-paced, motivating cognitive tasks, partly in combination with environmental noise of $65-70$ $\mathrm{AB}$ to enhance fatigue or stress effects [5]. During the 'before' and 'after' cognitive assessments, the environment was quiet. No incentives were offered.

The experimental session included the following mental activities:

Activity $1(11.45-12.10)$ : repetitive performance of a psychometric test (memory comparison task; paper and pencil version; [13]), interrupted for a quick lunich.

Activilty 2 (12.15-12.45): self-paced computerised geometrical recognition task (Vienna Test System, Schuhfried GMBH, Austria).

Activity 3 (12.45-13.10) Divided attention test (Vienna Test System, Schuhfried GMBH, Austria).

Activity $4(13.15-13.45)$ : Bourdon-Wiersma concentration task [22].

Activity $5(13.45-14.15)$ : self-paced computerised arithmetic (Vienna Test System, Schuhfried GMBH, Austria) with environmental nolse "

Activity 6 (14.15-14.40) Divided attention test. 
Activity 7 (14.45-15,05): sham wideo-recorded speech task, in which the subject was requested to speak about her own positive personality traits. Subjects were allowed 10 minutes to prepare and then had to talk for 5 minutes.

Activity 8 (15.05-15.30): self-paced computerised reaction time task with environmental nolse.

\section{Contral session}

Except for the divided attention test at 1245-1310 and 14.15-14.40, the subject was free from 11.45 to 15.45 to choose one of the following activities: reading popular family journals, listening to soft music or watching short segments of amusement video. The subject was left alone in a separate room.

\section{Neuropsychological tests}

The following tests were used in the 'before' and 'after' assessments:

1. Verball memory task with interference. The Auditory Verbal Learning Test (AVLT) [13] was presented via a cassette recorder. The AVLT was adapted for the Dutch language. The test consisted of a list of 15 monosyllabic well-known meaningful words, presented at 1 second intervals. During each interval an additional monosyllabic word was spoken by the experimenter in order to create verbal interference with the task. Fiwe trials were carried out. The subject was requested to recall as many of the tape-presented words as possible after each trial. The variable used in this study was the total number of correct words over all trials. A different parallel version of the AVLT was used for each presentation.

2. The concept shifting task (CST) is a test of visual scanning and conceptual tracking, much like the Trail Making Test [13]. The CST consists of three subtasks. In each subtask the subject has to cross out small circles containing digits or letters in the correct order. The small circles are arranged in a larger circle on a sheet of paper. The subject is requested to perform the task as quickly as possible. In the first subtask (A) the subject has to cross out consecutively numbered (1-16) circles, in the second subiask (B) 16 lettered circles $(A-P)$. In subtask $C$ the subject is presented with 16 circles containing 8 digits and 8 letters $(A-H)$ and is asked to alternate between the two sequences $(1-A-2-B$ etc). The amount of extra time needed for subtask $C$ represents the concept shifting score ( $t C-0.5(t A+t B) ; t=t i m e$ in seconds).

3. Divided attention task

In the computerized divided attention task, dots were presented at irregular time intervals within a fixed rectangular $6 \times 10$ matrix on a monitor screen $(20 \times 28 \mathrm{~cm}$ ) (Vienna Test System, Schuhfried GMBH, Austria). The subject was instructed to press a button when 4 dots formed a square (=the signali). Fach square was illuminated for 3 seconds while other dots appeared and disappeared. The maximum number of different points 'moving' simultaneously was three. In the total testing time of 25 minutes 150 signals were presented. The number of correct detections was recorded.

\section{Salivary cortisol}

Saliva was collected by holding an absorbent cotton roll in the mouth for 1-2 minutes. The roll was then placed in a capped plastic viall ('Salivette", Sarstedt B.V.). Cortisol levels in saliva collected with the Saliwette cotton rolls do not differ from levels in matched samples collected in plain tubes (Sulon, pers. comm.). The samples were stored at $-20 \circ \mathrm{C}$ until analysis. Salivary cortisol was determined in duplicate by direct radioimmunoassiay [1] by Dr. J. Sulon of the Steroid Laboratory, University Hospital Liegge, Belgium. The lower detection llimit of the assay was $25 \mathrm{ng} / \mathrm{dl}$, with an intra-assay coefficient of variation of $4.4 \%$. All samples were analysed in the same assay.

Statistical analysis

The 4 afternoon cortisol samples were compared for each session with an analysis of variance for repeated measures; paired t-tests were used for comparisons between ses- 
sions at each sampling time. In addition, individual difference scores were calculated (continuous task session minus control session). Difference scores for the three latest afternoon cortisiol samples were highly intercorrelated; therefore the mean of these three measures was calculated as an index of cortisol reactivity. Subjects with cortisol levels above the group median $(25.2 \mathrm{ng} / \mathrm{dl})$ on this index were defined as 'cortisol responders", whereas subjects with levels below the median were considered 'non-responders".

Although a pre-test assessment and the use of different parallel versions reduce the likelihood of there being practice effects in the cognitive tests, some tests may still demonstrate practice effects over repeated assessments. Therefore, the absolute difference between scores (after minus before) was calculated for each sesision in order to control for possible practice effects. These 'after-before' difference scores were analysed with an ANOVA with repeated factors per session (continuous tasks vs. control), with group variables for age ( 2 levels), sequence (2 levels) and cortisol (responders vs. non-responders). Tukey's studentized range test (controlling for type I experimentwise error rate) was performed on significant main-effects means [17].

\section{$\underline{\text { Results }}$}

Cortisol secretion in saliva. Individual differences in cortisol reactivity provoked by the continuous task session were rather high with values of the index ranging from -16.2 up to $124.3 \mathrm{ng} / \mathrm{dl}$ (mean \pm SD: $32.5 \pm 34.2 \mathrm{ng} / \mathrm{dl}$ ); See chapter 9 for further details.

There was no significant relationship between the cortisol reactivity index and either of the between-subjects factors 'sequence' $(t=1.05$, ns) or 'age' ( $t=-0.01$, ns). In addiltion, there was no significant correlation between the cortisol reactivity index and the 'baseline' cortisol levels measured at 10.20 am before the continuous tasks session (Pearson's $r=0.08$, ns). Relationships between individual cortisol reactivity and personality traits are reported elsewhere (Chapter 9).

\section{Cogmitive performance}

The scores for the verbal memory task (AVLT) and concept shifting tests (CST) showed large inter-subject differences. Repeated measures analysis did not show a significant overall session effect for either of the cognitive test parameters (AVLT: $F(1 ; 20)<1$, ns; CST: $F(1,20)=2.64, n s)$. In addition, there were no significant interactions: session"sequence (AVLT: $F(1,20)=1.71$, ns; CST: $F(1,20)<1$,ns), session"age (AVLT: $F(1,20)=1.11$, ns; CST: $\mathrm{F}(1,20)<1, \mathrm{~ns}$ ) and session ${ }^{*}$ cortisol (AVLT: $\mathbb{F}(1,20)<1$, ns; $\mathrm{CST}: \mathrm{F}(1,20)=1,93, \mathrm{~ns}$ ).

With respect to the divided attention task, the 3-way ANOVA with repeated measures falled to demonstrate an overall session effect $(F(1,20)=1.55$, ns $)$, but yielded a significant cortisol"session interaction $(\mathrm{F}(1,20)=5.31 ; \mathrm{p}<0.05)$. In contrast, there were no significant interactions between 'session" and "age' or 'sequence' $(\mathrm{F}(1,20)=3.44$, ns, and $\mathrm{F}(1,20)<1$, ms, respectively). 'Tukey's studentized range test indicated that the 'after-before' difference scores at the control session were significantly higher for the subgroup of 'cortisol responders' in comparison with the 'cortisol non-responders' (minimum significant difference $=5.18$ ).

ANOVA's with repeated measures for "session" were performed separately for each "cortisol" subgroup in order to further evaluate this effect. Results revealed a significant overall session effect for the 'cortisol responders': $F(1,9)=10.56 ; P<0.01$. The performance of the 'cortisol responders' tended to decline after the continuous tasks session (mean difference" $-2.66 \pm$ SEM 2.13), but thended to improve after the control session $(+2.92 \pm 1.47)$. This indicates a relative deterioration after the continuous task session: the subjects tend to perform better under conditions of lower stress.

In contrast, the "cortisol non-responders" did not show a significant overall session effect $(\mathbb{F}(1,9)<1$, ns). The cortisol non-responders tended to show a non-significant decrease after both sessions: after the continuous task session $-4.5( \pm 3.82)$ and after the control session $-5.5( \pm 1.96)$. 


\section{Discussion}

The stress that is related to 4 hours of continuous mental activity elicited a significant increase in cortisol secretion. Salivary cortisiol proved to be a sensitive and useful index of mental stress, in that rather small increases were shown by a large percentage of the subjects. There were fairly large differences between the cortisol levels of subjects after 4 hours of continuous mental activity.

To date, little attention has been paid to indiwidual differences in the response of the psychoendocrine system in relation to the performance of cognitive tasks. Brandenberger et al. [5] found a positive correlation between individual plasma cortisol increments and error and omission rates on a memory task, but were not able to reproduce these resulis [21].

In the present study, cortisol was measured in saliva, which has the advantage that collecting salliwa is easy, repeatable, and stress-free. With respect to cognitive performance, the present experiment failed to demonstrate a negative cognitive after-effect for the group as a whole. However, within-subject analysis indicated that the subgroup with higher cortisol responses performed relatively less well on the divided attention task after the continuous task session than after the control session. Although the subgroup with no or lower cortisol responses tencled to decrease in attention after both sessions, these differences were not significant between the two sessions.

In the present study divided attention was investigated by means of a signal detection test. Within the framework of signal detection models, the filter theory describes instances of missed signals in terms of lapses in attentional mechanisms [9]. In addition, King et al. [11] propose that lapses or intermittent breaks in attention are the key to the stress-performance relationship, and that the frequency of these short-lasting lapses increases with higher levels of stress.

It is unclear whether the stress-related rise in cortisol observed in the present study causes the cognitive after-effect directly or whether it is simply a marker for ineffective coping with the demands of continuous tasks. Nevertheless, there are reports that glucocorticoids have a number of neural effects, including the abillity to decrease hippocampal electrical activity [15] and to imcrease the latency of synaptic neurotransmission [16]. In addition, it has been found that pharmacologic concentrations of glucocorticoids are neurotoxic, preferentially damaging the hippocampus and the hypothalamus [2]. This of interest because corticosteroid receptors in the rat brain are highly concentrated in the hippocampus [14].

In the present study, aspects of verbal learning and concept shifting were not related to the pattern of cortisol secretion. A possible explanation for this finding may be that these two tests are not as sensutive as the computerized attention task in detecting subthe changes in performance. Whether attention as an 'extrinsic' cognitive function [18] is more susceptible to modulation by stress than 'intrinstc' more primary memory functions remains unclear.

Given the subject population, it is not possible to determine whether middle-aged or elderly females differ from their younger or male counterparts in their psychobiological response to mental stressors. "The elderly and middle aged subjects in our study did not differ in their mean cortisol response to the continuous task session.

In summary, our results indicate that 4 hours of continuous mental activity produced a significant elevation in salivary cortisol levels compared to the effect of a control session. The results further suggest that increased cortisol secretion may identify a subgroup of individuals who are more vulnerable to the negative effects of stress, and might help explain the apparent lack of significant after-effects of prolonged work on cognitive measures when data are aggregated at the group level. Further research should be aimed at a more integrated approach, i.e. using a combination of biological and psychological measures, to study the effects of stress on human performance, so as to better understand individual differences in vulnerability to stress. 


\section{Reterences}

1. Ansseau M, Sulon Is Doumont A, Cerfontain JL, Legros J, Sodoyez JC, Demey-Ponsart E (1984). The use of saliva cortisol in the dexamethasone suppression test. Psych Res 13, 201-211.

2. Aus der Muhlen $K$, Ockenfels H. (1969), Morphologische Veranderungen im Dienoephalon und Telencephalon nach Storungen des Regelkreises Adenohypophyse-Nebennierenrinde: III. Ergebnisse bein Meerschweinden nach Verabreichung won Cortison und Hydrocontison. Z Zellforschung, 93, 126-141.

3. Baade E, Ellertsen B, Johnsen TB, Ursin H. (1978). Physiology, psychology and performance. In H. Ursïn, E. Baade, S. Levine (Eds), Psychobiology of stress (pp. 163-182). New York: Academle press.

4. Brandenberger $G$, Follenius $M$, Wittersheim $G$, Salame P. (1980). Plasma catecholamines and pituitary adrenal hormones related to mental task demand under quiet and noise conditions: Biol Psychol 10, 239-252.

5. Frankenhaeuser M. (1986). A psychobiological framework for research on human stress and coping. In MH Apley, R Trumbull (Eds), Dynamics of stress (pp. 101-116). New York: Plenum Press.

6. Hockey R, Hamilton P. (1983). The cognitive patterning of stress states, In R. Hockey (Ed), Stress and fatigue in human performance (Pp. 331-362). New York: Wiley \& Son.

7. Hockey GRJ. (1986). Changes in operator efficiency as a function of environmental stress, fatigue and circadian rhythms. In: KR Boff, L. Kaufman, JP Thomas. (Eds.) Handbook of perception and human performance. Vollume 2, (p44.1-44.49), New York: Willey.

8. Holding D. (1983). Fatigue. In: R Hockey (Ed.), Stress and fatigue in human performance (pp. 145-168). New York: Wiley \& Son.

9. Hubert W, De Jong-Meyer R. (1989). Emotional stress and saliva cortisol response. I Clin Chem Clin Biochem 27, 235-237.

10. King M, Stanley $\mathrm{G}_{r}$ Burrows G. (1987). Stress. Theory and Practice. Sydney: Girune \& Stratton, Inc.

11. Levine S. (1978). Cortisol changes following repeated experiences with parachute training. In: H Ursin, E Baade, S Levine (Eds.), Psyrchobiology of stress (pp. 51-56). New York: Academic press.

12. Lezak MD. (1983). Neuropsychological assessment. New York: Oxford University Press.

13. McE wen B, Weiss \, Schwartz L. (1968). Selective retention of corticosterone by limbic structures in rat brain. Nature 220, $911-912$.

14. Ffaff DW, Silva MT, Weiss JM. (1971). Telemetered recording of hormone effects on hippocampal neurons. Science $172,394-395$.

15. Reichlin S. (1974). Neuroendocrinology. In: RH Williams (Ed.), Textbook of Endocrinology (pp. 774-831). Philadelpha: Saunders.

16. SAS User's Guide: Statistics. Version 5 Edition, 1985. North Carolina, Cary: SAS Institute Inc.

17. Squire LR, Davis HP. (1981). The pharmacology of menory: a neurobiological perspective. Ann Rev Pharmacol Toxicol 21, 323-356.

18. Verhage R. (1964). Intelligentie en leeftijd. Dissertation. Assen. The Netherlands.

19. Vining RF, MoGinley RA. (1986). Hormones in saliva. CRC Crit Rev Clin Lab Sclences, 23, 95-146.

20. Wittersheim $\mathrm{G}_{n}$ Brandenberger $\mathrm{G}_{r}$. Follenius M. (1985). Mental task-induced strain and its after-effect assessed through variations in plasma cortisol levels. Biol Psychol 21, 123-132.

21. De Zeeuw J. (1981). Algemene psychodiagnostiek I-Testmethoden. Lisse, The Netherlands: Swets and Zeitlinger. 


\title{
Chapter 11
}

\section{Coping Styles, Cortisol Reactivity and Performance on a Vigilance Task of Patien ts with Persistent Postconcussive Symptoms after a Mild Head Injury}

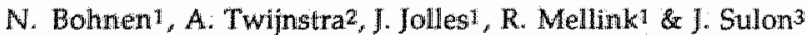

1 Department of Neuropsychology \& Pychobiology, University of Limburg, Maastricht, The Netherlands;

2 Department of Netrology, Uniwersity Hospital Maastricht, The Netherlands;

3 Laboratoire des Steroides, Centre Hospitaller Universitaire Sart Tilman, Liege, Belgium.

\section{Submitted.}

\section{Abstract}

Some pattents experience persistent postconcussive symptoms (PCS) after a mild head injury (MHI). According to the coping hypothesis, PCS result from the increased stress that head-injured patients experience when they are not able to cope with envirommental demands. This study examined the coping ability and cortisol reactivity of MHI patients with and without PCS and uninjured controls. Patients with PCS 12-34 months after injury were individually matched with MHI patients without PCS (N$=11$ ) and healthy controls $(N=11)$ for the time elapsed since the injury, age, sex, education and $1 Q$. Firstly, we found that patients with PCS reported being less able to cope with problems. These patients appeared to be inferior in active problem solving and had a more depressive attitude toward problems than subjects of the two control groups. Secondly, we found no differences between the three groups in the mean cortisol response during a vigilance task. These results only partly support the coping hypothesis.

With respect to cognitive performance, we found that decrements in a vigilance task were related to an increased cortisol response during this task, especially in apparently "recovered" (asymptomatic) MHI patients. The latter finding may point to an increased cognitive vulnerability of apparently recovered MHI patienis when exposed to a CNS stressior.

Key Words: cognitive impairment, cortisol, mild head injury, postconcussive symptoms, stress

\section{Introduction}

Patients with mild head injury (MHI) may complain of a number of postconcussive symptoms (PCS), including headache, fatigue, and cognitive problems [15]. Exidence is accumulating to indicate that even mild to moderate head injury may produce subtle cognitive deficits [13] and there is circumstantial evidence that the cognitive difficu]ties are especially experienced when MHI patients have to perform information processing and attention tasks under time pressure or stress [9]. Patients may have a decreased work performance, become less efficient, make mistakes, and exhaust themselves trying to keep up. Although patients may recover quickly after $\mathrm{MHI}$, there is a subgroup of patients who complain of persisting PCS beyond the first weeks of recovery [9]. Recently, Leininger et al. [14] found that MHI patients with persistent PCS had neuropsychological deficits in comparison with nonconcussed control subjects. These findings indicate that patients with subjective disabilities after MHI may have demonstrable objective deficits. As an explanation for the persistence of symptoms in some patients after head injury, Van Zomeren [24] formulated the "coping hypothesis" 
and suggested that PCS (in his terms 'intolerance' or 'neurotic' lype of complaints) may result from a chronically increased mental effort by patients to compensate for post-traumatic cognitive deficits. Thus, it is possible that head-injured patients have an impained adaptive ability and increased perceived stress following head injury, with their symptoms being hypothesized as similar to those of stress reactions [10].

Coping can be defined as an individual's cognitive and behavioral efforts to master demands and conflicts [11]. Coping responses represent the specific actions that people take to deal with a given problem or stressor; for example, by talking it over with others, ignoring the situation, or taking direct action to solve the problem [3, 18]. Little has been reported in the literature about the coping strategies used by head-injured patients. The few studies on coping and head injury only concern severely head-injured patients [10, 19], and provide evidence that less effective coping strategies contribute to patients' post-traumatic symptoms.

Taken together; there is circumstantial evidence to suggest that post-traumatic stress reactions contribute to the pathogenesis of PCS when head-injured patients are unable to cope with environmental demands. Although there is evidence of decreased coping ability after the injury, there are very few studies that have operationalized concepts like "mental effort' and 'stress'. For example, Brouwer and Van Wolffelaar [5] found no performance-related increase in heart rate variability in head-injured patients during a vigilance task, although the authors commented that there were baseline differences between the groups before the start of the task [see also 24]. The secretion of cortisol into body fluids has often been used as a measure of the biological response to stress [12]. Bohnen et al. [3] found a relationship between salivary cortisol secretion and individual coping ability during mental stress. A possible involvement of the stress hormone cortisol in tasks involving continuous mental effort is suggested by the study of Bohnen et al. [2], who demonstrated a negative relationship between increased cortisol reactivity and attentional performance. There is no information avaliable on the role of stress hormones in head-injured patients and the relationship to postconcussive symptoms and cognitive performance. It is possible that within the context of the coping hypothesis, MHI patients with persisting PCS have a reduced coping ability and may respond with an increased cortisol secretion during a mental task.

The first aim of the present study, therefore, was to test the hypothesis that patients with persisting postconcussive symptoms after MHI have a less effective coping ability than matched, asymptomatic MHI patients and nonconcussed controls. A second aim of the study was to test the hypothesis that MHI patients with postconcussive complaints have an increased stress response, in terms of cortisol reactivity, during cognitive performance in a wigilance task in comparison with the two control groups of patients.

We measured cortisol levels in saliva because saliva can be collected repeatedly and without stress. In addition, cortisol concentrations in saliva are highly correlated with the plasma "free fraction", which is considered to be the biologically active hormone, and are independent of the flow of saliva [26].

\section{Subjects and Methods}

\section{Subjects}

Patients $(n=11)$ with persistent PCS were selected from a larger group of patients with mild head injury. The criteria for inclusion in the study included a post-traumatic interval of between 12 and 34 months (median 21 months), a post-traumatic amnesia not exceeding 60 minutes, a period of unconsciousmess of less than 15 minutes, a Glasgow Coma Score of 15 on admission, and no serious traumatic physical complication (including the absence of orthopedic injury). Patients who had been drinking alcohol before the trauma or who had a skull fracture were also excluded. One subject was involved in a ligitation-compensation affair; none had a history of a neuropsychiatric disorder. No patient was under medication at the time of testing and none suffered 
from any severe perceptual (wisual or auditory) or motor problem that would prevent them from undertaking the reaction task. The MHI patients without PCS $(n=11)$ were selected from the same population on the basis of matching criteria with the patients with persistent PCS. The uninjured subjects $(n=11)$ were selected from a pool of nonconcussed healthy volunteers. Both the patients without PCS and the healthy volunteers were individually matched with the patients with $\mathrm{PCS}$ for age $(+1-6$ years), sex, education $(+/-1$ level $[25]$, and $1 Q(+/-810$ points). Levels of $1 Q$ were measured with the Grominger Intelligence Scale [17]. Each group consisted of six males and five females. The mean age, time elapsed after trauma, and educationall level are presented in table 1. All subjects gave their informed consent. Three of the patients in the PCS group were also subjects in a previous study of our research group.

\section{Procedure}

Sallva samples for the determination of cortisol were taken immediately before and after a cognitive test (vigilance task). Patients were tested only in the afternoon or early evening as cortisol levels in this period are low and stable relative to the diumal pattern. Patients relaxed in a quiet environment for 15 minutes before the start of the vigilance task. After blood had been collected for the second time, a coping questionnaire was completed (see below). This study was the first part of a larger netwropsychological project involving MHI patients. Details of the neuropsychological results of the study will be presented elsewhere.

Table 1

Mean age, time after the trauma (months), and educational level [25] and IQ [17] of patients with persistent PCS (group 1), patients without PCS (group 2) and nonconcussed subjects (group 3). SD are presented within brackets.

\begin{tabular}{|c|c|c|c|}
\hline & GROUP 1 & GROUP 2 & GROUP 3 \\
\hline age & $27.2(10.2)$ & $(10.1)$ & $28.1(9.6)$ \\
\hline time & $22.6 \quad(7.0)$ & 22.9 & \\
\hline educ & $4.6 \quad(1.3)$ & $5.1 \quad(1.2)$ & $(1.0)$ \\
\hline 10 & $105.3(11.3)$ & $110.1 \quad(8.2)$ & $107.1(15.3)$ \\
\hline
\end{tabular}

Postconcussive symptoms

A checklist of postconcussive symptoms was completed, which included items of headache, nausea, dizziness, difficulties with concentration and memory, fatigue, and sleep disturbances. As these symptoms also occur in healthy individuals [7], the symptoms were scored for the absolute or increased appearance after the injury in comparison with the pretraumatic condition. Six patients with persistent PCS $(N=11)$ complained of 3 symptoms or more, and five patients complained of 2 symptoms. By definition, patients without PCS did not report any symptom.

Vigilance task

In the computerized sustained attention task, a small spot, which was moving in a stepwise fashion along an imaginative circle (diameter $11 \mathrm{~cm}$ ), was presented on a monitor screen of $20 \times 28 \mathrm{~cm}$ (Vienna test system, Schuhfried GmbH, Austria). The spot miade 50 small regular steps (7.2 degrees) per round, randomly interspersed with a double step (5 per round). The total time per sitep was 1 second. The subjects were requested to press a button when a double step occurred (= the signal). A hundred signals occurred within the total testing time of 12.5 minutes. Each session was preceded by a practice session of 2.5 minutes. A vigilance parameter was calculated as the difference between the mean reaction times of the first and second half of the test (RT2-RT1). 
been derived by factor analysis [21]. Süm scores are calculated for each of the seven subscales. Subscale 1 ( 7 items) 'active problem solving' describes a direct and rational approach towards problem situations. Subscale 2 (8 items) "palliative response' include items of seeking distraction, trying to feel better by smoking, drinking, or relaxing. Subscale 3 (8 items) "avoidance and passive expectancy' involves items of problem avoidance or awaiting the consequences. Subscale 4 (6 items) "seeking social support" includes items of seeking help from others. Subscale 5 ( 7 items) 'depressive reaction" involves items of being overwhelmed by the problem and of being pessimistic about the outcome. Subscale 6 ( 3 items) 'expression of emotion and anger' defines an expressive emotional reaction to problems. Finally, subscale 7 (5 items) "comforting cognitions' includes items of considering the problem in a relative way, of self-encouragement, and of a positive reframing of the situation.

\section{Salivary cortisol}

Saliva was collected by holding an absorbant cotton roll in the mouth for 1-2 minutes. The roll was then placed in a capped plastic viall ('Sallivette', Sarstedt B.V.) and stored at $-20^{\circ} \mathrm{C}$ until analysis. Experiments in our laboratory have demonstrated that cortisol levels in saliva collected with Salivette cotton rolls do not differ from levels in matched samples collected in plain tubes (Sulon, pers comm.). Salivary cortisol was determined in duplicate by direct radioimmunoassay [1], using 1251-cortisol (Farmos diagnostica, Finland) and anticortisol antiserum (made against the 3-CMO-BSA conjugate) (Dr. J. Sulon of the Steroid Laboratory, University Hospital, Liege, Belgium). Saliwary cortisol was measured from nonextracted saliva ( 25 microliters), as we have found a very high correlation between extracted (with ethylacetate) and nonextracted saliva ( $r=0.99, \mathrm{n}=20, \mathrm{P}<0.001$ ), confirming the absence of corticosteroid-binding protein in saliva. The lower detection limit of the assay was $0.69 \mathrm{nmol} / 1$, with an intra-assay coefficient of variation of $4.4 \%$. All samples were analyzed in the same assay.

\section{Statistical analysis}

Difference scores of "after' minus 'before" cortisol values were calculated and used for analysis (cortisol response"). An analysis of variance was used to assess differences between the three groups. Duncan's multiple range test was used to evaluate significant main effects [20]. As the results for the cortisol response did not approximate a Gaussian distribution, ranks over all observations were calculated and used for statistical analysis [6]. Probabilities greater than 0.05 were considered nonsignificant.

\section{Results}

Results on the coping styles are presented in table 2. ANOVA revealed significant 'group' effects for the coping styles 'active problem solving' and 'depressive reaction". Patients with PCS had lower scores on the active problem solving' scale than asymptomatic patients. In addition, the symptomatic patients displayed a greater depressive reaction toward problems than the subjects of the two control groups (see table 2).

There was no significant group effect for the cortisol parameter (ANOVA; table 3). Scores for the vigilance task were analyzed with an ANOVA, with the cortisol parameter as covariate. There was an overall significant test effect $[\mathrm{F}(1,27)=3.92, \mathrm{P}<0.01]$, with a significant group ${ }^{*}$ cortisol interaction term $[F(1,26)=3.40, P<0.05]$, a significant main effect for "group" $[F(1,32)=3.45, P<0.05]$, and a significant 'cortisol" covariate term $[F(1,32)=4.47, P<0.05]$. Duncan's multiple range test of the main 'group' effect indicated that the PCS patient group performed the vigilance task significantly less wrell than the nonconcussed control subjects but not worse than the asymptomatic patient group (table 3). The covariate term of the cortisol parameter indicated that the decrements in the vigilance task were positively correlated with higher cortisol responses during the task $(\mathrm{R}=0.54 ; \mathrm{P}<0.05)$. The group ${ }^{*}$ cortisol interaction term was evaluated by further 
subgroup analysis. Comparison of the Spearman correlation coefficients between the indivdual cortisol response and the scores on the vigilance task within each separate group revealed a stronger correlation in the asymptomatic patient group $(\mathrm{R}=0.79)$ than in the PCS group $(R=0.10)$ and the nonconcussed group $(R=0.34)$. Pairwise comparisons between groups indicated that performance in the vigilance task was significantly more related to the cortisol response in the asymptomatic patient group than in the PCS group $[F(1,17)=4.67 ; \mathrm{P}<0.05]$ or in the nonconcussed group $[F(1,17)=3.89 ; \mathrm{P}<0.05)]$.

\section{Tablle 2}

Mean scones on the copling style subscales and behavioral rating scales for differemt groups (SD are presented within bracketsy).

\begin{tabular}{|c|c|c|c|c|}
\hline & $\begin{array}{l}\text { MHI patients } \\
\text { with PCS }\end{array}$ & $\begin{array}{l}\text { MHI patients } \\
\text { without PCS }\end{array}$ & $\begin{array}{l}\text { Healthy } \\
\text { Controls }\end{array}$ & $F(1,32)$ \\
\hline scale 1 & $17.45 \quad(2.94) \mathrm{a}$ & $21.80(3.33) \mathrm{a}$ & $19.18(3.68)$ & $4.49^{*}$ \\
\hline scale 2 & $17.18 \quad(3.22)$ & $19.30(5.10)$ & $16.09(3.11)$ & $1.85 \mathrm{~ns}$ \\
\hline scale 3 & $15.91 \quad(3.45)$ & $16.00(3.06)$ & $15.82(3.71)$ & $<1 \mathrm{~ns}$ \\
\hline scale 4 & $10.82 \quad(2.52)$ & $11.90(4.01)$ & $10.55(3.14)$ & $<1 \mathrm{~ns}$ \\
\hline scale 5 & $15.18 \quad(4.02)$ ab & $9.50 \quad(2.17) \mathrm{ya}$ & $11.64(3.78)^{\mathrm{b}}$ & 7. $29^{* *}$ \\
\hline scale 6 & $6.27 \quad(2.20)$ & $6.80 \quad(1.69)$ & $6.91 \quad(1.76)$ & $<1 \mathrm{~ns}$ \\
\hline scale 7 & $11.07 \quad(1.81)$ & $12.50(2.12)$ & $12.55(3.27)$ & $1.19 \mathrm{~ns}$ \\
\hline
\end{tabular}

A common suparscript signifies a statistically significant difference according to the Duncan Mulitiple Range post thoc test.

Stale 1 "active problem solving"; scale 2 'palliative response"; scale 3 "awoidance and passive expectancy"; scale 4 'sedking social support; scale 5 'depressive reaction"; scale 6 "expression of emotion and anger; scalle 7 'comforting cognitions'.

\section{Table 3}

Results of the vigilance task are presented together with the oortisol values before and after this task (Meanst/-SD; Cortisol: mmol/1)

$\begin{array}{lll}\text { MHI patients } & \text { MHI patients } & \text { Healthy } \\ \text { with PCS } & \text { without PCS } & \text { Controls }\end{array}$

\begin{tabular}{lcccccc}
\hline $\begin{array}{l}\text { Cortisol Response } \\
\text { cortisol before }\end{array}$ & 2.29 & $(0.98)$ & 1.76 & $(1.27)$ & 1.96 & $(0.82)$ \\
cortisol after & 2.36 & $(1.56)$ & 1.38 & $(0.86)$ & 1.65 & $(0.71)$ \\
& & & & & \\
Vigilance Task (time in seconds) & $0.56(0.11)$ & 0.50 & $(0.06)$ & 0.51 & $(0.07)$ \\
first hall (RT) & $0.60(0.13)$ & 0.52 & $(0.08)$ & 0.51 & $(0.07)$ \\
second half (RT) & & & & & &
\end{tabular}

\section{Discussion}

According to the coping hypothesis $[10,23]$, postconcussive complaints may result from the chronic effort patients make to compensate for their cognitive deficits, leading to a chronic stress reaction. This notion is supported by data reported by Bornsteun et al. [4], who found a positive relationship between emotional disturbance and cognitive deficits in patients with minor head injury. To try to understand more about factors determining patients residual complaints and long-term adjustment to disability, Hinkeldey and Corrigan [10] examined the coping strategies used by head-injured subjects to deal with their difficultives. Severely head-injured patients reported a significantly greater use of avoidance and affective regulation as a method of coping, 
and a decreased use of logical analysis and information seeking strategies. Further evidence for the coping hypothesis was provided by our results, which showed that symptomatic patients demonstrated a decreased use of the coping style "active problem solving' and reacted more with a depressive attitude toward problems. Thus, the stress tolerance of MHI patients with PCS may be decreased, and frustation readily develops when previously mastered activities at home or work prove challenging if not impossible. Difficulties in cognitive functioning may reduce the effectiveness in coping with stress. Post-traumatic adaptive skills are viewed as the net effect of premorbid adjustment, response to cognitive impairment, and the patient's own standard, expectancy, and level of perceived stress [16, 23]. These adaptive skills have to be considered in the perspective of environmental demands. The development of effective techniques for stress management, such as the provision of information and assistance in developing more adaptive coping strategles, could be an important component of treatment programs for MHI patients.

With respect to cortisol reactivity during the cognitive task, we did not find that symptomatic $\mathrm{MHI}$ patients had a significantly increased cortisol response during a vigilance task in comparison with MHI patients without PCS and healthy subjects. The lack of an increased cortisol response in MHI patients with PCS does not support the coping hypothesis. It is possible that, given the evidence of a decreased coping ability in the PCS group, these patients may experience a chronic stress reaction that is rather insensitive to the superimposed stressor in the present model. Factors that may be related to the outcome of the present study include the relatively long time after the injury, and the mild nature of the head injury. Given the nonsignificant trend of a slightly increased cortisol response in the PCS group (table 3), it is possible that the same experiment with more severely injured patients in a subacute stage after injury would reveal an increased cortisol response. Fatigue can be discarded as a biasing factor in a short-lasting, low-event rate vigilance task. Moreover, the task was preceded by a rest period of about 15 minutes.

To date, little attention has been paid to individual differences in the response of the psychoendocrine system in relation to performance in cognitive tasks. Bohnen et al. [2] reportied that an individually increased cortisol reactivity during mental stress was negatively related to attentional performance. The cortisol response identified those individuals who were more vulnerable to the negative effects of stress. We now present similar evidence that performance in a cognitive task decreases with increased cortisol reactivity. Further subgroup analyses indicated that this effect was significantly greater in the group of apparently recovered MHI patients than in nonconcussed subjects and symptomatic $\mathrm{MHI}$ patients. Similar results were reported by Ewing et al. [81, who found that apparently recovered MHI patients manifest a greater CNS vulnerabillity to stressors than nonconcussed controls. It is possible that these apparently recovered patients because of their better coping ability-compensate for their latent cognitive deficits when the stress is not too high. Whether or not such a hypothesized compensatory effort is related to an increased controlled processing of information [22] needs to be studied further. Although the performance of the PCS group in the vigilance task was significantly worse than that of the two control groups, this performance decrement was not related to the cortisol response. it is possible that the cognitive dysfunction in the PCS group reflects some form of structurai brain damage [23] or has other origins, such as depression.

It can be summarized that patients with persisting PCS after MHI make less use of effective coping mechanisms. In addition, performance in a vigillance task appears to be related primarily to cortisol reactivity during this task, especially in apparently recovered patients. Although we found no direct evidence for an increased cortisol response in the symptomatic patient group, further research is needed the address the complex issue of mutual effects of structural brain damage, stress susceptibility, and coping ability in MHI patients. Clarification of the relationships between post-traumatic brain dysfunction, cognitive functioning, and objective assessment of 
the stress response will contribute to a further understanding of the persistence of postconcussive sequelae after a mild head injury.

\section{Referenges}

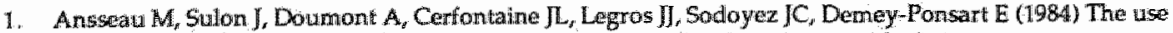
of saliva cortisot in the dexamethasone suppression test. Psychiat. Res 13: 201-211.

2. Bohnen N, Houx P. Nicolson N Jolles J (1991a) Cortisol reactivity and cognitive periormance in a contiruous mextal task paradigm. Biol Psychol: in press.

3. Bohnen $N$, Nicolson $N$, sullon J, Jolles I (199tb) Coping style, trait anxiely and cortisol reactivity during mental stress. I Psychosom Res 35: 141-147.

4. Bornstein RA, Miller HB; Van Schoor JT (1989) Neuropsychological deficit and ernotional disturbance in head-infured patients. I Neurosurgery 70: 509-513.

5. Brouwer WH, wan Wolffelaar PC (1985) Sustained attention and sustained effort after closed head injury: detection and $0.10 \mathrm{~Hz}$ heart rate variability in a lowe event rate vigilance task. Cortex 21: 111119.

6. Conover WJ, Iman RL (1981) Rank transformations as a bridge between parametric and non-parametric statistics. Am Statist 35: $124 \times 129$.

7. Dikmen S, McLean A, Terrkin N. (1986) Neuropsychological and psychosacial consequences of minor head injury. J Neurol Nearosurg Psychiatry 49:1227-1232.

8. Ewing R, McCarthy D, Gronwall D, Wrightson P (1980) Persisting effects of minor head injury obser* vable during hypoxic stress. J Clin Neuropsychol 2: 147-155.

9. Gromwall D,Wrightson P. (1974) Dellayed recowery of inkellectual function after minor head injury. Lancet 2:605-609.

10. Hinkeldey NS, Corrigan ID (1990) The structure of head-injured patients" neurobehavioral complaints: a preliminary study. Brain Injury 4:115-133.

11. Holroyd KA, Lazarus RS (1982) Stress, coping and somatic adaptation. In: L. Goldberger, S Breznitz (eds) Handbook of stress: theoretical and clinical aspects. New York: Free Press.

12. Hubert W, de Jong-Meyer $R$ (1989) Emotional stress and saliva cortisol response. J Clin Chem Clin Büchem 27: 235-237.

13. Fugenholtz H, Stuss DT, Stethem LL, Richard MT. (1988) How long does it take to recover from a mild concussion? Neurosurgery 22:853-858.

14. Leininger BE, Gramling SE, Farrell AD, Kreutzer IS, Peck EA III (1990) Neuropsychological deficits in symptomatic minor head injury patients after concussion and mild concussion. I Neurol Neurosurg Psychiatry 53: 293-296.

15. Lishman WA, (1988) Physiogenesis and psychogenesis in the "post-concussional syndrome", Br J Psychiatry $153: 460-469$.

16. Long CI, Webb WL (1983) Psychological sequelae of head trauma. Psychiatr Med 1: 35-77.

17. Luteijn and Van der Ploeg FAE (1983) Handleiding Grominger Intelligentie Test (G.LT.). Lisse: Swets \& Zeitlinger.

18. Menaghan EG (1982) Measuring coping effectiveness! a panel analysis of marital problems and coping efforts. I Health Soc Behav 23: 220-234.

19. Moore AD, Stambrook M, Peters LC (1989) Coping strategies and adjustment after closed-head injury: a duster analytical approach. Brain Injury 3: 171-175.

20. SAS (1985) User's Guide: Statistics Version 5 Edition. North Carolina, Cary: SAS Institute Inc.

21. Schreurs $\mathbb{P J} G_{*}$ Wan de Willige $G_{\text {, Tellegen }}$, Brosschot JF (1987) De Utrechise Coping Lijst: UCL. Lisse, The Netherlands: Swets and Zeitlinger.

22. Shiffrin RM, Schneider W (1977) Controlled automatic human information processing: II. Perceptual learning, automatic attending and a general theory. Psychol Revilew 84: 127:190.

23. Van Zomeren $A H$, Van den Burg W (1985) Residual complants of patients two years after severe head injury. J Neurol Neurosurg Psychiatry 48: 21-28.

24. Vatn Zomeren AH (1981) Reaction time and attention after closed head imjury. Thesis. Universily of Groningen, The Netherlandls.

25. Verkage R. (1964) Intelligentie en leeftijd. Dissertation. Assen: The Netherlands.

26. Vinimg RF, MoGinley RA (1986) Hormones in saliwa. Crit Rev Clin Lab Sei 23: 95-146. 


\section{Chapter $\mathbb{1} 2$}

\section{Concluding Remarks}

'I believe that we have no unequivocal criteria, no final distinction, between physiogenic and psychogenic because the search implies a dualism which is not there. There is no sense in supposing that one must always decide whether late postconcussional syndrome is physiogenic or psychogenic. There will always be some of the latter in the causation, there may be quite a lot of the former (Lewis, 1942) ..... that a man with a hurt brain should have a disturbed mind is to be expected" (Symonds, 1942). [5]

The present study sought to increase our understanding of the postconcussional effects of MHI by looking at neurobehavioral functioning from several perspectives. The primary purpose of this study was to evaluate the subacute neurobehavioral effects and clinucal course of uncomplicated minor head injury, and care has been taken to overcome methodological difficulties encountered in previous research on MHI. With respect to the generalizibility of the results, the experiments described and conclusions drawn are restricted to young and middle-aged adult subjects with an uncomplicated MHI. Children and aged adults were not included. By definition, patients with a purie cervical whiplash injury were excluded from the study. In addition, our results apply to patients who received a good diagnosis, information, and supervision of the injury. We acknowledge that there are constraints on generalizing our results to patients in whom a minor head injury is superimposed on previous head trauma [4], chronic abuse of alcohol, or evidence of other neuropsychiatric disorders. Extension of our study to all consecutive admissions for MHI would require the recruitment of suitable controls, including proportionate representation of subjects with various neuropsychiatric disorders and a history of substance abuse. Nevertheless, our limitation to patients with an uncomplicated MHI provides a conservative estimate of the frequency and intensity of postconcussional morbidity. For instance, patients with preexisting neuropsychiatric dysfunction appear to be at higher risk of developing postconcussional sequellae [4].

The introductory chapter (Chapter 1) presents a review on the postconcussion syndrome. The pendulum on the debate on PCS has swung between physiogenic and psychogenic theses. The two main streams of opinion seem to have flowed largely independently of each other for more than 100 years. It is only in the last few decades that these streams have met, and a good deal of turbullence has resulted. The postconcussion symdrome is currently being viewed as the consequence of a complex interaction between many potential pathophysiological factors. Experimental evidence accumulated in the last few decades indicates that the direction of the discussion will be towards acceptance of an organic base for PCS, whatever nonorganic elaborations may be (and often are) erected on this organic basis. The more precise and accurate the tests become, from whatever specialty, the more likely it seems that an organic dysfunction will be found. The postconcussion syndrome may be a real neurological disorder and not a purely psychological subjective reaction to head trauma.

There is a clear need for objective assessment of MHI and PCS. Newly developed methods for assessing post-traumatic neurobehavional deficits are described in the first group of chapters (section $A$ ). The psychophysical method for assessing tolerance to light and sound, and the application of neurobehavioral rating scales may contributte to a more objective and more reliable assessment of MHI and PCS.

Even mild concussion can cause significant impaiments of attention and information processing in the absence of apparent neurological problems. Specific neuropsychological tests are necessary to reveal the deficit. Cognitive impairments may sometimes be so subtle that they are overlooked. The results described in Chapter 3 
indicate that modification of the Stroop Color Word Interference test so asso to make more complex cognitive demands on subjects makes the test disproportionately more difficult for MHI patients than nonconcussed subjects when data are aggregated at a group level. It will be clear that the application of the modified subtask is especially useful when the original subtask is not sensitiwe enough to detect subtle attentional deficits. In contrast, a comparison of patients with and without persisting symptoms reveals a clear difference between the performance of these patientgroups in the original interference task. In this instance, the application of the modified task has no extra value. The results further indicate that $M H I$ patients represent a heterogeneous population, with subgroups of patients having varying degrees of cognitive dysfunction. It is possible that new neuroimaging techniques, such as MRI, may detect subdinical lesions in certain patients, for example, in the fronto-temporal region, that could be related to the cognitive dysfunctions [3].

The prospective multidiagnostic approach of charting the recovery of a selected group of MHI patients, as described in group B, provides an opportunity to deepen our in sight into the complex multifactorial and interactional nature of the postconcussion syndrome. For example, the finding that patients with persisting PCS have at the same time clear deficits in objective tests that presumably reflect an organic basis, and complain more and more of emotional and vegetative complaints points to the interactional nalure between different factors. There are a number of patients with persisting subjective disabilities up to six months after an uncomplicated MHI who appear to have demonstrable neurobehavioral deficits. The ecological validity of studying the subtle deficits after head injury merits further attention. For example, many patients themselwes admit that although back at work they are not performing at full capacity. The lack of cognitive speed and efficacy when performing complex tasks of information processing and attention under time pressure may well correspond to the complaints regarding everyday life. The rapid increase in fatigue in cognitively complex situations may be related to the increased mental effort needed to perform tasks which went automatically in the premorbid period. The patients appear to cope with the demands of everyday life only when there is no time pressure and when they are allowed to do one thing at the time at their own tempo. It is possible that subtle (or even. stress-related) deficits in these patients may reflect brain damage. Here again, it is not wise to adhere explicitly to an organic or a nonorganic vilewpoint. Post-traumatic brain dysfunction, CNS vulnerability, premorbid personality factors, and levels of environmental stress have to be evaluated in an integrated perspective.

The results of the third group of chapters (C), in which the coping hypothesis was evaluated in MHI patients, only provided limited support for this hypothesis. Although symptomatic patients reported themselves as being less able to cope with problems, their mean cortisol response during a cognitive task was not different from that of asymptomatic patients and nonconcussed control subjects. It is possible that our laboratory model does not reflect the effects of a chronic stress reaction in real-life situations, or that patients should be studied in an earlier phase after the injury. Alternatively, it is possible that the decreased cognitive performance of the symptomatic patient group reflects some form of primary brain damage or depression. Prospective studies which simultaneously examine post-traumatic deficits in relationship to real-life stress levels, together with sampling of salivary cortisol and assessment of coping ability, may be of relevance for a better evaluation of the merits of the coping hypothesis (for example, by means of the 'experience sampling technique'[7]). The operationalization of am experimental model integrating individual cognitive functioning and coping ability as well as the nature and quantity of psychosocial demands or stress may essentially deepen our insights into the persisting postconcussional syndrome. The finding that an increased cortisol response was negatively related to attentional performance may shed new light on the nature of post-traumatic 
cognitive deficits in MHI patients. Interestingly, the enhanced cognitive vulnerability to a stressor in the apparently recovered (asymptomatic) patients suggests that there are residual impairments after MHI. We are all vulnerable to stress, but NHI patients contimue to have an extra cognitive 'fragillity' to stress. Similar results were reported by Ewing et al. [2]. This extra vulnerability may reflect a diminution in cerebral reserve capacity after MHII [1]. It is possible that these apparently recovered patients- because of their better coping ability- may compensate for their latent cognitive deficits, in most cases when the stress is not too high, by, for example, an increased controlled processing of information. It is only when the stress is too high that the deficits may become manifest.

$25 \%$ of our patients had continued problems six months after an uncomplicated MHI, the need for ongoing evaluation and follow-up is evident. There is a clear need for further research and improvements in definition, measurement, and conceptualization of MHI and PCS in order to better understand the causes of the symptoms and disabilities experienced by patients after mild head injury. The methodological problems in research on neurobehavioral consequences of traumatic head injury are particularly salient for investigaling MHII.

Patients with MHI cover a heterogeneous population as there are subgroups of patients who recover quickly, within days, whereas other have persistent PCS after the first weeks of recovery. Most studies performed so far have compared head-injured patients with nonconcussed subjects instead of directly comparing patients with and without postconcussive symptoms [6]. Well-designed, interdisciplinary prospective research is warranted. In addition, studies of $\mathrm{MHI}$ should be long-term, and multidimensional, taking into account antecedent factors, clinical factors, and interactional effects. More research is especially needed to identify persons at high risk of persistent PCS, emotional distress, and disability, as these persons should receive more intensive preventive support.

In conclusion, neurologists, neuropsychologists, psychiatrists and general practitioners have a great deal to offer in the treatment of individuals experiencing PCS. Previous debate over the pathophysiology has been plagued by a tendency toward over. simplification. PCS are traumatic consequences of a minor injury that sometimes are not taken seriously enough. Clinicians are encouraged to be sensitive to the potentially serious consequences of MHI even in cases where loss of consciousness is minimal. Neuropsychological evaluation of patients with PCS will often provide justification for the many complaints that might otherwise erroneously be attributed to neuroticism or greed. Test results are also useful in developing individualized rehabilitation programs and in determining when individuals are capable of resuming vocational or academic routines. The combination of the results obtained with different neurobehavioral tests are best interpreteted when integrated into a multidimensional profile of individual neurobehavioral functioning. For practical purposes, it is advisable to provide the patient with an educational pamphlet and create the opportunity for a return wisit when symptoms persist for longer than 3-4 weeks. Researchers are encouraged to shift their attention from a description of typical recovery to early identification and rehabilitation of affected individuals. Knowiedge of the complex interplay between organic and psychogenic factors provides a unique perspective on a prevalent health problem and may lead to a logical treatment rationale.

\section{References}

1. Binder LM (1986) Persisting symptoms after mild head injury: a review of the postooncussion syndrome J Clin Exp Neuropsychology $8: 323-346$

2. Ewing $\mathrm{R}, \mathrm{McCartiy} \mathrm{D}, \mathrm{Gronwall} \mathrm{D}$, Wrightson (1980) Persisting effects of minot head injury obser vable during hypoxic stress. ] Clin Neuropsychol 2: 147-155.

3. Levin HS, Amparo E, Eisenberg HM, Willams DH, High WM, McArdle CB, Weiner RL (1987a) Mag- 
netic resoname traging and computerized tomography in relation to the neurobehavioral sequelae of mild and moderate head injury. I Neurosurg 66, 706.713.

4. Leyin HS, Matts 5, Ruff RM, Eisenberg HM, Marshall LF, Tabaddor K, High WM, Frankowski RF (1987h) Newrotehawional outcome following minor head injury: a three-center study. I Neurosurg 66 $234-243$.

5. Lewis $A$, symonds CP (1942) Discussion on differential diagnosts and treatment of post-concussional sitated. Proc Roy Soc Med 35, 601-604.

6. Lishman WA. (1988) Physiogenesis and Psychogenesis in the posticoncussional sybdrome. Br I Psychiatry $153: 460-469$

7. de Vries MW (1987) Introduction: Iriwestigiting mental disorders in their natural settings. I Nerv Ment Dis 175; 509:513. 




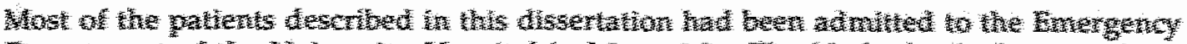

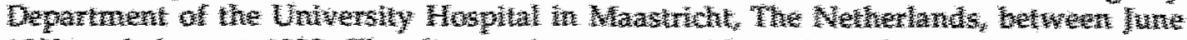

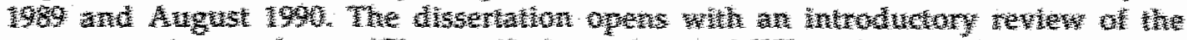

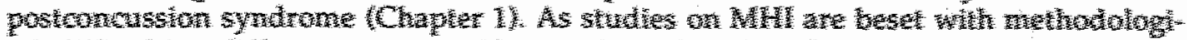

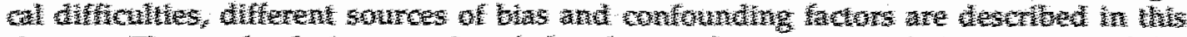

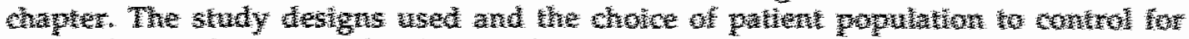

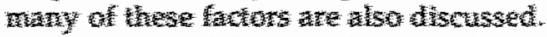

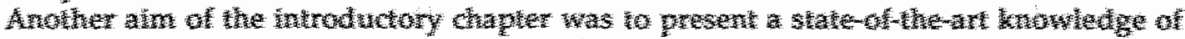

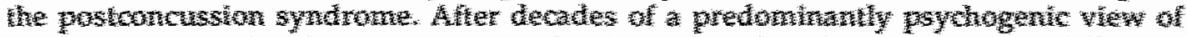

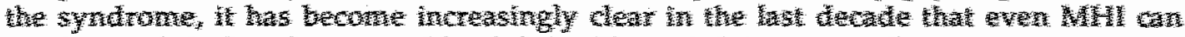

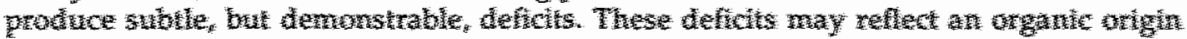

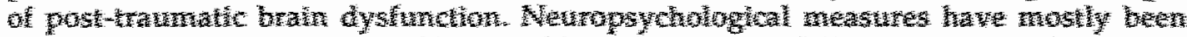

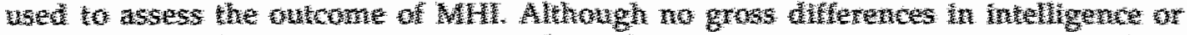

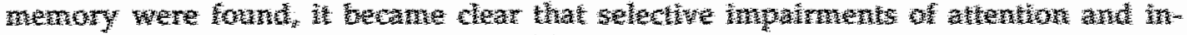

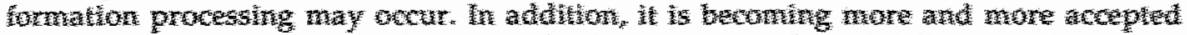

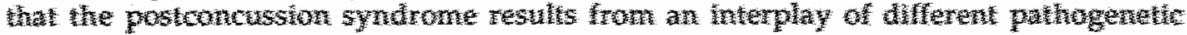

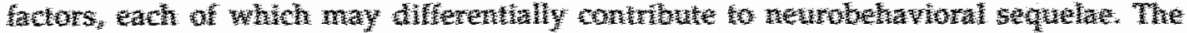



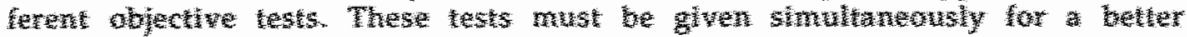

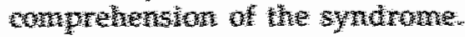

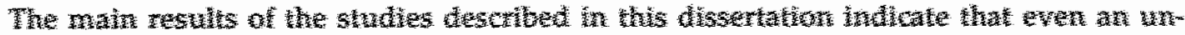

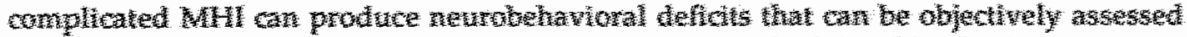

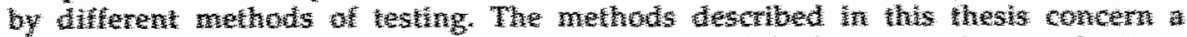

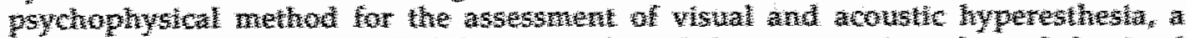

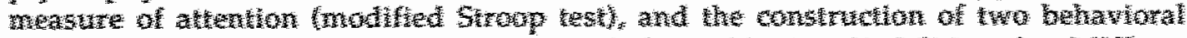

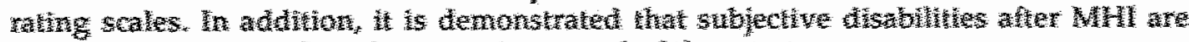

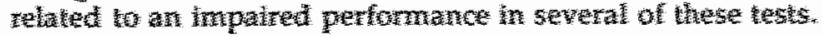

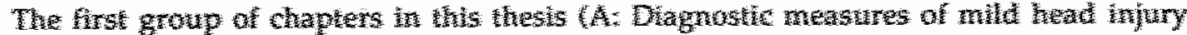

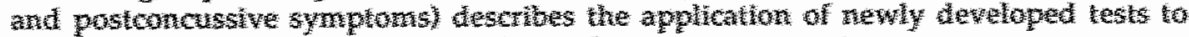

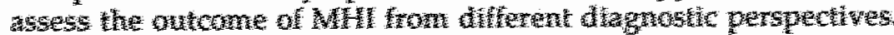

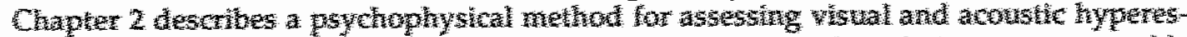

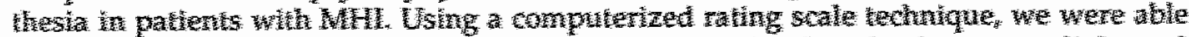

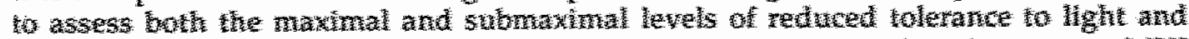
sound for a wide range of stimuli. We found that $3-6$ days after the tratma MHI patients were significanty less tolerant to stimuli of intensities from $71 \mathrm{~dB}$ and 500 Iux lewels than nonconcussed controls. The implications for meallufe situations for MHI patients are clear, and indicate that MHI patients may easily get disturbed when exposed to these intensittes that commonly occur in dally-life.

Chapter 3 addresses the issue of subte attentional deficits which can occur after MH. Most neuropsychological studies on MHI performed so far have applied rather tradithonal neuropsychological tests, which may lack sensitivity to detect subtle post-traumatic deficits. The Stroop color word interference test has beeth used by various research groups to study the effects of head injury on aspects of selective attention. The results consistently indicate that head-injured patients are not disproporthonately slower on the interference subtask than nonconcussed controls. It is possible that the interference subtask is not difficult enough for milly head-injured subjects. We therefore tested the hypothesis that more complex subtask of color word interference would be disproportionately more difficult for MHI patients than for nonconcussed controls. The third (interference) subtask was modified to include a fourth subtask which requires extra flexbility for the naming and reading of the ltems depending on special visual cue given with the words. The study compared the performance of 
MHI patients and nonconcussed control subjects in this test. In accordance with the findings reported in the literature, we did not find a difference between the wo groups with the original interference subtask. In contrast, it was found that the patients were significantly slower at the modified subtask of increased complexity than the controls. The findings support the hypothesis that the cognitive disturbances in MHI patients may be sublle and only demonstrable with more sensitive tests.

The aspecific and vague nature of PCS causes researchers methodological difficulties when they try to quantify or conceptualize these complaints. Moreover, there is controversy about whether these symptoms have an organic basis or are primarily related to the psychological and emotional state of the subject. We therefore studied the interrelationships between rather traditional $P C S$ and more emotional and vegetative symptoms in MHI patients in Chapter 4 . Results from a factor analysis indicated that the traditional PCS did not load together with these emotional items, and may therefore have a different origin. Furthermore, PCS are usually quantified by counting the total number of different symptoms per patient. It is clear that this is an arbitrary and rather rough method for assessing the intensity of the postconcussion syndrome. The application of rating scales may be more reliable for this purpose. Unfortunately, there were no such scales for the postconcussion syndrome avallable. We therefore constructed two rating scales of the relewant items of the two factors: one scale for postconcussive/cognitive complaints and another for motional/vegetative complaints. Results indicated that $\mathrm{MHI}$ patients reported postconcussive/cognitive complaints significantly more than nonconcussed control subjects, but did not differ in the ratings on the emotional/vegetative complaints scale. This could imply that PCS may have a different basis than a pure emotional one. In addition, patients with multiple head injuries or pre-existing problems had higher scores on both scales than control MHI patients. It was concluded that the newly developed rating scales would be useful in MHI research and would contribute to a better operationalization of PCS.

The second group of chapters (B) describes the application of the newly developed tests to patients with an uncomplicated MHI during recovery. Strict eligibility criteria were applied to reduce the effects of possible confounding factors to a minimum.

Chapter 5 describes the application of the psychophysical method described in Chapter 2 and the behavioral rating scales described in Chapter 4 . Tolerance to light and sound was tested at 10 days and 5 weeks in a group of nonhospitalized patients after an uncomplicated MHI. Although there was a significant overall recovery from both visual and acoustic hyperesthesia, $25 \%$ of the patients were still not able to endure intense stimuli after 5 weeks. In addition, patients with persistent PCS 5 weeks after injury tolerated the light and sound stimuli less well than patients without persistent symptoms. Analysis of data obtained with the two rating scales indicated that the visual hyperesthesia was specifically related to the postconcussive/cognitive complailnts scale.

Chapter 6 describes the further follow-up of the cohort of patients $(N=41)$ described in Chapter 5 at 3 and 6 months after the injury. The aim was to chart the time course of recovery from a multidiagnostic perspective. It was investigated whether patients with persistent PCS differed in the outcome of the various diagnostic measures in comparison with patients with few or no PCS and nonconcussed control subjects. Three months after the trauma ten patients still complained of 3 PCS or more. There were nine patients with at least 3 PCS at six months. Results obtained with the psychophysical method and the Stroop test indicated that this PCS group had a significantly reduced tolerance to light and sound stimuli and performed significantly less well on the Stroop interference measure in comparison with MHI patients with few or no PCS and nonconcussed subjects.

Interestingly, symptomatic patients were found to complain more and more of emotional and vegetative complaints with time. It was concluded that although most patients may substantially recover after $\mathrm{MHI}$ about $25 \%$ of patients may retain a 
residue of neurobehavioral deficits. The results support the notion that patients with persistent PCS should be evaluated in a multidagnostic and objective way in order to gain a better understanding of the nature and origin of the subjective symptoms.

In Chapter 7 the psychophysical method described in Chapter 2 was applied to nvestigate the tolerance to light and sound of MHI patients with persisting PCS about six months after a MHI. In contrast to Chapter 2, where MHI patients as a group were compared with nonconcussed subjects, a double control group design was used that compared MHI patients with PCS with MHI patients without PCS and nonconcussed controls for a wide range of stimuli. The results confirm the findings of the previous chapter $(=6)$, namely, that symptomatic patients have a significantly reduced tolerance to intense light and sound stimuli. There were no overall differences between MHI patients without PCS and matched nonconcussed subjects. The psychophysical method proved to be an objective measure for the evaluation of the late persistent postconcussion syndrome.

There is much debate on the nature and duration of the cognitive deficits after MHI. As mentioned in the Introduction, most neuropsychological studies performed so far have compared head-injured patients with nonconcussed. subjects instead of directly comparing patients with and without PCS. We found that patients with symptoms at six months after MHI had attentional deficits in comparison with asymptomatic MHI patients and nonconcussed subjects. These findings demonstrate that MHI patients with subjective symptoms have demonstrable cognitive deficits in comparison with asymptomatic MHI patients and nonconccussed control subjects. In contrast, there were no significant differences between asymptomatic patients and nonconcussed control subjects in the neurobehavioral tests.

The third group of chapters (C) deals with an experimental evaluation of the coping hypothesis. According to the coping hypothesis, PCS may result from the chronic effort of patients to compensate for the increased mental effort and stress related to post-traumatic cognitive deficits. The strength of the coping model is that it comsiders different factors that may interact with one and another to produce PCS. Cognitive and environmental factors are considered as well as personal factors (coping ability ${ }_{n}$ personality, level of aspiration). The attractiveness of this model is further accentuated by the striking similarity of some PCS and symptoms of a stress reaction in nonconcussed individuals.

The few experimental operationalizations of the mental effort and stress of head-injured patients described in the literature, including the measurement of heart rate variability, do not provide direct support for the coping hypothesis in head-injured patients. The measurement of cortisol is another approach for studying the effects of stress. As the field of the psychobiology of stress, coping ability, and mental function is not well established in man, we first studied the effects of mental stress and coping ability on cognitive functions and salivary cortisol reactivity in thealthy nonconcussed subjects. Salivary cortisol reactivity proved to be an effective measure of mental stress (Chapter 9) and was related to individual coping characteristics. The cognitive results of this study are described in Chapter 10. It was found that an individually increased cortisil response during mental stress was negatively related to attentional performance (Chapter 10). The experimental methods of Chapters 9 and 10 were then applied to a study of symptomatic and asymptomatic MHI patients (Chapter 11) to evaluate the coping hypothesis with salivary cortisol as measure of stress. Results obtained with a coping questionnaire confirmed the coping hypothesis in MHI patients, in that symptomatic patients had a less effective coping ability than asymptomatic MHI patients and nonconcussed control subjects. In contrast, we did not find a significantly elevated cortisol response during a cognitive task in the symptomatic patient group in comparison with the two control groups. Results obtained with the vigilance task indicated that there was a negative relationship between an individually increased cortisol response during the task and performance on the vigilance task. Strikingly, it ap- 
peared that the asymptomatic patients were cognitively more susceptible to the negative effects of stress than nonconcussed subjects. There was no evidence of such an effect in the symptomatic patient group. The finding that apparently recovered MHI patients are more susceptible to a stressor may point to a selective vulnerability of the CNS after MHI. It is posstble that these apparently recovered patients -because of their better coping ability- may compensate for their latent cognitive deficits in most situations when the stress is not too high by, for example, an increased controlled processing of information. It is only in very demanding situations when the stress is too high that the deficis may become manifest.

In the last chapter (12, Concluding remarks), it is postulated that even an uncomplicated MHI can produce neurobehavioral deficits that can be objectively assessed. These deficits may reflect that PCS has an organic basis. Nevertheless, it is stressed that the postconcussion syndrome has a multifactorial pathogenesis wherein psychogenic and physiogenic factors mutually interact with one and another. In addition, patients with MHII cover a heterogeneous population of different subgroups wilh warying degrees of neurobehavioral deficits. Guidelines for future research that take these characteristics into account are provided. The presence of neurobehavioral deficiss, especially attentional impairments, and the reduced coping ability of patients with persisting subjective disabilities after injury stress the meed for a more intensive program of diagnosis and treatment of mildly head-injured patients. So far, MHI patients have largely been ignored from a rehabilitation point of view. Evaluation of MHI patients should be directed at an early selection of patients at risk of developing PCS: 


\section{Samenvatting}

De dissertatie beschrijft een onderzoek naar het voorkomen van restklachten na een ongecompliceerd licht trauma capitis. Met behulp van verschillende testmethoden zijn diverse aspecten wan het gedragneurologisch functioneren onderzocht. Het grootste deel van de in dit proefschift onderzochte patiênten-populatie werd in de periode tussen juni 1989 en augustus 1990 op de Eerste Hulp van het Academisch Ziekenhuis Maastricht gezien in verband met een licht diffuus trauma capitis.

De dissertatie begint met een een overzicht over het postcommotionele syndroom (hoofdstuk 1). Na enkele decennia van een overwegend psychogene visle op het syndroom, is het de laatste jaren meer en meer duidelijk geworden dat zelfs een lichte hersenschudding (commotio cerebri) lichte, mar wel aantoonbare stoornissen kan veroorzaken. Deze stoornissen kunnen berusten op een organische basis van het postcommotionele syndroom. Om de gevolgen van een commotio te onderzoeken worden neuropsychologische tests het meest toegepast. Alhoewel er geen grote verschillen zijn gevonden in intelligentie en geheugenfuncties, komen er steeds meer aanwijzingen dat er selectieve stoornissen in aandachts- en informatieverwerkingsfuncties kunnen optreden. Momenteel wordt algemeen aangenomen dat het postcommotionele syndroom voortvloeit uit een interactie van verschillende pathogenetische factoren, waarvan iedere factor op een specifieke manier aan het postcommotionele klachtenpatroon kan bijdragen. De multifactoriële aard van het syndroom vereist een multidiagnostische benadering met verschillende objectieve tests om een beter inzicht in dit ziektebeeld te krijgen.

Studies over het postcommotionele syndroom zijn gekenmerkt door veelvuldige methodologische problemen. In dit eerste hoofdstuk komen voorts de verschlllende soorten van methodologische bias aan de orde. Bij de studie-opzet en de selectie van de pattienten in dit proefschrift is met een groot deel van deze factoren rekening is gehouden.

De belangrijkste resultaten van de huidige studie laten zien dat zelfs een eenvoudig, ongecompliceerd trauma capitis gedragsneurologische afwijkingen kan veroorzaken die met verschillende tests vastgesteld kunnen worden. De testmethoden die in de huidige studie gebruikt zijn betreffen een psychofysische meetmethode ter bepaling van de visuële en acoustische hyperaesthesie, een aandachtstest (gemodificeerde Stroop test) en twee scorelijsten. Het bleek dat patiënten met persisterende klachten na een commotio cerebri gestoorde prestaties hebben op verschillende onderdelen van deze tests.

De eerste groep hoofdstukken (Cluster A: diagnostische meetmethoden voor commotio cerebri em postcommotionele symptomen) beschrijft de toepassing wan nieuw ontwikkelde testmethoden die gebruikt kunnen worden on de gevolgen van een commotio vanuit verschillende diagnostische invalshoeken te bestuderen.

Hoofdstuk 2 beschrifft de toepassing van de psychofysische methode ter bepaling van visuele en acoustische hyperaesthesie bij comotio cerebri patiënten. Met behulp van deze computergestuurde techniek is het mogelijk om zowel maximale als submaximale niveaux van verminderde gevoeligheid voor licht- en geluidsstinuli vast te stellen voor verschillende frequentles. We vonden dat commotio patiënten binnen 3 tot 6 dagen na het trauma significant slechter intensiteiten boven $71 \mathrm{~dB}$ en 500 lux konden verdragen in vergelijking met mensen zonder een hersenschudding. De gevolgen hiervan voor het alledaagse leven zijn duidelijk en geven aan dat commotio patiënten al snel gehinderd worden door frequent voorkomende geluids- en licht-intensiteiten.

Hoofdstuk 3 gaat over de lichte aandachtsstoornissen die na een commotio cerebri kunnen optreden. De meeste neuropsychologische studies die verricht $z i j n$ bij commotio cerebri patiënten hebben (gangbare) tests toegepast die mogelijk niet woldoende 
gevoelig zijn om te subtiele postraumatische stoomissen te kunnen aantonen. De Stroop kJeur woord interferentie test is veelvuldig toegepast bij trauma capitis patiënten om aspiecten van selectieve aandacht te meten. De resultaten laten overwegend zien dat de trauma pattënten niet extra trager zijn op de interferentie-taak in vergelijking met gezonde controle-personen. Het is echter mogelijk dat deze interferentietalak niel woldoende moeilijk is voor commotio patiënten. Derhalve onderzochten we de hypothese dat een meer complexe interferentietalk wel extra moeilijk was voor commotio-patiènten in vergelijking met gezonde proefpersonen. Hervoor werd de derde (interferentiletalk) gemodificeerd in een vierde taak waarin extra flexibiliteit werd vereist voor het benoemen en lezen van de onderdelen athankelijk van een specifiek visueel herkenmingsteken. De prestaties op deze test werden vergeleken tussen conmotio patienten en controlepersonen zonder een hersenschudding. In overeenstemming met de resultaten in de literatuur vonden we inderdaad geen verschillen tussen de beide groepen voor de prestaties op de originele interferentietaak (derde taak). Dit in tegenstelling tot de prestaties op de meer complexe gemodificeerde subtaak, waarbij commotio patienten well extra trager bleken te zijn in vergelijking met de controlepersonen. De bevindingen ondersteunen de hypothese dat de cognitteve stoornissen in commotio cerebri patiënten licht van aard zijn en alleen met woldoende gevoelige tests kunnen worden aangetoond.

De aspecifieke en vage aard van de postcommotionele klachten veroorzaken veel methodologische problemen voor onderzoekers in hun poging de subjectieve klachten te quantificeren of te conceptualizeren. Tevens bestaat er een grote controverse of deze postcommotionele klachten nu berusten op een lichamelijke basis of samenhangen met psychologische en emotionele factoren. Derhalve onderzochten we in hoofdstuk 4 de onderlinge samenhang tussen typische postcommotionele klachten en meer emotionele en vegetatieve klachten bij een groep commotio cerebrï patiënten. Resultaten, verkregen via een factor analyse lieten zien, dat de meer traditionele postcommotionele klachten niet sterk covariëerden met de meer emotionele klachten, en derhalve een verschillende origine zouden kunnen hebben. Tot nu toe heeft men overwegend getracht de postcommotionele klachten te quantificeren door middel van het optellen van het aantal verschillende klachten per patiënt. Het is duidelijk dat dit een vrij groffe en arbitraire methode is om de intensiteit van het postcommotionele syndroom te meten. De toepassing van scorelijsten zou in dit opzicht meer betrouwbaar kunnen zijn. Echter er bestonden geen speciale scorelijsten voor postcommotionele klachten. Derhalve construeerden we aan de hand van de resultaten van de factoranalyse twee vragenlijsten die als een meetinstrument gebruikt kunnen worden: een lifst betreft meer typisch postcommationele en cognitieve klachten, de andere lijst betreft meer emotionele en vegetatieve klachten. De toepassing van deze twee lijsten bij commotio cerebri patiënten liet zien dat commotio patiênten significant hoger scoorden op de postcommotionele/cognitieve vragenlijst, maar dat ze niet verschilden qua scores op de emotionele/vegetatieve lijst in vergelijking met controlepersonen zonder een hersenschudding. Deze gegevens zouden kunnen suggeren dat postcommotionele klachten voortkomen uit een andere basis dan een. zuiver emotionele. Voorts bleken patiënten met meervoudige traumata capitis en/of een neuropsychiatrische voorgeschiedenis aanzienlijk hoger te scoren op beide lijsten in vergelijking met patiênten met een ongecompliceerde commotio cerebri. Hieruit kan geconcludeerd worden dat de nieuw ontwikkelde scorelijsten van nut kunnen zijn bij onderzoek naar de gevolgen van een commotio cerebri en kunnen bijdragen aan een betere operationalisatie van postcommotionele klachten.

De tweede groep hoofdstukken (cluster B) beschrijft de toepassing van de nieuw ontwikkelde tests van cluster A (en anderen) tijdens het herstel van een cohort patiënten met een ongecompliceerd commotio cerebri. Stricte selectie-criteria werden toegepast om de invloed van mogelijke storende variabelen tot een minimum te beperken. 
Hoofdstuk 5 beschrijft de toepassing van de psychofysische meetmethode van hoofdstuk 2 en de scorelijsten van hoofdstuk 4. De gevoeligheid voor licht en geluid van een groep niet-gehospitaliseerde commotio patiëntten werd onderzocht zowel 10 dagen als 5 weken na het trauma. Alhoewel de gemiddelde gevoeligheid voor licht en geluid aanzienlijk verbeterde voor de groep als een geheel bleek dat ongeweer $25 \%$ van de patiënten 5 weken na het trauma nog steeds niet in staat was om fel licht en hard geluid te verdragen. Tevens bleek dat patiënten met subjectieve postcommotionele klachten de hoge intensiteiten voor licht en geluid significant minder goed konden verdragen in vergelijking met patiënten zonder klachten 5 weken na het trauma. Ver dere analyse van de data van de twee scorelijsten liet zien dat de mate van visuele hyperaesthesie specifiek gecorreleend was met de sicores op de postcommotionele/cognitieve klachtenlijst, doch niet met de scores op de emotionele/vegietatteve lijst.

Hoofstuk 6 beschrijft de verdere follow-up van het cohort patiënten $(\mathbb{N}=41)$ van hoofdstuk 5 voor de tijdstippen 3 en 6 maanden na het trauma. De doelstelling was om het tijdsbeloop van herstel in kaart te brengen vanuit een multidiagnostisch perspectief. Voorts werd nagegaan of patiënten met persisterende postcommotionele klachten verschillende resultaten hadden op de diagnostische tests in vergelijking met patiënten met weinig of geen posttraumatische klachten. Drie maanden nat het trauma bleken 10 patiẻnten nog steeds te klagen over 3 of meer postcommotionele klachten, terwijl dit voor 9 patienten het geval was 6 maanden na het trauma. De resultaten. verkregen met de psychofysische meetmethode en de Stroop kleur woord test gaven aan dat de groep van patiënten met duidelijke persisterende subjectieve posttraumatische klachten significant minder fel licht en hard geluid konden verdragen en meer inteferentiegevoelig waren (Stroop test) dam commotio patienten met geen of weinig klachten en gezonde controlepersonen. Het was opvallend dat met het verstrijken van de tijd na het trauma de symptomatische patiënten meer en meer gingen klagen over emotionele en vegetatieve klachten. De conclusies van de studie waren dat -ondanks het feit dat het merendeel van de patiënten voorspoedig herstelden - ongeveer $25 \%$ van de patiënten blijft klagen over persisterende pastcommotionele klachten na een ongecompliceerde commotio cerebri en waarbij duidelijke gedragsneurologische stoornissen geobjectiveerd kunnen worden. De resultaten ondersteunen het beleid om patiënten met persisterende postcommotionele klachten te onderzoeken met multidiagnostische en objectieve tests teneinde meer inzicht te krijgen in de aard en oorsprong van de subjectieve klachten.

In hoofdstuk 7 wordt de psychophysische meetmethode van hoofdstuk 2 gebruikt om de gevoeligheid voor licht en geluid (voor een breed bereik van verschillende intensiteiten) te onderzoeken bij commotio patiënten met persisterende klachten ongeveer 6 maanden na het trauma. Terwijl in hoofdstuk 2 commotio patiënten werden vergeleken met gezonde proefpersonen, werd in het huidige hoofdstuk gebruik gemaakt van een dubbele controlle groep met zowel controle commotio patienten zonder postcommotionele klachten en gezonde personen zonder een hersenschudding. De resultaten bewestigen de uitkomst van het vorige hoofdstuk $(=6)$ dat symptomatische commotio patiënten significant meer gevoelig zijn voor fel licht en hard geluid dan commotio patiênten zonder subjectieve klachten. Er waren geen verschillen in de gemiddelde gevoeligheid voor licht en geluid tussen asymptomatische patiënten en de gezonde controlepersonen. De psychofysische meetmethode blijkt een objectieve maatstaf te zijn woor de evaluatie van het persisterende postcommotionelle syndroom. Er is veel discussie over de aard en de duur van cognitieve stoornissen na een commotio cerebri. Zoals toegelicht in het inleidende hoofdstuk worden in de meeste neuropsychologische studies trauma capitis patienten (ongeacht de aarwezigheid van eventuele klachten) vergeleken met personen zonder een hersenschudding in plats van een directe vergelijking tussen patiènten met en zonder posttraumatische klachten. Wij vonden in hoofdstuk 8 dat commotio patiënten met persisterende klachten ongeveer 6 maanden na een trauma capitis aandachtsstoornissen hadden (in het bijzonder stoomissen in sielectieve en verdeelde attentie) in vergelijking met patiênten 


\section{List of Publications}

\section{Main papers}

Bohnen $N$, Houx $P$, Janknegt $\mathbb{R}$ \& Jolles J (1989) Effects of an overnight fluid infusion on cognitive functions in preoperative patients. Int J Neurosci 48: $233-241$.

Bohnen N, Twijnstra A, Terwel D \& Jolles J (1990) Csf arginine-vasopressin decrease during dehydration in a patient with post-traumatic diabetes insipidus. Horm Metab Res 22: 508-509.

Bohnen N, Nicolson N, Sulon J \& Jolles J (1991) Coping style, trait anxiety and cortisol reactivity during mental stress. J Psychosom Res 35: 141-147.

Bohnen N, Houx P, Nicolson N \& Jolles J (1991) Cortisol reactivity and cognitive performance in a mental task paradigm. Biol Psychol: in press.

Bohnen N, Twijnstra A, Kroeze I \& Jolles J (1991) A psychophysical method for assessing visual and acoustic hyperesthesia in patients with mild head injury. Br J Psychiat: in press.

Bohnen $N$, Twijnstra A, Wijnen G\& Jolles J (1991) Tolerance to light and sound of patients with persistent postconcussional symptoms six months after mild head injury. $J$ Neurol: in press.

Bohnen N, Twijnstra A, Wijnen $G$ \& Jolles I. Recovery from visual and acoustic hyperaesthesia following mild head injury in relation to patterns of behavioral dysfunction. J Neurol Neurosurg Psychiatry : accepted for publication.

Bohnen N, Twijnstra A \& Jolles J. Performance in the Stroop Color Word Test in relationship to persistence of symptoms following mild head injury. Acta Neurologica Scandinavica: accepted for publication.

Bohnen N, Jolles J \& Twijnstra A. Neuropsychological deficits in patients with persistent symptoms six months after mild head injury. Neurosurgery: accepted for publication.

Bohnen N, Twijnsitra A \& Jolles J. Persistence of postconcussive symptoms in uncomplicated mild head-injured patients: a prospective cohort study. Neuropsychiat Neuropsychol Behav Neurol: accepted for publication.

Bohnen N, Terwel D, Twijnstra A, Markerink M \& Jolles J. Effects of apprehension of lumbar puncture procedure on plasma vasopressin and salivary cortisol (submittedl).

Bohnen N, Verhey FRJ \& Jolles J. Neuropsychological deficits in cervical whiplash patients without direct headstrike (submitted).

Bohnen N, Terwel D, Markerink M, ten Haaf JA \& Jolles J. Pitfalls in the measurement of plasma osmolality: Biasing effects of storage time and temperature (submitted).

Bohnen $\mathrm{N}$, Degenaar $\mathrm{C} \&$ Jolles J. Influence of age and sex on 19 blood variables in healthy individuals (submitted). 
Bohnen N, Twijnstra A, Jolles J, Mellink R \& Sulon J. Coping styles, cortisol reactivity, and performance in a vigilance task of patients with persistent postconcussive symptoms after a mild head injury (submitted).

Bohnen N. Jolles J \& Twijnstra A. Modification of Stroop Color Word test improves differentiation between patients with mild head injury and matched controls (submitted).

Bohnen $\mathrm{N}$, Twijnstra A Jolles J. Post-traumatic and emotional symptoms in different subgroups of patients with mild head injury (submitted.

Bohnen N, Twijnstra A \& Jolles J. Persistence of postconcussional symptoms and disturbances in water metabolism (submitted).

Bohnen $\mathrm{N}$ \& Jolles J. Assessment and evaluation of postconcussive symptoms after mild head injury.

Bohnen $\mathrm{N}$, Twijnstra A \& Jolles J. A placebo-controlled trial shows no effect of a vasopressin-analogue (DGAVP) on subjective and cognitive recovery immediately after mild head injury (submitted).

Main papers in preparation (July 1991)

Bohnen N, Jolles J \& Degenaar CP. Levels of trace elements in blood of aging healthy subjects.

Bohnen N, Jolles I \& Degenaar CP. Lower levels of witamin B12 are related to decreased. performance on the Stroop color word test in healthy subjects.

Bohnen N, Jolles J \& Degenaar CP. Zinc Blood levels and cognitive performance in healthy subjects.

Bohnen $N$, Wijnen $G$. Twijnstra $A$, van Zuthphen $W$ \& Jolles J. Late outcome of mild head injury: Results from a controlled postal survey.

Bohnen N, Jolles J, Twijnstra A \& Mellink R. Neuropsychological functions in patients with persistent symptoms after mild head injury: Relationship to behavioral dysfynction.

\section{Abstracts}

Jolles I, Verhey FRJ \& Bohnen N (1989) Veranderingen in het centrale zenuwstelsel bij veroudering en de gevolgen hiervan op de urineproductie. Ned Tijdschr Geneeskd 133: 1811-1812.

Bohnen N, Twijnstra A \& Jolles J (1990) Persisting post-concussional symptoms and water metabolism. I Neurol (suppl vol 237): $586-62$.

Twijnstra A, Bohnen N, Terwel D \& Jolles (1990) Plasma vasopressin and fluctuating intracranial pressure. J Neurol (Suppl voll 237): 535-25.

Bohnen N \& Jolles J (1990) Cortisol reactivity and cognitive performance in a cognitive stress paradigm. In: CNS effects of stress hormones and neuropeptides. XIth International Congress of pharmacology, Amsterdam: P52. 
Jolles J, Houx P, Vreeling FW, Bohnen N \& Reyersen-van Butren E (1990) Biological risk factors for accelerated cognitive aging and dementia: findings from a multiple cohort study. Neurobiol Aging 11: 293 .

Bohnen $\mathbb{N}_{s}$ Jolles J \& Degenaar $\mathrm{C}$ (1990) Vitamins, metals and routine blood chemistry un normal aging: results from a multiple cohort study. Neurobiol Aging 11: 336. 


\section{Dankwoord}

Het verrichten van hersenen en gedrag onderzoek is ten interdisciplinaine anngelegenheid waarbij meerdere personen een rol spelen. In de eerste plaats wil ik mijn promotor professor Jolles danken woor zijn uitstekende begeleiding. Jelle, ik ben je zeer dankbaar dat je me alle gelegenheid geboden hebt om onze ideeen in de praktijk uit te kunnen voeren. Jouw bijna niet te stuiten stroom van inspirerende ideeen, je accurate en snelle 'manuscript-service' en je enthousiasme vormden de basis voor een uiterst efficiënte en prettige samenwerking. Dr. Alberk Twijnstra wil ik danken voor zijn klinisch-neurologische supervisie en voor zijn bijzondere moeite watardoor $1 \mathrm{k}$ patiêntgebonden onderzoek binnen de afdeling neurologie kon verrichten. De professoren F.H.M. Verhey (klinische psychiatrie) en P.J.M. van der Lugt (neurologie) ben jk zeer erkentelijk voor hun facilitaire steun. De leden van de beoordelingscommissie will ik danken voor de accurate en deskundige evaluatie van het manuscript.

Bovenal wil ik in het bijzonder Germa Wijnen danken die in de laalste twee jaar van mijn project mijn dagelijkse steun en toeverlaat was. Haar minitieuze arbeid was een conditio sine qua non woor het welslagen van het gehele project.

Dr. José Sulon, je veux vous remercier pour votre effort et des analyses du cortisol. Mijn collega's Huub Hamers, Peter Houx, Marjanne Markerink, Nancy Nicolson en Dick Terwel will ik danken woor de fijne samenwerking evenals mijn studenten Marlies Adriaans, Liesbeth Bloemers, Coline Bongers, Timeke Klaassen, Rob Mellink, Sylvia Oudsen en Gerlinda Sneijders. Franz Josef van der Staay wil ik damken voor zijn statistische begeleiding, dr. Jane Sykes woor haar stylistische en taalkundige correcties van het manuscript en dr. J. Kroeze voor zijn fysusche en psychonomische adviezen. Bijzondere waardering gaat uit naar de medewerkers van de afdeling neurologie $A \mathrm{ZM}_{\text {* }}$ mw. Mariëlle Koeman-Bonekamp en de secretariaten van de dames Lisianne PetersLenaerts en Elsa Misdom. Veel damk ben ik verschuldigd aan alle patiënten en vrijwilligers voor de soms toch belastende onderzoeken.

Mir, tegelijkertijd promoveren, studeren en kiezen voor het buitenland is een zware combinatie. Jij weet wat dalt betekent. Miriam, merci beaucoup de tout mon coeur. 


\section{Curriculum Vitae}

De auteur van deze dissertatie werd op 27 november 1960 te Susteren geboren. Na het behalen van het Gymnasium-B diploma (c.1.) aan het Bisschoppelijk College te Sittard begon hij in 1979 met de geneeskunde studie aan de Kattolieke: Universiteit te Nijmegen (propaedeuse c.l. 1980; kandidaatsexamen c.1. 1981; doctoraalexamen c.l. 1985; artsexamen 1987). De studie geneeskunde werd van $8 / 83$ toit. $8 / 84$ onderbroken voor een studieperiode filosofie te Parijs, Frankrijk (Programme de License de la Philosophie, Université de Paris IV Sorbonne-Panthéont Diplóme de la 1 e Année de l'École d'Anthropologie de Broca; Course de Prof. Michel Foucault, College de France) waar hij tevens zijn echtgenote Miriam van Emde Boas leerde kennen. Tijdens de studie geneeskunde werden (extra-)curriculaire coschappen doorlopen in Turkije (Primary Health Care, 1983), Parijs (l'Höpital Pitie-Salpetriere, Neurologie en Neuropsychologie 1984), Hong Kong/China (Community Medicine, 1986) en Duitsland (huisartsgeneeskunde, 1987). Van 1987 tot 1991 was de promovendus als assistent in opleiding verbonden aan de afdeling Neuropsychologie en Psychobiologle (hoofd: Prof. Dr. J. Jolles), Rijksuniversiteit Limburg te Maastricht waar hij zich met verschilende onderzoekslijnen heeft beziggehouden. De trauma capitis hin wormt de basis voor de huidige studie. Amerikaans artsexamen in 1991. (FMGEMS Basic and Clinical Sciences (88) \& ECFMG English test). Voorafgaande aan de specialisatie tot neuroloog zal de auteur met ingang van september 1991 als wetenschappelijk medewerker verbonden aan de Mayo Clinic (Mn) neurologisch veldwerk verrichten naar het voorkomen van A.L.S.-Parkinson-Dementie complex in Guam (U.S.A.). 